Portland State University

PDXScholar

$1-1-1977$

\title{
An improved approach for "optimization" of multiple policy objectives
}

Perihan Soliman Tawfik

Portland State University

Follow this and additional works at: https://pdxscholar.library.pdx.edu/open_access_etds Let us know how access to this document benefits you.

\section{Recommended Citation}

Tawfik, Perihan Soliman, "An improved approach for "optimization" of multiple policy objectives" (1977). Dissertations and Theses. Paper 568.

https://doi.org/10.15760/etd.568

This Dissertation is brought to you for free and open access. It has been accepted for inclusion in Dissertations and Theses by an authorized administrator of PDXScholar. Please contact us if we can make this document more accessible: pdxscholar@pdx.edu. 


\title{
AN IMPROVED APPROACH FOR "OPTIMIZATION" \\ of MULTIPLE POLICY OBJECTIVES
}

\author{
by \\ PERIHAN SOLIMAN TAWFIK
}
A thesis submitted in partial fulfillment of the requirements for the degree of

\author{
DOCTOR OF PHILOSOPHY \\ in \\ SYSTEMS SCIENCE
}

\author{
Portland State University \\ 1977
}


TO THE OFFICE OF GRADUATE STUDIES AND RESEARCH:

The members of the Committee approve the thesis of

Perihan Soliman Tawfik presented February 24, 1977.

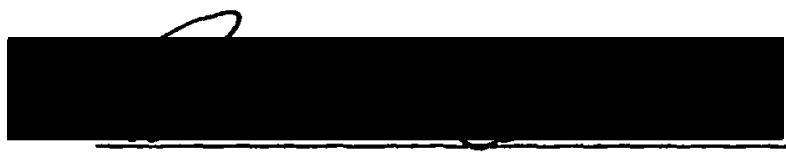

Robert E. Good, Chairman

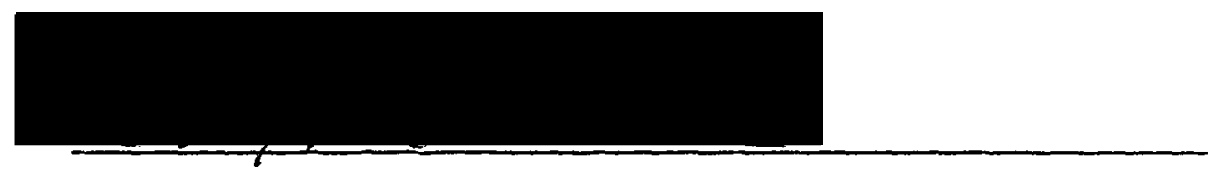

Barry F. Anderson

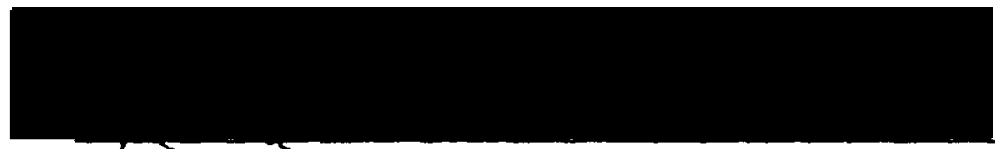

Richard C. Duncan

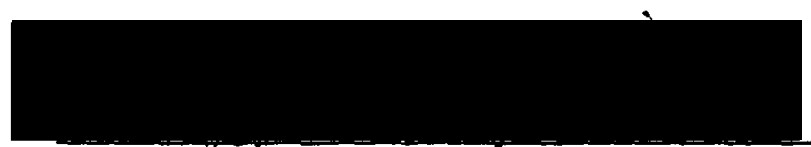

Grover Rodich

APPROVED:

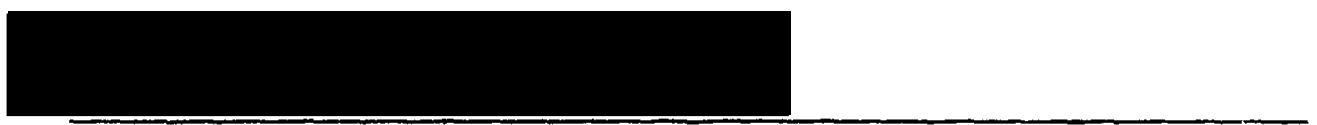

Harold A. Linstone, Director, Systems Science Ph.D Program

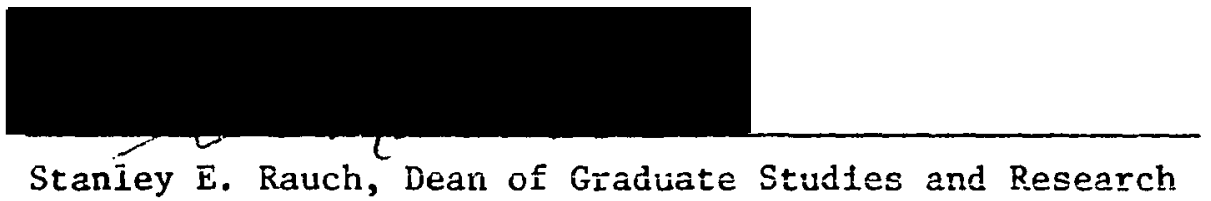


AN ABSTRACT OF THE THESIS OF Perihan Soliman Tawfik for the Doctor of PhIlosophy of Systems Sclence presented February 24, 1977.

Title: An Improved Approach for "Optimization" of Multiple Policy Objectives.

APPROVED BY MEMBERS OF THE THESIS COMMITTEE:

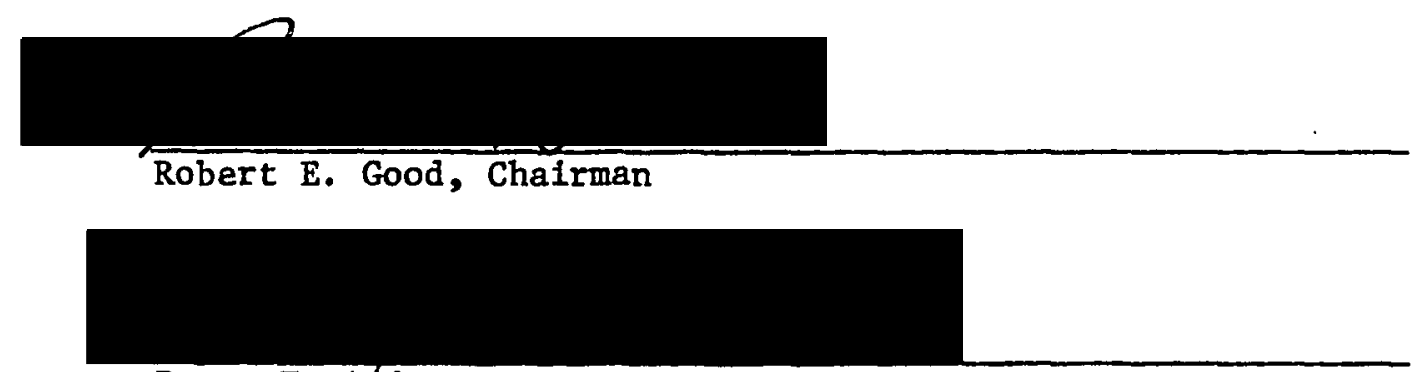
Barry F. Anderson

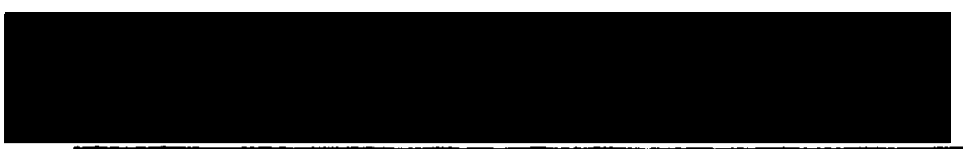

Richard C. Duncan

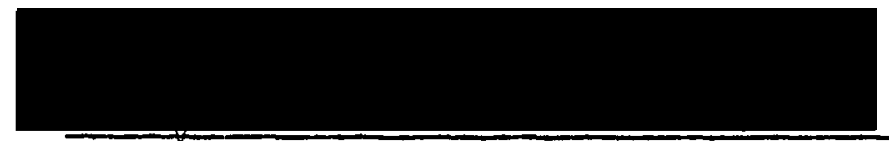

Grover W. Rodich

This thesis involved three categorles of activity; development and testing of an expanded version of ELECTRE II, also the development of a computer software program for ELECTRE II.

The expanded version of ELECTRE II took the form of an input aidins questionnaire along with a tallored structure to sult a particular prob1em. The contents of the questionnafre were based on general problem solving concepts (techniques, strategles) gleaned from the systems science 
1iterature. This questionnaire assumed a programmed instruction format in contrast to that of an interactive computer software package, so that it would not be prohibitive in terms of expenses in its use.

The second part of the research was the comparative testing of group decision quality. Improved ELECTRE II was compared to a competitive method called SPAN, regular ELECTRE II, and unaided group decision-making. The effectiveness of the improved "Front End" ELECTRE II was tested as follows :

TREATMENT

Group A Decision using ELECTRE II with the improved Front End.

CONTROLS

Group B Unaided decision.

Group C Decision using regular ELECTRE II.

Group D Decision using "SPAN" consensus taking method.

The hypothesis that ELECTRE II and Front End ELECTRE II provide equally good bases for group decision making as SPAN (which had numerous claims for its effectiveness), was tested using appropriate statistical methods. Results of the experiments showed that the regular ELECTRE II did not perform as well as SPAN. However, the improved version of ELECTRE II developed for this thesis did perform as well as but not better than SPAN. It is important to note, however, that the "experimental" task was clearly not favorable to ELECTRE II. Had the task displayed more complexity, we believe the improved version of ELECTRE II would have outperformed SPAN.

We feel that our results provide evidence for the value of this improved version of ELECTRE II which, we hope, will lead to its widespread use. 
To my father, mother and husband

to the tree of mutual love

whose shades infinitely extend

whose flowers and fruits never end

to them also

to the river lavishing love without limit

Love was given, sacrifice was granted

devoid of expectation. . . .

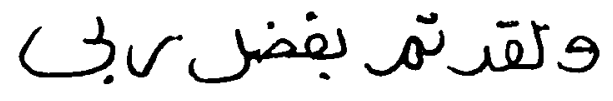




\section{ACKNOWLEDGEMENT}

For his dedication and conscientious efforts, for his sincerity in undertaking the dutles of his responsibilities, for his earnest interest, his encouragements, his valuable aid, useful recommendations and the long hours spent on discussing and criticizing this work, for his generous cooperation; my thanks, appreciation and deep gratitude to professor Robert Good will not suffice. I would like to endorse that I was fortunate to work with such a trustworthy person.

It is a pleasure to acknowledge the helpful advices and kind encouragements offered by professor Grover Rodich. I would also like to recognize the valuable suggestions given by professors Barry Anderson and Quentin Clarkson. I thank professor George Lendaris for his generous efforts, his constructive criticism and valuable recommendations while reviewing this work and for kindly supplying materials from the Systems Approach 1iterature. My appreciation also goes to professor Richard Duncan for his efforts as a member of my comittee.

To all of the above, my thanks for revlewing this manuscript.

I thank professor Kostas Dervitsiotis for suggesting the ELECTRE II technique, professor Lucien Duckstein (University of Arizona) for his interest and the material supplied, professor B. Roy for sending confidential and most recent research from Paris, and E. Castano for the material supplied.

I am indebted to professor Harold Linstone, director of the Systems Science Program, for the assistance provided during the course of 
my studies.

Special thanks and appreciation go to Karen Birky for her efforts in typing this manuscript, to Michelle Carlson for proofreading it, to Marie Brown, Jenny Reed and Chris Butcher (in the office of graduate studies) for giving ready answers to my many questions. I would also like to recognize the friendly and helpful secretaries in the Systems Science Ph.D program Kathleen Francis and Kim 01in.

My apprectation to Mostafa Hamid, director of the computer sciences facilities in the American University in Cairo, for his help and for allowing the use of the facilities.

My indebtedness goes to the American Friends of the Middle East for offering the study grant in the USA, and to professor AdII Bishai, chairman of the Materials Engineering and Physical Sciences Department in Cairo, for selecting me for this grant.

Finally, I thank my baby girl for the happiness, wonder and joy of discovery she brought in spite of her capricious demands and overloading care. 
TABLE OF CONTENTS

PAGE

ACKNOWLEDGEMENT . . . . . . . . . . . . . . . . . . . . iv

LIST OF TABLES . . . . . . . . . . . . . . . . . . . ix

LIST OF FIGURES . . . . . . . . . . . . . . . . . . . . xii

THESIS OVERVIEW . . . . . . . . . . . . . . . . . . xiii

CHAPTER

I THE PROBLEM . . . . . . . . . . . . . . . . . . 1

Introduction . . . . . . . . . . . . . 1

Existing Difficulties . . . . . . . . . 3

Types of Problem Situations Suited to ELECTRE II • 3

II ALTERNATIVE APPROACHES . . . . . . . . . . . . . 6

Alternative Approaches to Multiple Objective

Optimization . . . . . . . . . . . 6

Earlier Applications of ELECTRE II . . . . . . . 11

Team Decision Making .. . . . . . . . 12

SPAN, a Competitive Method Used As a Control

Technique In This Investigation . . . . . 14

III EXPLANATION OF ELECTRE II . . . . . . . . . . . . . 17

General Statement (Layman's Explanation) . . . . 17

User Steps (Input By DM)

Reference Example

ELECTRE Computational Preference Generating

Algorithm

Advantages of ELECTRE II . . . . . . . . . 22

Presentation of the Method .......... 23

Problem Formulation

Preference Relation

Rank Ordering 
III EXPLANATION OF ELECTRE II (cont'd)

Sensitivity Analysis

Additional Explanation on the Physical Meaning of Concord and Non-Discord Indices

Nature of Data

Table of Scales

Weight of Criteria

Parameters of Preference

Concordance Indices

METHODOLOGY AND HYPOTHESES . . . . . . . . . . . . . 40

Research Methodology. . . . . . . . . 40

Developmental Phase

Problem Solving Strategy Aiding Questionnaire Development

General Guidelines For Building The Abbreviated Version

Abbreviated Questionnaire Used In The Experiment

Comprehensive Questionnaire Instructions

Comprehensive Questionnaire

Software Package Development For ELECTRE II

Main Hypothesis

Reasons For Expected Equivalence of Improved ELECTRE II With The We11 Established SPAN Method

Experimental (Phase). . . . . . . . . . . 59

Objective

Task

Hypotheses

Experimental Technique and Design

Step Sequence for Experiment 1

Step Sequence for Experiment 2

Step Sequence for Experiment 3

Step Sequence for Gilmartin's Investigation (SPAN, NONSPAN)

Comparability of SPAN Subjects and ELECTRE II Participants 
IV METHODOLOGY AND HYPOTHESES (cont'd)

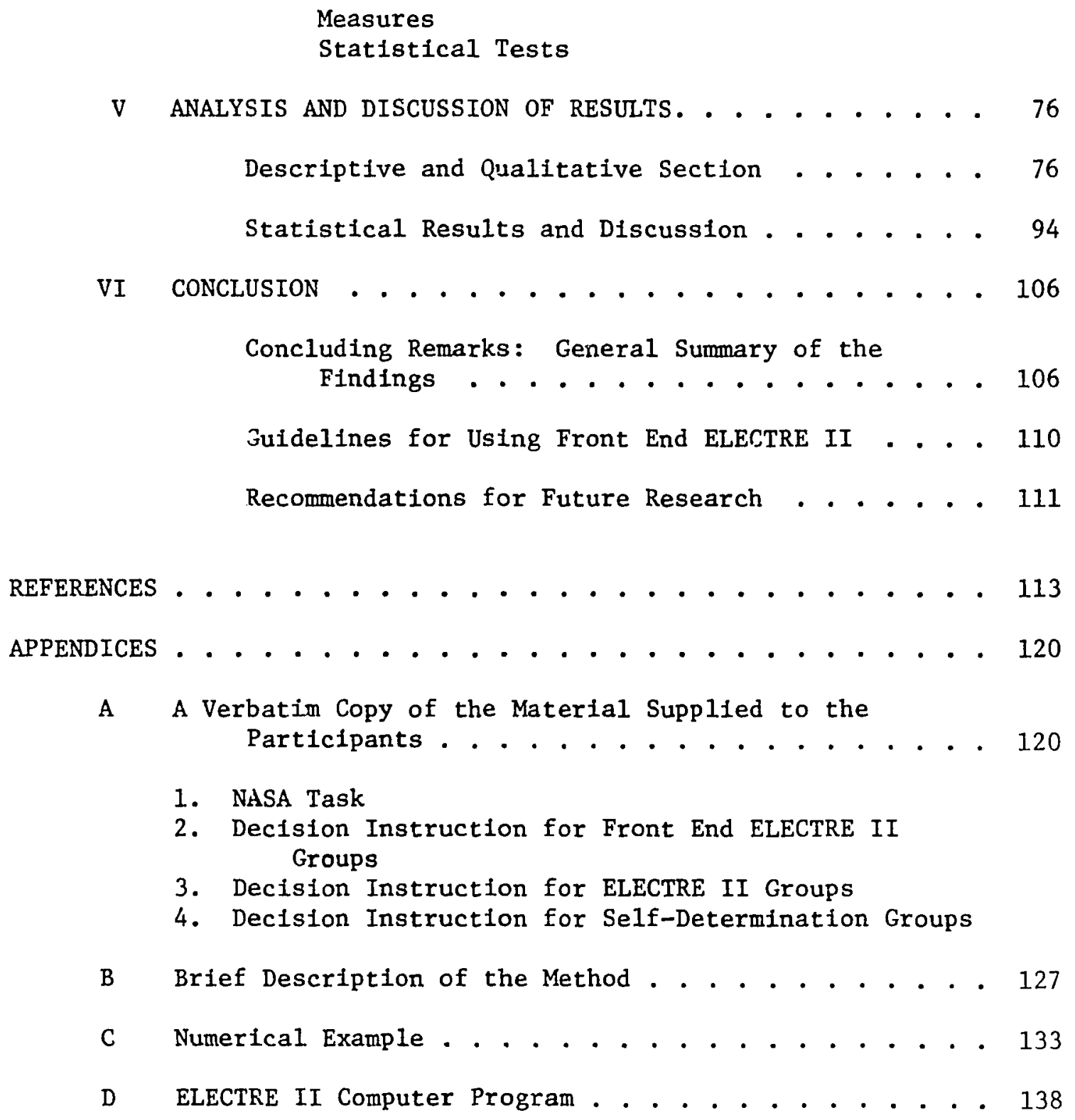

A A Verbatim Copy of the Material Supplied to the 
LIST OF TABLES

TABLE

PAGE

I Matrix of Evaluations Attributed to the Projects

Relative to the Ten Criteria ......... 20

IIa Step Sequence for the Three Experiments Performed

in This Thesis............. 69

IIb Experimental Design of Thesis........... 70

IIc Experimental Design Used by Gilmartin . . . . . . 71

III Group Adequacy Index Scores for F.E. ELECTRE II . . . 78

IV Group Adequacy Index Scores for Regular ELECTRE II . 79

V Group Adequacy Index Scores for "Any" Group Method . 79

VI Results of NASA Task Experiment I: Group Adequacy

Index Scores for F.E. ELECTRE II . . . . . . 80

VII Experiment II: Group Adequacy Index Scores for

Regular ELECTRE II . . . . . . . . . . 81

VIII Experiment III: Group Adequacy Index Scores for

Self-Determination (Any Group) Method . . . . 81

IX Group Adequacy Index Scores for SPAN Groups . . . . . 82

$\mathrm{X}$ Index of Relative Upgrading for F.E. ELECTRE II

Versus Group Resources . . . . . . . . 83

XI Index of Relative Upgrading for ELECTRE II Versus

Group Resources . . . . . . . . . . 84

XII Index of Relative Upgrading for "Any" Group Method

Versus Group Resources . . . . . . . . . 84 
XIII F.E. ELECTRE II and ELECTRE II Group Adequacy Index Scores............. . 85

XIV F.E. ELECTRE II and ELECTRE II Relative Upgrading . . 86

XV F.E. ELECTRE II and "Any" Group Method Group Adequacy Index Scores . . . . . . . . .

XVI F.E. ELECTRE II and "Any" Group Method Relative Upgrading . . . . . . . . . . . . .

XVII ELECTRE II and "Any" Group Method Group Adequacy Index Scores . . . . . . . . . . . 88

XVIII ELECTRE II and "Any" Group Method Relative Upgrading

XIX Comparison of Our Results with SPAN F.E. ELECTRE II and SPAN Group Adequacy Index Scores . . . . .

XX Comparison of Our Results with SPAN F.E. ELECTRE II and SPAN Group Relative Upgrading . . . . . 90

XXI ELECTRE II and SPAN Group Adequacy Index Scores . . . 91

XXII ELECTRE II and SPAN Relative Upgrading . . . . . 92

XXIII "Any" Group Method and SPAN Group Adequacy Index Scores................... . . 93

XXIV "Any" Group Method and SPAN Relative Upgrading . . . 93

XXV Analysis of Variance for F.E. ELECTRE II, ELECTRE II and "Any" Group Method Individual Averages Prior to Using These Group Techniques . . . . . . 95 XXVI Analysis of Variance for F.E. ELECTRE II, ELECTRE II, and "Any" Group Method Decision Index Scores.. 
XXVII Analysis of Variance for F.E. ELECTRE II, ELECTRE II, and "Any" Group Method Decision Index Scores .

XXVIII Comparison of Means and Standard Deviations of

F.E. ELECTRE II, ELECTRE II, and "Any" Group

Method . . . . . . . . . . . . . 


\section{LIST OF FIGURES}

1 Multiple Objective/Multiple Attribute Decision Methods

2 A Digraph of the Reference Example . . . . . . . .

3 A Verbatim Copy of the Material Supplied to the Participants . . . . . . . . . . . . . . 


\section{THESIS OVERVIEW}

NATURE OF IMPORTANT DECISIONS

Many of the really important decision situations are characterized by multiple, and often conflicting, objectives which need to be optimized jojntly. For example, the U.S. Forest Service must decide how to reach its "multiple use" objectives, or a group must select the "best" of, say, five alternatives where each alternative may be superior In some dimensions of evaluation but inferior in others. Any method which could be shown to help produce superior decisions in such circumstances would be of great interest and potential value to society.

\section{ELECTRE II}

ELECTRE II (ELimination and (Et in French) Choice Translating REality) is one quantitative method which has been devised to aid decision making where there may be multiple objectives. Unlike methods which merely select an alternative based on the highest total (summed) score (on multiple evaluation criteria, weighted or unweighted), ELECTRE II provides an explicit algorithm for dealing with the amount of agreement (concordance test) and the number of instances and strength of disagreement (discordance test). As with statistical significance testing, threshold levels may be set (or experimented with) in order to determine the extent to which a clearly preferred alternative does or does not exist.
A variety of other epproaches to decision making under conditions 
of multiple options and multiple evaluation criteria are avallable. ELECTRE II appears to be particularly appropriate in situations where:

a) Choice alternatives are inherently difficult to compare.

b) The decision maker(s) is (are) unwilling or unable to arrive at preference decisions on all criteria for all choice a1ternatives.

ELECTRE II has been applied to problems such as media planning and ranking of long-range water resource development plans.

\section{LIMITATIONS}

A major weakness of ELECTRE II (and other multiple criteria optimization methods) lies in its "front end" - that is, the portion of the method in which choice alternatives and evaluation criteria are generated for data input. Better methods are needed for:

a) Developing the relevant evaluation criteria to be used in a decision situation.

b) Helping the deciston-maker to explore and discover his own preference.

In order to have ELECTRE II be a practical tool, several problems needed to be solved. First, a practical and effective methodology for improving the scope and quality of data input to ELECTRE II had to be developed and programmed. [The computer program was not available; it is kept confidential in Paris.] Finally, both the original and the improved version of ELECTRE II has to be tested to demonstrate the effectiveness of the improvement.

NATURE OF RESEARCH

The research involved three categories of activity:

1. Development of a "front end" for ELECTRE II. 
The "front end" presented herein takes the form of a questionnaire in a programmed-instruction format, along with a tailored structure to suit a particular problem.

The author believes that this modification makes a significant step toward turning the ELECTRE II technique into a practical dectsion-making tool.

2. Development of a computer software program to carry out the ELECTRE II methodology.

3. Testing the augmented ELECTRE $\mathrm{II}^{1}$ method against a competitive method called SFAN, the unimproved version of ELECTRE II, and unaided group decision-making.

Hopefully, the results presented herein will provide evidence of the value of this new decision methodology and will lead to its widespread use.

RESEARCH METHODOLOGY

The ELECTRE II input aiding questionnaire structure and the abbreviated version that is tailored to the particular problem were developed. The tailored version with ELECTRE II was pilot tested.

The effectiveness of the improved "front end" for ELECTRE II was as follows:

TREATMENT

Group A Decision using ELECTRE II with the Improved Front End.

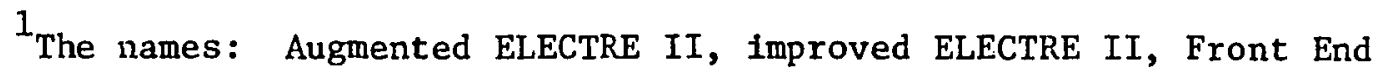
ELECTRE II, and F.E. ELECTRE II are used interchangeably throughout the thesis. 
CONTROLS

Group B Unaided decision.

Group C Decision using regular ELECTRE II.

Group D Decision using "SPAN" consensus taking method.

Measures included such things as decision adequacy index scores

for the individuals and for the groups (this index is expressed in terms of the summed deviations between the individual's rankings and that of the NASA expertsi) and group resources (Individual averages). The above measures expressed the decision quality in terms of a known outcome (via a controlled laboratory policy problem - the NASA moon survival exercise).

THE PROBLEM

1. Will the decision quality resulting from Front End ELECTRE II, ELECTRE II and "any" group method be equivalent in a NASA task as measured by the decision adequacy index scores? The significant differences among the three methods will be tested using an analysis of variance test.

2. Will the decision quality resulting from Front End ELECTRE II be equivalent to the results obtained by Gilmartin (1974) as measured by the decision adequacy index scores? The significant differences among the two methods will be tested using a t-test.

\section{SIGNIFICANCE OF THE RESEARCH}

Multiple and conflicting objective optimization is an important class of decision problems. Critical policy decisions are often made within such a context. ELECTRE II is a promising "optimization" 
technique for such problems but needs an improved methodology for deve1oping evaluation criteria and eliciting preferences.

The developmental phase of this research contributed the following:

a) an improved "front end" for ELECTRE II consisting of an input afding questionnalre in a programmed-instruction format to improve input data, both in its scope and quality.

b) A software package to actually run ELECTRE II.

The testing phase of this research consisted of the following:

a) Testing ELECTRE II in terms of objective measures of decision quality.

b) Testing ELECTRE II with an improved "front end."

c) Testing ELECTRE II against realistic "controls" (i.e. a competitive alternative methodology) rather than naive "controls" alone.

The results of this development and testing provide an improved version of ELECTRE II and evidence of its advantages that should support more widespread use of this method to deal with important policy decisions.

\section{Newness of Testing}

To the author's knowledge, no prior controlled test of ELECTRE II has ever been performed; particularly to compare it with other techniques, such as SPAN.

IMPORTANCE OF THE CONTRIBUTION

The importance and need of this research is vital with today's complexities. ELECTRE II is a decision aiding instrument that could be 
exploited in varied applications because of the generality of problems it attempts to resolve and the simplicity of procedure it utilizes. The importance of such a technique could become more apparent with its use in potential applications such as: choice of regional or urban development projects, selection of research projects or organizational development, elaboration of equipment plan or heavy investment, recruiting of personnel, different computer configurations, marketing and publicity.

The difficulites associated with any multi-criterion analysis justify the importance of the "Front End" ELECTRE II. De Montgolfier (Bertier and De Montgolfier, 1973) states that there is a difficulty in selecting an optimum number of points of view. Castano (1975) sees that the assumption that preferences are known is another difficulty. Duckstein (1976) states that we have to start with good data.

Martin (1976) and the author of this work are aware of the scarcity of methods that generate new items and stimulate new solutions. Among the few avatlable techniques are general brainstorming and the class of methods known collectively as Delphi.

From the above, we see the Importance of the "Front End" ELECTRE II.

Importance of the Contribution in Terms of Group Decision Making According to Gilmartin (1974), one of the major tasks of group decision making per se ts to surpass the quality of the decisions obtained from averaging the scores of individuals forming the group. Any method of group decision making must establish that it can significantly upgrade the performance of the group resources before it can be a useful means of decision making.

The Importance of SPAN appeared in such a context. It upgraded 
the performance of the group as compared to the averages of the individual scores of the group members.

We tested Front End ELECTRE II and ELECTRE II with the NASA task In order to compare them with SPAN (the effectiveness of SPAN in solving the NASA task was investigated by Gilmartin in 1974). Yet, the specific task used in these tests is relatively trivial, as compared to the potentialities of ELECTRE II. ELECTRE II is most useful in complex situations where the data are not easily comparable, or in problems that cannot be solved unaided. Yet, if this technique proves helpful in simple problems like the one tested here, we then can argue for its widespread use for minor group decision as well as for more complex policy issues. The currently available group decision making methods improve the quality of decisions substantially. This is tantamount to enhancing (upgrading) human intelligence. With further development, such techniques are expected to improve to a point where they will revolutionize the decision making quality output.

If SPAN increases the effective I.Q. of the problem solving group as claimed by its developers; ELECTRE II might do the same for complex problems (i.e. those policy issues which cannot be crammed into an optimization technique). So any slight improvement in these policles or strategies will constitute substantial contribution. 
CHAPTER I

THE PROBLEM

This investigation centers on the development and testing of a

refined procedure for applying a quantitative method for "optimization"1 of multiple objectives (ELECTRE II: ELimination and (Et in French) Choice Translating REality).

\section{INTRODUCTIION}

A serious problem wich exists today concerns the ability of decision makers to make decisions which involve multi-criteria or multiobjective optimization. Complex real life systems, which must be dealt with, require the optimization of many objective functions often contradictory or incommensurable.

These objectives or criteria can take diverse forms: They can represent different characteristics, they can reflect different appreciations of non-quantifiable factors, they can represent different levels of accomplishment of objectives, or they can represent values resulting from economic calculations.

Thus procedures for optimizing a single, well-defined objective function are not applicable in many decision making situations. The

$1_{\text {ELECTRE Ir "optimizes" in the sense that it systematically seeks }}$ out the most preferred alternatives (most preferred being defined as most concordance and least discordance with a specific hypothesis la specific hypothesis is a particular set of weights for the criteria used]). 
three major characterisifics of problems where multi-criteria approaches are needed are: (Roy and Bertier, 1973)

1. First, an imperfect knowledge of the preferences of the decision maker (DM); principally how a simultaneous gain with respect to one criterion and losses with respect to other criteria may be obtained while taking into account their amplitudes and the different levels at which these gains and losses are situated.

2. Then, imprecise information with which to characterize each object according to each criterion (including subjective judgments, crude evaluations, approximate calculations, etc...).

3. Lack of independence of the contribution of each criterion to the global utility of an alternative. Usually, techniques based on utility functions require the hypothesis of such independence of contribution.

ELECTRE is a technique for multiple objective optimization which meets these needs. ELECTRE I permitted the DM to choose a sub-set of alternatives containing the most interesting objects and the least comparable (most diversified). It was shown, however, to be preferable for the DM to dispose, of a real taxonomy of objects, instead of a single dichotomy separating the good from the less good. ELECTRE II is the fruit of such observations. 
EXISTING DIFEICULTIES

Three main difficult tasks arise in any multi-criterion analysis (Bertier and De Montgolfier, 1970).

1. To select "good" points of view, neither too many as to render the analysis infeasible, nor so few as to ignore some important aspects of the problem. A viewpoint is any aspect of reality that the client considers relevant while examining the cholce between projects.

2. To express the selected point of view in terms of criteria. One can distinguish between nominal criteria expressing typological points of view (such as the variable color), ordinal criteria expressing qualttative points of view (such as variables with values "very good, good, bad, very bad"), and cardinal criteria which express quantitative ones (such as number of people, a length, a price), (Bertier and De Montgolfier, 1973).

3. To find a way to compare the specified criteria. Castano, (1975) Indicates that a severe limiting factor in the applicability of the ELECTRE method lies in the assumption that the preferences among the attributes or viewpoints is known. TYPES OF PROBLEM SITUATIONS SUITED TO ELECTRE II

While a variety of other approaches to multiple objective optimization are avallable, ELECTRE II appears to be the most appropriate in situations where: choice alternatives are inherently difficult to compare, 
and where the DM(s) is(are) unwilling or unable to arrive at preference decisions on all criterla for all choice alternatives. Some of the significant characteristics of problems, users (DM), and situations in which the use of ELECTRE II seem particularly appropriate are:

\section{Problem Characteristics:}

1. The task is to rank-order a number of alternative projects.

2. Each project is evaluated according to a number of distinct criteria of performance.

3. The extent to which the different projects fulfill such criteria is not readily obvious.

\section{User Characteristics:}

The structure of the method allows for application by users with average sophistication. The Front End, developed in this work, makes it even more accessible to users with moderate skills. The input formats are easy to fill, the conceptual structure is easy to grasp and the user does not interface with the mathematical manipulation.

\section{Situational Characteristics:}

A certain amount of time is required to understand the basics of its use, (our subjects used 4 minutes for $15 \times 5$ matrix; this amount of time was barely adequate). Ad hoc groups that are meeting for one hour are not recommended but they might succeed.

ELECTRE II is very inexpensive to operate (costs $\$ 2$ for compilation, and few cents per run). But it requires that a computer be avai1able. 
It can be used by public and private sectors and large and small organizations. It can be used by politicians to select the best strategies for campalgning. Finally, it can be used by anyone interested in reaching the best solution in terms of preference mapping structure. ELECTRE II has been applied to problems such as: multi-criterion ranking and choice of long-range water resource development plans (Duckstein, 1975), as a general exploration tool, and in choice of regional or urban development projects. (Good data is necessary in such tasks). 
CHAPTER II

ALTERNATIVE APPROACHES TO MUTIPLE OBJECTIVE OPTIMIZATION

A variety of methods exist for dealing with multiple objective, multiple attribute or multiple criteria decisions.

Multiple objective problems arise in many different contexts. Not all multiple objective decision situations are the same, since the characteristics of both the DM (decision maker) and the environment will often vary. Therefore, some methods for multiple objective optimization are more suitable under particular situations than others. (MacCrimmon, in Cochrane and Zeleny, 1973, pp. 18-44). Often a combination of methods proves more effective than a single technique applied to solve multiple optimization problems.

MacCrimmon (in Cochrane and Zeleny, 1973) presents four broad categories for the various multiple objective optimization methods, they are: Weighting methods, Sequential Elimination methods, Mathematical Programming methods and Spatial Proximity methods. (Numerous sub-categories fall under these four broad categories).

Weighting Methods:

This class of methods has received the most attention. Although diverse, all methcds in this category have the following characteristics:

- A set of available alternatives with specified attributes and attribute values;

- a process comparing attributes by obtaining numerical scalings of attribute values (intra-attribute preferences) and numerical weights across attributes (inter-attribute preferences); 
- A well-specifled objective function for aggregating the preference into a single number for each alternative;

- a rule for choosing the alternative (or rating the alternatives) on the basis of the highest welght. (MacCrimmon, 1973)

Weighting methods can be grouped into three main sub-categories shown in Figure 1.

In general, in the Simple Additive Welghting method (which is one sub-category of the Welghting methods), the DM assigns importance or weights to the attributes which become the coefficients of the variables. He then obtains a total score for his attributes. Although this technique is easy to apply and widely used, it runs the risk of ignoring the different Interactions among the attributes.

The Maximin and the Maximax methods, two other sub-categorles of Weighting methods can only be used when the attributes have a high degree of comparability.

Sequential Elimination Methods:

These are less demanding of the decision maker than weightings methods. They are characterized by:

- A set of available alternatives with specified attributes and attribute values;

- scalings, perhaps only ordinal, of attribute values (intraattribute preferences) and in some cases an ordering across attributes;

- a set of constraints (but in some cases empty) across attributes;

- a process for sequentially comparing alternatives on the basis of attribute values so then alternatives can be elther eliminated or retained. (MacCrimmon, 1973).

According to MacCrimon, (1973) there are four Sequentlal Elimination methods, that can be grouped into three main sub-categories (shown in Figure 1).

Dominance, sub-category of Sequentlal Elimination methods, is 
also widely used; but unfortunately of ten does not succeed in eliminating very many alternatives.

Mathematical Programming Methods:

This class of programming methods has recently begun to receive muct attention. It has the following characteristics:

- An infinite, or very large, set of alternatives which are inferable from a set description (1.e. constraints specified on the attribute values);

- a set of technological (or sometimes preference) constraints;

- an objective function, either global or local, that is compensatory;

- an algorithm to generate more preferred points in order to converge to an optimum. (MacCrimmon, 1973)

There is only one method in each sub-category (shown in Figure 1). Interactive Multi-criteria Programming (a sub-category of mathematical programing methods), consists of different iterations made up of a calculation phase and a decision-making phase, until an optimal solution is reached. In mathematical programming methods it is preferred that the objective function be put in linear form.

Spatial Proximity Methods:

These are more speciallzed methods that are also receiving attention. These methods are characterized by the following:

- A set of identified alternatives, In some cases with vague attribute values;

- a process for obtaining intra- and inter- attribute judgments (or perhaps just an aggregated judgment);

- the construction of a spatial representation;

- the identification of 1deal configurations and the choice rule based on the proximity of alternatives to these ideal configurations. (MacCrimon, 1973).

These methods are in many ways quite different, although they share the above properties. The sub-categories consist of the methods themselves. 
A. Weighting Methods

1. Inferred Preferences

a. Linear regression

b. Analysis of variance

c. Quasi-linear regression

2. Directly assessed preferences: general aggregation

a. Trade-offs

b. Simple additive weighting

c. Hierarchial additive weighting

d. Quasi-additive weighting

3. Directly assessed preferences: specialized aggregation

a. Maximin

b. Maximax

B. Sequential Elimination Methods

1. Alternative versus standard: comparison across attributes

a. Disjunctive and conjunctive constraints

2. Alternative versus alternative: comparison across attributes

a. Dominance

3. Alternative versus alternative: comparison across alternatives

a. Lexicography

b. Elimination by aspects

C. Mathematical Programming Methods

1. Global objective function

a. Linear programming

2. Goals in constraints

a. Goal programing

3. Local objectives: interactive

a. Interactive, multi-criterion programming

D. Spatial Proximity Methods

1. Iso-preference graphs

a. Indifference map

2. Ideal points

a. Multi-dimensional, non-metric scaling

3. Graphical preferences

a. Graphical overlays

Figure 1. Multiple objective/multiple attribute decision methods

An Indifference Map (a sub-category of Spatial Proximity methods) can be obtained for the DM's preferences in the form of indifference surfaces which show the combinations of attribute values that are equally preferred.

${ }^{1}$ MacCrimmon, K. R., "An Overview of Multiple Objective Decision Making", in Cochrane, J. L. and Zeleny, M. eds., 1973, Multiple Criteria Decision Making, University of South Carolina Press, Columbia, South Carolina, pp. $18-46$. 
This technique has been used in a transportation system planning together with graphical overlays. Although this method has the advantage of obviating the need for a considerable past history of similar situations, it has the disadvantage of possibly finding that the DM is unable to verbalize his true preferences.

Other multi-objective optimization techniques (Sakawa and Sawaragi, 1975; and Vemuri, 1974) require an extensive mathematical background which is liable to scare the decision maker. These methods refine the concept of "optimal solution" by introducing the set of Pareto-optimal solutions (Pareto, 1971) or the set of "noninferior solutions". Optimization in a multiple-objective context, boils down to determining the set of noninferior solutions which is facilitated by relating it, in a one-to-one manner, to a family of auxiliary scalar optimization problems, and, for a certain class of problems, the entire noninferior set can be obtained by solving the auxiliary scalar problem.

Sakawa and Sawaragi (1975) borrow from optimal control theory to the new class of systems, such as for example, ecological, social, economic, regional development, urban development systems, etc... which change their structure in time as a result of growth, evolution, development, Investments, etc... Unfortunately, these methods, as previously stated, require extensive theoretical background.

Other methods rely on building a utility function (Briskin, in Cochrane and Zeleny, 1973, pp. 236-245). The methods depend on establishing a generalized multi-attribute utility function in the form $U$ $\left(x_{1}, x_{2}, \ldots, x_{n}\right)$. Utility functions may be used in all normal mathematical processes. Separable problems, both continuous and discrete, are relatively easy to solve. Inseparable problems may present difficulties 
of differential equations solutions and/or optimization.

Roy (1970) distinguishes four approaches to the problem of solving multiple objective function, closely related to those of MacCrimmon (in Cochrane and Zeleny, 1973). These are:

1. Aggregation of multiple objective functions into a unique function defining a complete preference order;

2. Progressive definition of preference together with exploration of the feasible set.

3. Maximum reduction of uncertainty and incomparability;

4. Definition of a partial order stronger than the product of the n complete orders associated with the $n$ objective functions.

ELECTRE II, the method chosen in this research, is defined above in 4. It works best with problems involving incomparable alternatives. It is considered in cases in which the DM is able or willing to arrive at preference decisions for only a few pairs of vectors, while for others he is either unwilling or unable to arrive at a decision. He may feel that the data are too crude, or that validating the decision would require too expenstve a study. ELECTRE II also attempts to combine the simplicity and the realism desired by the user with the elegance and strictness demanded by theoreticians (Roy and Bertier, 1973).

\section{EARLIER APPLICATIONS OF ELECTRE II}

The ELECTRE II method has been applied successfully to the solution of a forest management problem (De Ḿontgolfier, 1973). 
Duckstein (1975) made use of ELECTRE II in multi-criterion ranking of long range water resource development plans. Roy (1971), on the other hand, illustrates its application with a simple example: the choice of one among 4 cars.

ELECTRE I was used by Buffet, Grémy, Marc and Sussmann (publication year not available) for three different applications. It was first applied as media-planning modeling effort. It was later used to determine the hierarchial importance of perceived defects in cigarettes on the basis of results of an inquiry with a sample of smokers. It has also been employed in the choice of a new product or a new activity for a firm.

ELECTRE II can be used by an individual or by a decision making group. The focus in this thesis has been on its use for group decision making.

\section{TEAM DECISION MAKING}

One area predicted to become of major importance is decision making as a group process. A team approach will not insure either downgrading or upgrading of decision quality, (G1lmartin, 1974). The nature of the groups utilized and other factors tend to influence the performance of the group.

A salient criticism (concerning social psychology) in the area of group decision making has been raised against the nature of the groups utilized. Lorge et al (1958, cited in Gilmartin, 1974) warn against the practice of generalizing the results dealing with groups of strangers to established groups.

An experiment conducted by Hall and Williams (1966, cited in Gilmartin, 1974) using established and experimentally created ad hoc groups 
indicate the superior decision quality produced by established groups as compared to that of ad hoc groups. In that experiment, ad hoc groups handled conflict by compromise, which downgraded their group decision quality. In contrast, established groups responded to conflict with creativity and subsequent quality increases in group decisions.

There are other factors that tend to influence the performance of the group. Gilmartin (1974) presents to us different psychological factors that tend to downgrade the final group output, and other forces that may affect the group output in a positive manner. He conceptualized the group attempting to make a decision as a field of potential energy with forces that can move decision quality in either direction.

Forces that potentially downgrade the quality of decisions made by the group are (Martino, 1972; Gilmartin, 1974): the strain for convergence or the apparent need of the group to coalesce. Hall and Watson (1970, cited in Gilmartin, 1974) hypothesized that group members need to generate a decision as rapidly as possible and evade the responsibility of making the decision. These groups, Hall believed, were more concerned with reaching a decision than with the decision reached.

The democratic process or the technique of majority-rule and compromise to reduce conflict of opinion is another source of pressure that tends to downgrade group decision quality, (Martino, 1972). Hall and Williams, (1970, cited in Gilmartin, 1974), have shown that these techniques produce group decision comparable to an average member output. The intensity of the verbal output is another factor that may affect group decision quality, (Martino, 1972; Literature on Delphi).

Forces that affect the group output in a positive manner are the amount and diversity of group potential. Groups comprised of individuals 
of heterogeneous backgrounds generate solutions more fully acceptable to the group while having higher rating in inventiveness, (Hoffman, 1959, Hoffman and Maier, 1961; Lorge and Solomon, 1955, 1959, 1960; Lorge et al., 1955; Tuckmann and Lorge, 1962; a11 cited in Gilmartin, 1974).

\section{SPAN, A COMPETITIVE METHOD USED AS A CONTROL TECHNIQUE IN THIS \\ INVESTIGATION :}

According to Gilmartin, the psychologist should intervene by attempting to develop techniques which will maximize those forces tending to upgrade the quality of group decision. He believes that the SPAN technique invented by W. J. MacKinnon (1966a; 1966b; MacKinnon and MacKinnon, 1969; cited in Gilmartin, 1974) is capable of maximizing the positive forces affecting a group while at the same time eliminating the attenuating forces.

In the SPAN investigation, groups were assessed when the label "ad hoc" was appropriate and then again after human relations training; other groups were assessed only after training. According to Gilmartin, if one of the purposes of human relations training is to increase the sensitivities of the members of the group to each others' abilities, this obtained effect was as readily realized with the SPAN process. Besides establishing the ability to effectively use SPAN as an outcome measure in human relations training, Gilmartin's study tested the hypothesis that SPAN would produce superior group decisions with respect to unstructured group discussion in both ad hoc and established groups.

The SPAN (Social Participatory Allocative Network) technique, which is one of the control methods used for this thesis, has been shown to significantly improve group decision quality above the level generated by 
existing methods in groups of various sizes and with a variety of problem tasks (Hitchcock, 1967, 1971; Kelly, 1968; Willis, 1966; Willis, Hitchcock and Mackinnon, 1969; al1 cited in Gilmartin, 1974).

A basic rationale of the SPAN technique is that it allows group members to specifically assess the abilities of other group members to solve the particular task (not only the potential solutions to the task problem).

In the SPAN process each member divides his parcel of power (i.e. his vote) between two classes: the remaining group members and the available solution to the task. These classes are called representatives and options respectively. After the initial division of parcels, the individual is permitted to specify allocations (of his vote) to specific representatives and specific options. The cyclic computation of the SPAN process is computerized and results in all points passing from the representatives category to the options category (Gilmartin, 1974), i.e. SPAN allows bifurcated channeled allocations of portions of one's own votes to options and/or recipients. A confidence estimation accompanies each allocation.

In the first empirical work with SPAN, Willis (1966) proved it to be superior to two other techniques that permitted only direct allocations.

SPAN has also the capability to perform what Tuckman and Lorge (1962, cited In Gilmartin) "consider one of the most important tasks needed in group research, that of developing routes for bringing the best individual effort [knowledge, capability] forward." SPAN has been tested for partial enhancement of apparent group intelligence (i.e. quality of judgments/solutions) in various tasks such as the following: 
(Martin, 1976):

1. City council, planning and zoning commission budget prioritysetting exercises;

2. a VA hospital staff effectiveness training workshop on group problem solving (Gilmartin, 1974);

3. an assessment of the interdependence of obstacles to investment in a central business district;

4. for obtaining models to provide convenient and accessible 1 ibrary facilities for the year 2000 for a large city;

5. as a general system planning for urban design;

6. in a military simulation group problem solving task dealing with mined roads (Wil1is, 1966);

7. on a public safety citizens' task force regarding neighborhood safety.

Neither SPAN nor ELECTRE II generate new items in the solution, and do not attempt to enhance invention and creativity; hence, the potential importance of the "Front End ELECTRE II" developed as part of this thesis. 
CHAPTER III

EXPLANATION OF ELECTRE II

GENERAL STATEMENT (LAYMAN'S EXPLANATION)

ELECTRE II analyzes and structures data (including incomparable data like different rating scales and measures. It borrows from methods of aggregation, rank ordering and graph theory. It emphasizes convenient manipulation of multiple points of view (i.e. different criteria, weights and thresholds of acceptance or rejection, etc...).

The method consists of developing alternative projects, strategies or policies, defining different criteria, and assigning different weights and scales for each one of these criteria. ELECTRE II can be used to rate each project, strategy, policy or item according to its respective fulfillment of the various criteria. These ratings are built according to known or semi-known preferences and qualitative data.

One ends up with better structured data that aids in decision makIng.

User Steps (i.e. Input by the Decision Maker)

The user has to imput the following:

a Judgments:

1. Generate alternative projects, strategies or policies to 
be evaluated.

2. Identify the different criteria or evaluation attributes to be used.

3. Assign a set of weights (relative importance) to these criteria.

4. Rate each alternative policy or project on the extent to which it meets evaluation criteria.

The above 4 steps are subject to change and sensitivity analysis. They can be used repetitively to explore the DM's preferences using different assumptions.

b Setting ELECTRE II Parameters (Thresholds): ${ }^{1}$

1. Set the parameters of agreement of preference $c_{1}, c_{2}, c_{3}$, (i.e. strength of agreement of the majority point of view).

2. Set the parameters of rejection $d_{1}, d_{2}, d_{3}$, (i.e. strength of disagreement of the minority point of view).

3. Set $s$, the number of disagreements (number of dissenting votes).

The above 3 steps are subject to sensitivity analysis.

${ }^{1}$ For further explanation, refer to the rest of the chapter and appendices $B$ and $C$. 
c Individual versus Group DM use:

The individual uses ELECTRE II by filling out the input steps described above. He may explore his preferences by watching the outcome of his ratings and changing the thresholds if desired.

For a group to apply this method, two alternative modes of operation are available. One way is to average the individual members' inputs on ratings and weights; another is to represent the different individual points of view as different criteria, and the number of voters for these points of view as weights of the criteria (see De Montgolfier and P. Bertier, 1973). With this latter method, objective ratings would be furnished by technical experts in the usual way, and subjective ratings would be an average of the individual ratings.

Reference Example (Grolleau and Tergny, 1971)

A convenient way to gain a deeper understanding of input to ELECTRE II is through an example. The example consists of a rank ordering of a regional development project in the form of a study to aid in the selection of development strategies.

There are 7 projects: (A, B, C, D, E, F, G) that we want to evaluate. They could be related to education, research, sanitary control, formation of specialized personnel, etc. . . 10 criteria are considered in the evaluation of each project. Examples of some possible criteria are:

- Impact due to decline of mortality rate. (Est.imated by experts).

- Socio-economical and sanitary priorities.

- Regional needs.

- Technical feasibility. 
We have two groups of experts (with two different opinions) that will estimate the relative importance of the various criteria. We wish to obtain an ordering or a classification corresponding to each of the two groups. (These are called "hypotheses"). The data are shown in Table I.

TABLE I

MATRIX OF EVALUATIONS ATTRIBUTED TO

THE PROJECTS RELATIVE TO THE

10 CRITERIA

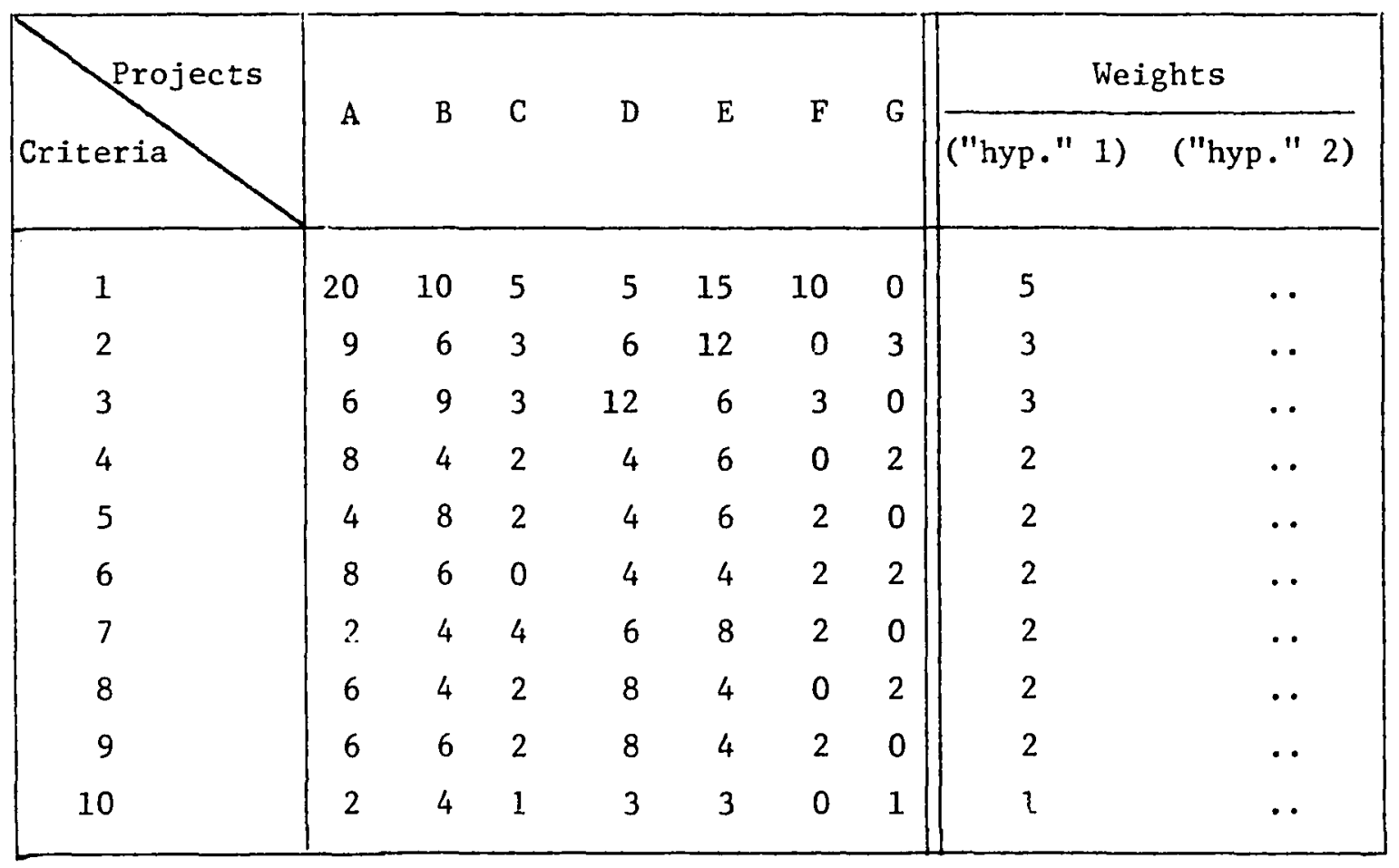

We oiserve that criterion 1 is scaled from 0 to 20 , criteria 2 and 3 are scaled from 0 to 12 , criteria $4,5,6,7,8,9$ from 0 to 8 , and finally criterion 10 from 0 to 4.

ELECTRE II can process several alternative sets of weights (sensitivity analysis or ratings by different groups). Each set of weights is referred to as an "hypothesis" (number 1 and number 2 in our refer- 
ence example).

Weightings:
(1)
(2)
(3)
(4)
(5)
(6) (7)
(8)
(9) (10)

First

"Hypothesis"

$\begin{array}{llllllllll}5 & 3 & 3 & 2 & 2 & 2 & 2 & 2 & 2 & 1\end{array}$

Second

"Hypothesis"

\section{Indices of Concordance and Discordance:}

The standard values proposed for the indices of concordance and discordance (i.e. thresholds of agreement and disagreement) are the following:

$C_{1}=3 / 4, \quad C_{2}=2 . / 3, \quad C_{3}=3 / 5$

$D_{1}=1 / 4, D_{2}=1 / 3, D_{3}=2 / 5$

$c_{i j} \geq 3 / 4$ and $d_{i j} \leq 1 / 4$ means that more than $3 / 4$ of the criteria should revea 1 that item $i$ is preferred to item $j$, and less than $1 / 4$ of the criteria should reveal that item $j$ is preferred to item $i . s=2$ means that ( $s-1$ ) or only one criterion can be opposed to item $i$ being preferred to item $j$ in order for that preference to be accepted. (For further explanation see the rest of this chapter and appendices $B$ and $C$ ).

\section{ELECTRE II Computional Preference Generating Algorithm}

ELECTRE II is a procedure for manipulating the 4 inputs and the 3 thresholds cited above; then setting and determining 3 conditions of preference ranking (i.e. deciding which items are strongly preferred to others, which are indifferent, and which are clearly not preferred, etc...). ELECTRE II provides a hierarchy (or rank ordering) of prefer- 
ence differences, ELECTRE II shows when no significant difference (as defined by the three thresholds) in preference between alternatives exist.

\section{ADVANTAGES OF ELECTRE II}

Extensive literature search in multi-objective optimization has shown the difficulty of integrating and aggregating more or less qualitative criteria into a synthetic model. ELECTRE II is a multi-objective optimization method which has many significant advantages:

1. One unique advantage of ELECTRE II (comparable to the statistical significance testing) is where a minor point advantage, aj.though considered, is not assigned more importance than it deserves (i.e. shows the difference in preference score is not significant).

2. No other method allows explicitly for both the intensity and amount of disagreement.

3. It does not rely on many mathematical assumptions. (One example is the majority of weighting methods which, while multiplying the different ratings by their weightings also multiply the potential errors in their evaluations). No special equation form is assumed.

4. Although based on rigorous and logically valid foundations, it is easy to use. The users need not understand the computational procedures or theoretical basis of ELECTRE II to comprehend the basic logic of the approach. 
5. The method is comprehensive in the sense that it accepts both objective and subjective input.

6. It takes into account intransitivity through the building of an outranking relation.

7. It places the data in proper perspective. Not allowing the data to say more than it really can, whether in regards to qualitative or quantitative Information (Roy and Bertier, 1973).

8. It is flexible enough to allow performing sensitivity analysis on the results. It is important to allow the DM to assess the effects of changes in the data (Roy and Bertier, 1973). It thus allows explanation so that real preferences can become known to the user.

PRESENTATION OF THE METHOD ${ }^{2}$ (Grolleau and Tergny, 1971)

\section{Problem Formulation}

Consider the set $(x, y, z, \ldots)$ of m elements (i.e., strategfes or alternatives) that need to be classified or rank ordered. Each element is evaluated according to $n$ criteria or points of view by an individual or a group.

Different criteria can have different scales. The criterion scales assigned to alternatives are referred to as $\gamma_{i}(x)$, where $\gamma_{i}=$ weights

${ }^{2}$ See appendix $C$ for a numerical example to illustrate the ELECTRE II algorithm. 
(scales) and $x, y, z$, etc... are the alternative strategies.

Example of Scales ${ }^{3}$ :

POSSIBLE VALUES

$\underline{\text { SCALE }}$

(bad, acceptable)

(bad, fair, average, good, very good)

(round percentage figure)

(gains in monetary units)

$(0,1)$

$(1,2,3,4,5)$

$(0,1, \ldots, 100)$

(set of positive

real numbers)

The expression $\gamma_{i}(y) \geq \gamma_{i}(x)$ (or $y R x$ ) means that for specific criterion $\gamma_{i}$, y ranks better or higher than $x$.

The evaluation of $\mathrm{m}$ strategies (or elements) according to the $\mathrm{n}$ criteria produces a table or matrix with $\mathrm{m}$ columns and $\mathrm{n}$ rows. This matrix should help in synthesizing the preferences of the decision maker.

Weighting by Individuals

It can happen that some points of view (i.e. criteria) have more importance than others. These different levels of importance of the decision maker are translated by assigning weights $p_{i}$ to the different criteria. The greater the weight, the greater the importance of the criterion. The decision maker might estimate that criterion (i) is more important than criteria (k) and (1) together. Also, that (k) and (1) are as important as $(j)$. The weights might then be represented as follows:

3 Four standard scales are usually designed but the user can introduce others. 
hypothesis 1: $\quad \begin{array}{llll}1 & j & k & 1 \\ 5 & 4 & 2 & 2\end{array}$

or, alternatively, hypothesis 2 :

$\begin{array}{llll}6 & 5 & 3 & 2\end{array}$

(The weights could also be derived from the percentage of voters [Bertier, and De Montgolfier; 1973]).

\section{Preference Relation}

Element (or strategy) $\mathrm{x}$ will be preferred to another element (or strategy) $\mathrm{y}$ when $\mathrm{x}$ is at least as good as $\mathrm{y}$ according to each criterion, assuming reliability of data.

More generally, if $\mathrm{x}$ is better than $\mathrm{y}$ according to certain criteria, less good according to others, equivalent in still another group of criteria, the DM(s) and the analyst should explicitly determine the conditions under which one can affirm either that $\mathbf{x}$ is largely preferred to the others, or that no conclusion can be drawn; the risk of error in that latter case 1s very large.

This notion of "largely preferred" or "largely better under certain conditions" is formalized by a relation denoted as "preference relation R." We will then say that an element $x$ is preferred to an element $y$ and will write $x \mathrm{R} y$, if at the same time we have:

1) The sum of the weights of the criteria, where $x$ is at least as good as $y$, is sufficiently high.

2) The difference of value for all criteria, where $x$ is less good than $y$, is not very significant. 
In some cases, different criteria can represent different members of a jury, the weight of each criterion will correspond to the number of voices alloted to it. The preference relation then defines the conditfons of voting in absence of unanimity.

In particular, rule 1 or condition of concordance imposes that a certain majority has to be in favor of $x$. Yet, this condition is not sufficient, since it can happen that in the minority, certain opinions are strongly opposed to the choice of $x$.

If a weak majority is in favor of $x$ and if there is no violent opposition among the opinions not favoring $\mathrm{x}$, we estimate that $\mathrm{x}$ is preferred to $y$. In contrast, if an opinion in the minority is violently opposed to $x$, we admit that such a veto legitimately prohibits the preference relation. This is the importance of rule 2 or condition of nondiscordance.

In order to define whether rules 1 and 2 are satisfied or not, the group must agree a priori upon acceptable levels of concordance and discordance. (For example, a value of $c_{i j} \geq 3 / 4$ and $d_{i j} \leq 1 / 4$ means that more than $3 / 4$ of the criteria should reveal that $x$ is preferred to $y$ and less than $1 / 4$ of the criteria should reveal that $y$ is preferred to $x$. In that case, $p=3 / 4$ and $q=1 / 4)$. We also introduce $s$ as: the number of the opposition as compared to d: the weight or importance of the opposition. ( $s=2$ means that $s-1$ or one person only can be opposed to $x$ being preferred to $y$ in order for that preference to be accepted. $s$ can also refer to the number of criteria), (Buffet et a1., 1967). (Further details on the indices of concord and discord, will be discussed in a later subsection).

Once rules 1 and 2 are simultaneously satisfied; we can distinguish 
between 2 cases: if these conditions of preference are largely filled, we speak of "strong preference;" if not, we then speak of "weak preference."

$\underline{\text { Rank Ordering }}$

The concept of "strong" and "weak" preference will enable us to reach one of five conclusions for each couple of objects $(a, b)$ :

- a is "strongly" better than b (denoted as a F b).

- $a$ is "weakly" better than b (denoted as a $f \mathrm{~b}$ ).

- The two objects cannot be directly compared considering the available information.

- $b$ is weakly better than $a$ ( $b$ f a).

- $b$ is strongly better than $a$ ( $b$ F a).

This information is then represented by a graph where each node represents one of the objects, and where there are two types of arcs:

- a full line arc denoting a strong preference relation.

- a dotted arc denoting a weak preference relation.

The following figure represents the rank ordering corresponding to the reference example using hypothesis 1. 


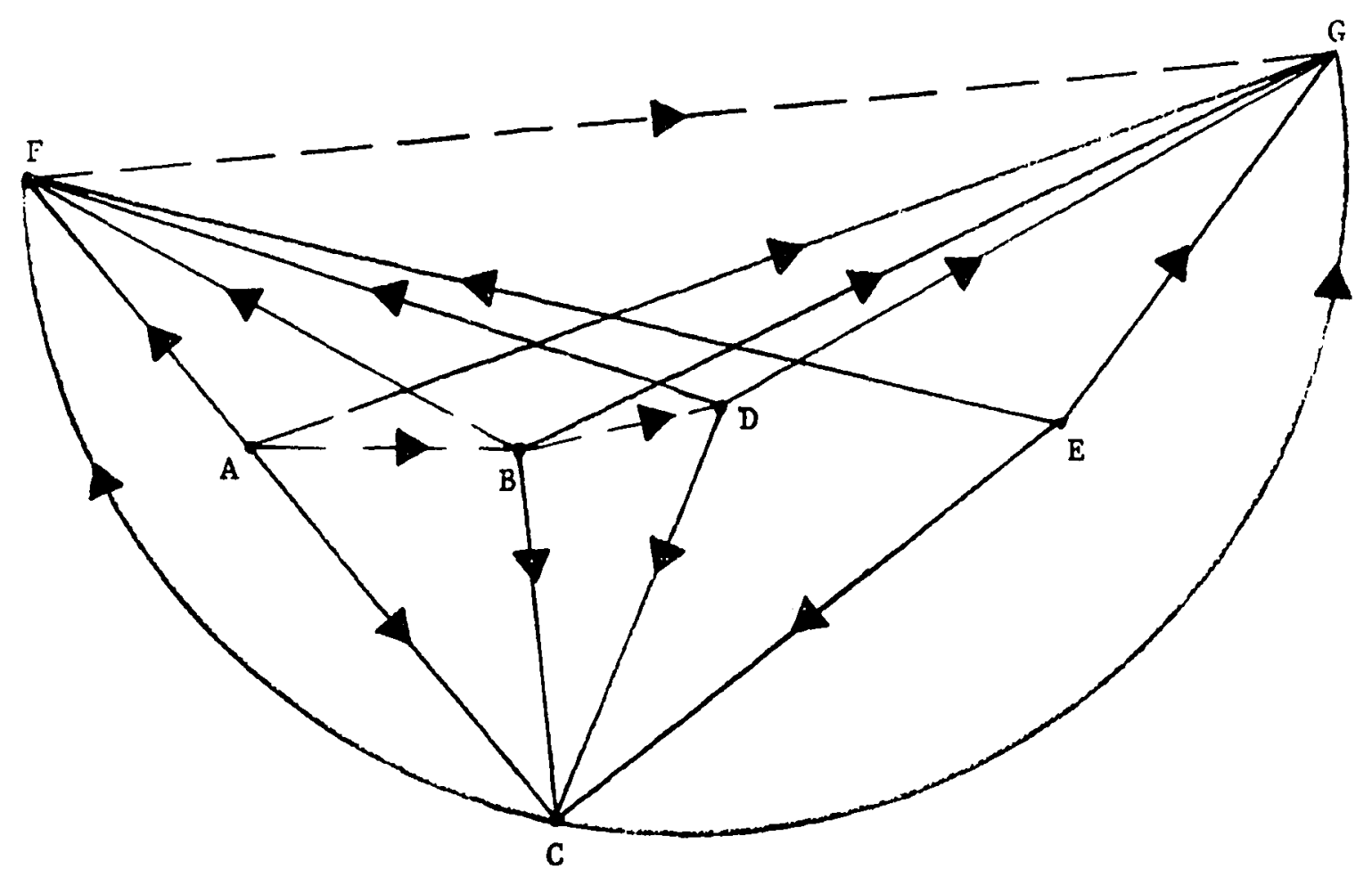

F1gure 2. A Digraph of the Reference Example

ELECTRE II allows construction of one (and eventually many) rankings of objects that depict best the synthesized information.

We will denote by $c(a)$ the ordering (or ranking) of the object $a$. The number of classes (or rankings) will be less than or equal to the number of objects (since one rank can include equivalent objects).

We first consider rankings compatible with the graph of strong preferences, 1.e., those verffying the relation:

$$
\mathrm{aFb} \rightleftharpoons \mathrm{c}(\mathrm{a})>\mathrm{c}(\mathrm{b})
$$

Relations of weak preferences will be considered whenever they permit refinement of the preceding order.

First Remark: If a circuit exists in the case of strong prefer- 
ences (for example: $a \mathrm{~F} b, \mathrm{bF}, \mathrm{cFd}, \mathrm{dFa}$ ) an approprlate ranking cannot be obtained for this graph and all nodes are then considered equiva1ent. We then reduce the number of nodes by replacing the nodes of the circuit with a unique representative of this class. The representative should dominate any object dominated by at least one of the elements of the circuit. It should be dominated by an object dominating at least one of them.

Second Remark: after reducing the graph, we will have simultanously: a F b, bFc, cFd, dFe. Any compatible ordering should verify the following relationship:

$$
\begin{aligned}
& c(a)>c(e) \quad \text { and this holds whether or not the relationship } \\
& \text { exists. The case of (eF a) being excluded after } \\
& \text { reduction]. }
\end{aligned}
$$

We then define the following:

Incident paths to an apex or a node (a): is defined as the set of apexes or nodes $\left(b_{1}, b_{2}, \ldots ., b_{k}\right)$ verifying $b_{1} F b_{2}, b_{2} F b_{3}, \ldots .$. $b_{k-1} F b_{k}, b_{k} F a$.

Issued paths to an apex or node (a): is defined as the set of nodes $\left(c_{1}, c_{2}, \ldots ., c_{p}\right)$ verifying a $F c_{1}, c_{1} F c_{2}, \ldots ., c_{p-1} F c_{p}$.

The lengths of such a path (incident or issued) is defined as the number of nodes forming the set.

\section{(i) Direct Ranking}

The nodes are classified according to the lengths of incident paths that reach them. A node will be classified (or ranked) as first, if no 
other node is strongly preferred to it. A node at the extremfty of the longest path will be ranked as last.

Example: Consider the graph in Figure 2, and neglect relations of weak preferences. The following is obtained:

$$
\begin{aligned}
& c^{\prime}(A)=c^{\prime}(B)=c^{\prime}(D)=c^{\prime}(E)=1 \\
& c^{\prime}(C)=2 \\
& c^{\prime}(F)=c^{\prime}(G)=3
\end{aligned}
$$

After integrating the information gained from the weak ranking, the following direct ranking is obtained:

$$
\begin{aligned}
& c^{1}(A)=c^{1}(E)=1 \\
& c^{1}(B)=2 \\
& c^{1}(D)=3 \\
& c^{1}(C)=4 \\
& c^{1}(F)=5 \\
& c^{1}(G)=6
\end{aligned}
$$

\section{(ii) Inverse Ranking}

Here, a node is better off the lengthier the path of issued arcs from it. Thus, the node "origin" belonging to the longest path will be ranked first, and any node not strongly preferred by any other will be 1ast.

Example: Consider the graph in Figure 2. The following inverse ranking is obtained:

$$
\begin{aligned}
& c^{2}(A)=1 \\
& c^{2}(B)=2 \\
& c^{2}(D)=c^{2}(E)=3 \\
& c^{2}(C)=4
\end{aligned}
$$


$c^{2}(F)=5$

$c^{2}(G)=6$

\section{(iii) Median (or fina1) Ranking}

This is the final ranking. It is intermediate between direct and inverse ranking. It is obtained by calculating the following for each object (i):

$$
v(i)=\frac{c^{1}(i)+c^{2}(i)}{2}
$$

We then order the objects in increasing order. The final median ranking of our reference example will be the following:
$C(A)=1$
$c(B)=c(E)=2$
$C(D)=3$
C $(C)=4$
$c(F)=5$
$c(G)=6$

\section{Sensitivity Analysis}

There are three modifications we can perform in ELECTRE II: the weightings (different hypotheses), the evaluations of the objects according to each criterion, and the different parameters defining the preference relation ( $p, q, s)$.

When the modifications in the evaluations and the parameters (within limits of the uncertainties and imprecision) produce little or no change in the median ordering; we say that the ordering (or ranking) is not sensitive: such an ordering deserves the greater confidence.

The extreme opposite case occurs when slight modifications in the data radically change the ranking. The ranking is considered here very 
sensitive: Such an occurrence will translate the fact that the furnished information is insufficient to permit valid ranking of the candidates.

We finally mention a precaution to be taken in the following special case: After application of ELECTRE II, a sudden or new constraint forces elimination of certain candidates. For example: A is first, $B$ second, $C$ third, $D$ fourth, E fifth, but $A$ and $C$ must be eliminated. In these conditions, one can be tempted to order the remaining candidates in accordance with the preceding ranking obtaining: B first, D second, E third.

In certain sensitive cases, this ranking can be different from the one obtained by application of ELECTRE II to the subset of candidates not eliminated. From here, the necessity of going through ELECTRE II again with the new subset appears.

Annex to Preference Relation: Additional Explanation on the Physical Meaning of Concord and Non-Discord Indices (Buffet et al., 1967)

Let us go back to the preference relation and obtain a more precise definition. This definition will also help review all hypotheses of the problem.

We notice that our concern in comparing two elements $i$ and $j$ (or a and b) while taking into consideration all points of view, implies, in particular, that we know how to compare them following each point of view taken separately. It is for this reason that one will have to presume that with each point of view, a corresponding scale of appreciation can be built and that each object can be associated to a level of each of these scales. (The contribution of this work is to alleviate 
the inadequacy of the above two assumptions).

In these conditions, two elements $i$ and $j$ can be compared with respect to each point of view, and it seems natural to admit that $i$ is preferred to $j$ when the proportion of points of view for which $i$ is at least as good as $j$ is higher. But one can object that the points of view might have different importance or weightings, as compared to the case of voting where we have different number of voters.

This leads us to associate with each point of view an integer, a weight (coefficient) that measures its importance. Now, we estimate the hypothesis; $i$ is preferred to $j$, is more legitimate if the sum of weights (coefficients) for points of view for which $i$ is a least as good as $j$ (number in favor of the hypothesis) is greater when divided by the sum of all weights (coefficients) (total number of votes).

We will define "concordance index with the related hypothesis that $i$ is preferred to $j "$ as the fraction of these two sums, and will designate it by $c_{i j}$ (or $c_{a b}$ ) - if our objects are called a and b. One should note that $c$ will always be between 0 and 1 .

Unfortunately, a certain inconvenience accompanies $c_{i j}$ : as much as $c_{i j}$ assigns importance to the MAJORITY (points of view in agreement with the hypothesis), it gives none to the MINORITY. Yet, it can happen that the disagreement with this hypothesis, originating from many points of view, is quite large; and that the corresponding points of view are particularly important. And as M. Marc (1967) (Buffet et a1., 1967) says "even if this minority is small in number,... It goes down in the street, machine guns in hand."

This leads us to complete the notion of preference by introducing a second index to attempt to measure the amp1itude of djscord or disa- 
greement that exists between major or minor points of view as to the legitimacy of the hypothesis that $i$ is preferred to $j$. We will qualify this index as "discord index" and will denote it by $d_{i j}$. This index is obtained by dividing the amplitude of the difference of the greatest disagreement by the amplitude of the greatest possible disagreement (height or range of the scale), such that $d$ is between 0 and 1 .

The above definition has one inconvenience: it does not explicitly take into account the amplitude of other disagreements; so we furthur consider an integer and arrange the disagreements in decreasing order. We then define $d_{i j}(s)$ as the fraction of the amplitude of the $s^{\text {th }}$ disagreenent to the amplitude of the greatest disagreement possible. (If we choose $s=1$, we will find that $d_{i j}(1)=d_{i j}$ ).

We, now, can be precise about the rules of decision that will lead to acceptance of the hypothesis of preference of $i$ to $j$ : we give a concordance level $\mathrm{p}$ and a discordance level $\mathrm{q}$. We will say that $i$ is preferred to $j$ for the two levels $(p, q)$ if and only if, simultaneously

$$
c_{i j} \geq p \text { and } d_{i j} \leq q
$$

i.e. if the concordance is sufficiently great and if, simultaneously, the discordance or the disagreement is sufficiently small.

\section{NATURE OF DATA}

\section{Table of Scales}

The criteria of different objects will have scales or evaluations that represent the appreciation of object $x_{j}$ according to criterion (or point of view) $i$.

If we have $\mathrm{M}$ objects and $\mathrm{N}$ criteria, we obtain a matrix of 
dimensions $(M) \times(N)$. There are four standard scales that are usually assigned to the criteria:

Type 0 (real positive values)

Type 1 (integer from $0-4$ )

Type 2 (integer from $0-10$ )

Type 3 (integer from $0-20$ )

There are other types which can be used with slight modifications in the program:

$$
\begin{aligned}
& \text { Type } 4 \text { (integer from } 0-12 \text { ) } \\
& \text { Type } 5 \text { (integer from } 0-6 \text { ) } \\
& \text { Type } 6 \text { (integer from } 0-1000 \text { ) }
\end{aligned}
$$

Weight of Criteria

Each criterion (i) will have associated with it a weight $p(i)^{4}$ (positive integer). The program allows various "hypotheses" of weights (twenty at the most). The rest of the matrix should remain the same.

Parameters of Preference: Definitions of Strong and Weak Preferences:

Let $x$ and $y$ (or $a$ and $b$ ) be two objects to compare, we note:

$I^{+}(x, y)$ the set of indices of criterion (i) for whtch $\gamma 1(x)>\gamma \perp(y)$. $I^{-}(x, y)$ the set of indices of criterion (i) for whj.ch $\gamma 1(x)<\gamma i(y)$. $I^{\prime}(x, y)$ the set of indices of criterion (1) for which $\gamma I(x)=\gamma i(y)$.

\footnotetext{
${ }^{4}$ A value of $\mathrm{p}(i)=0$ means that this criterion will not be con-
} sidered. 
Then:

$\begin{array}{ll}\mathrm{P}^{+}(\mathrm{x}, \mathrm{y})=\sum_{i \in I^{+}} \mathrm{P}_{1} & \text { for }(\mathrm{x}, \mathrm{y}) \\ \mathrm{P}^{-}(\mathrm{x}, \mathrm{y})=\sum_{i \in I^{-}} \mathrm{p}_{i} & \text { for }(\mathrm{x}, \mathrm{y}) \\ \mathrm{P}^{=}(\mathrm{x}, \mathrm{y})=\sum_{i \in I^{-} \mathrm{p}_{i}} & \text { for }(\mathrm{x}, \mathrm{y})\end{array}$

$\mathrm{x}$ will be preferred to $\mathrm{y}$ if the three following conditions are met:

a) $\frac{P^{+}(x, y)}{P^{-}(x, y)} \geq 1$

b) $\hat{c}(x, y)=\frac{p^{+}(x, y)+p^{=}(x, y)}{p^{+}(x, y)+p^{\prime}(x, y)+p^{-}(x, y)}$ is "sufficiently large."

c) For all $i \in I^{-}, \gamma i(y)-\gamma i(x)$ is "not too large."

\section{Example:}

Let us compare objects $A$ and $B$ in the reference example under hypothesis

1:

$\mathrm{P}^{+}(\mathrm{A}, \mathrm{B})=14 ; \mathrm{P}^{-}(\mathrm{A}, \mathrm{B})=2 ; \mathrm{P}^{-}(\mathrm{A}, \mathrm{B})=8$

From the above we have:

$\frac{P^{+}(A, B)}{P^{-}(A, B)}=1.75$ and $\hat{C}(A, B)=2 / 3$

and for all $i \in I^{-}(A, B)$, the values $\gamma_{i}(B)-\gamma_{i}(A)$ are the following:

$\underline{\text { i }} \quad$ Difference $\gamma_{i}$ (B) $-\gamma_{i} \underline{(A)}$

3

5

7

10

b) and c) will determine whether we have "strong preference" or "weak 
preference."

In particular:

** $\mathrm{x}$ is strongly preferred to $\mathrm{y}$ if:

$\frac{\mathrm{P}^{+}(x, y)}{\mathrm{P}^{-}(\mathrm{x}, \mathrm{y})} \geq 1$

and $\hat{c}(x, y) \geq c_{1}$

and $\gamma_{i}(y)-\gamma_{i}(x) \leq \Delta_{i}^{2}, \gamma_{i(x)}$ for all $i \in I^{-}(x, y)$

or if:

$\frac{\mathrm{P}^{+}(\mathrm{x}, \mathrm{y})}{\mathrm{P}^{-}(\mathrm{x}, \mathrm{y})} \geq 1$

and $\hat{\mathrm{C}}(\mathrm{x}, \mathrm{y}) \geq \mathrm{C}_{2}$

and $\gamma_{i}(y)-\gamma_{i}(x) \leq \Delta_{i}^{1}, \gamma_{i(x)}$ for all $i \varepsilon I^{-}(x, y)$

** $\mathrm{x}$ is weakly preferred to $\mathrm{y}$ if:

$\frac{P^{+}(x, y)}{P^{-}(x, y)} \geq 1$

and $\hat{C}(x, y) \geq C_{3}$

and $\gamma_{i}(y)-\gamma_{i}(x) \leq \Delta_{i}{ }^{2}, \gamma_{i(x)}$ for all $i \varepsilon I^{-}(x, y)$

with:

$0 \leq \Delta_{i}^{1}, \gamma_{i(x)} \leq \Delta_{i}^{2}, \gamma_{i(x)}$

and :

$c_{1} \geq c_{2} \geq c_{3}$

We now define the significance of parameters $\mathrm{c}$ and $\Delta$ : 
Concordance Indices: $\mathrm{C}_{\mathrm{j}}$

Parameters $\mathrm{C}_{1}, \mathrm{C}_{2}, \mathrm{C}_{3}$ are called "concordance indices."

The standard values proposed for these indices are the following:

$c_{1}=3 / 4$

$c_{2}=2 / 3$

$c_{3}=3 / 5$

The user can adopt different values, as long as the following inequalities are met:

$1>c_{1} \geq c_{2} \geq c_{3}>0$

Let us go back to the comparison of objects $A$ and $B$ of the reference example, and choose standard values for concordance indices, we obtain:

$\hat{C}(A, B)=2 / 3=C_{2}$

Then according to the values chosen for the discordance parameters $\Delta_{i}{ }^{1}, \gamma i(A)$ and $\Delta_{i}{ }^{2}, \gamma 1(A), A$ will either be strongly preferred to $B$ or weakly preferred to $B$ or will not be preferred to $B$.

$$
\begin{aligned}
& \Delta_{i}^{1}, \gamma_{i}(x)=p_{1}\left[\max \left(\gamma_{i}(x), s\right)\right] \\
& \Delta_{i}^{2}, \gamma i(x)=p_{2}\left[\max \left(\gamma_{\gamma 1}(x), s\right)\right]
\end{aligned}
$$

with:

$0 \leq p_{1} \leq p_{2} \leq 1$

In brief:

(1) In order to obtain (c) we get the sums of weights of criteria 
(where alternative $A$ is better than alternative $B$ ) and divide by the total weights of the criteria.

(2) In order to obtain (d) we get the largest disagreement and divide by the greatest possible disagreement in that criterion.

(3) For $s=4$, show four criteria where alternative $A$ is not preferred to $B$ with (d) as ratio,

* For further details, see Grolleau and Tergny, 1971. 
CHAPTER IV

METHODOLOGY AND HYPOTHESIS

DEVELOPMENTAL PHASE

\section{ELECTRE II Input Aiding Questionnaire Development}

After reviewing part of the problem solving, decisiom making and systems science literature, an input aiding questionnaire was developed to augment ELECTRE II (Ha11, III, 1969, The System's Analyst Decalogue, 1972; Martino, 1972; M'Pherson, 1974; Systems Sclence Program Description, 1975; Lendaris, 1976; Block, 1970). The more general problem solving suggestions, approaches, strategies or hints from the literature were examined and incorporated into the questionnaire. The purpose of this questionnaire was to improve the quality of input to the ELECTRE II framework.

The questionnaire directs the decision maker to consider many aspects (variables) that might pertain to the problem under study (e.g. technical, social, political, human, economic, managerial, ecological, etc.,[Martino, 1972]). Through the questionnaire, the decision maker (or group) is aided in developing the factors, variables, or criteria that should be considered in formulating the different goals or policies to be evaluated with ELECTRE II.

Some of the aiding hints offered by the questionnaire deal with:

- careful problem definition;

- revlew of the facts supplied;

- examples of we11-defined systems; 
- assessment of technological and social impact;

- combining similar or overlapping criteria into distinct aggregates;

- Importance of good factual data;

- careful reading of the instructions;

- caution on persuasiveness versus sound logic of group members;

- rechecking and reevaluating the various assumptions or judgments made;

- generally avoiding identical weights for criteria;

- comparing pairs of items for difficult rating decisions, etc...

The questionnaire is general in nature so as to be applicable across a broad spectrum of problems contexts.

An abbreviated version (1.e. a subset of questions) of this ELECTRE II input aiding questionnaire was also developed. The subset of questions most appropriate for the particular NASA moon problem was chosen on a subjective basis. For other problems, the user/administrator of ELECTRE II would need to select another subset from the larger questIonnaire that would fit the problem involved.

For the abbreviated questionnaire task specific vocabulary (the task name) was inserted for the "neutral" vocabulary (actually, blanks in the larger questionnaire to be filled by the user) of the larger questionnaire.

The questionnaire was originally envisioned as an interactive computer software package. To reduce costs and eliminate possible 1ogistical problems in conducting experiments, however, it was decided to 
put the questionnaire into a written, programmed-instruction format. This questionnalre form seemed to work well.

$$
\begin{gathered}
\text { GENERAL GUIDELINES FOR BUILDING } \\
\text { THE ABBREVIATED VERSION } \\
\text { (1.e. SUBSET OF QUESTIONS) }
\end{gathered}
$$

The various questions in the abbreviated version have their correspondents in the larger questionnaire: (viz. 1,2,3,4,5,6,7,8,9 correspond to $1,2,22,21,10 \mathrm{a}, 20,28,29,30$ respectively.)

Developing an abbreviated questionnaire requires the selection of subsets of general problem solving hints that would be most rele int to the particular problem, and filling in the blanks left in the larger questionnaire with appropriate vocabulary like the task name. It also requires embedding the various questions in a more succinct format. Thus, for the NASA problem used, the item dealing with system definition did not include the examples of well defined systems which were part of the larger questionnaire, as the abbreviated questionnaire was streamIined to get it all on one page. Given an individual or group with a reasonable amount of time and commitment (more than the one-hour period available for the test subjects), the larger more comprehersive version of the questionnaire could be used.

The ELECTRE II Input alding questionnaire improves the quality of input to ELECTRE II but does not modify the basic logic of ELECTRE II in any way. In the following sections both the full length and the condensed version (actually used) of the ELECTRE II input aiding questionnaire are presented. 


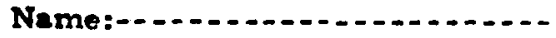

Group number:

O. The following questions are to help provide a general background perspective prior to fliling out the ELEC IRE II matrix.

1. Carefully define the problem (or the task).

2. Notice the facts given in the problem definition.

3. Try to determine who are the most knowledgeable, not necessarily the most vocal group members, with respect to the problem at hand (i.e. the rnoon survival problem).

4. Recheck and reevaluate assumptions or judgmenis you have made about the situation.

[You do not need to be consistent with your original individual decisions on the NASA task. In fact, you ought to solve the problem, the second time through, better, if you are able?.

I. The following questions are to help you fill out column 1 of the ELECTRE II matrix.

5. What are the criteria on which you will base (weigh) your decision?

(fill in column 1 in your ELECTRE II matrix).

5a. Carefully read instructions for column 1.

II. The following questions are to help you fill out column 2 of the ELECTRE II matrix.

6. Assign weights or importance to these criteria (1.e. fill in column 2 in your ELECTRE II matrix).

6a. Carefully read instructions for column 2.

7. It is generally better not to have all the weights identical unless they really are.

III. The following questions are to help you fill out cniumn 3 of the ELECTRE II matrix.

8. [first hint]: would it be helpful to group items into definitely important, maybe important, and not important?

9. [second hint]: for difficult rating decisions, comparing 2 items may help you decide which should be rated higher.

10. Carefully read Instructions for column 3. 
Name: -..........

Group number: ...

DIRECTIONS: Each individual should fill out the following matrix. It may be done either during and/or after group discussion.

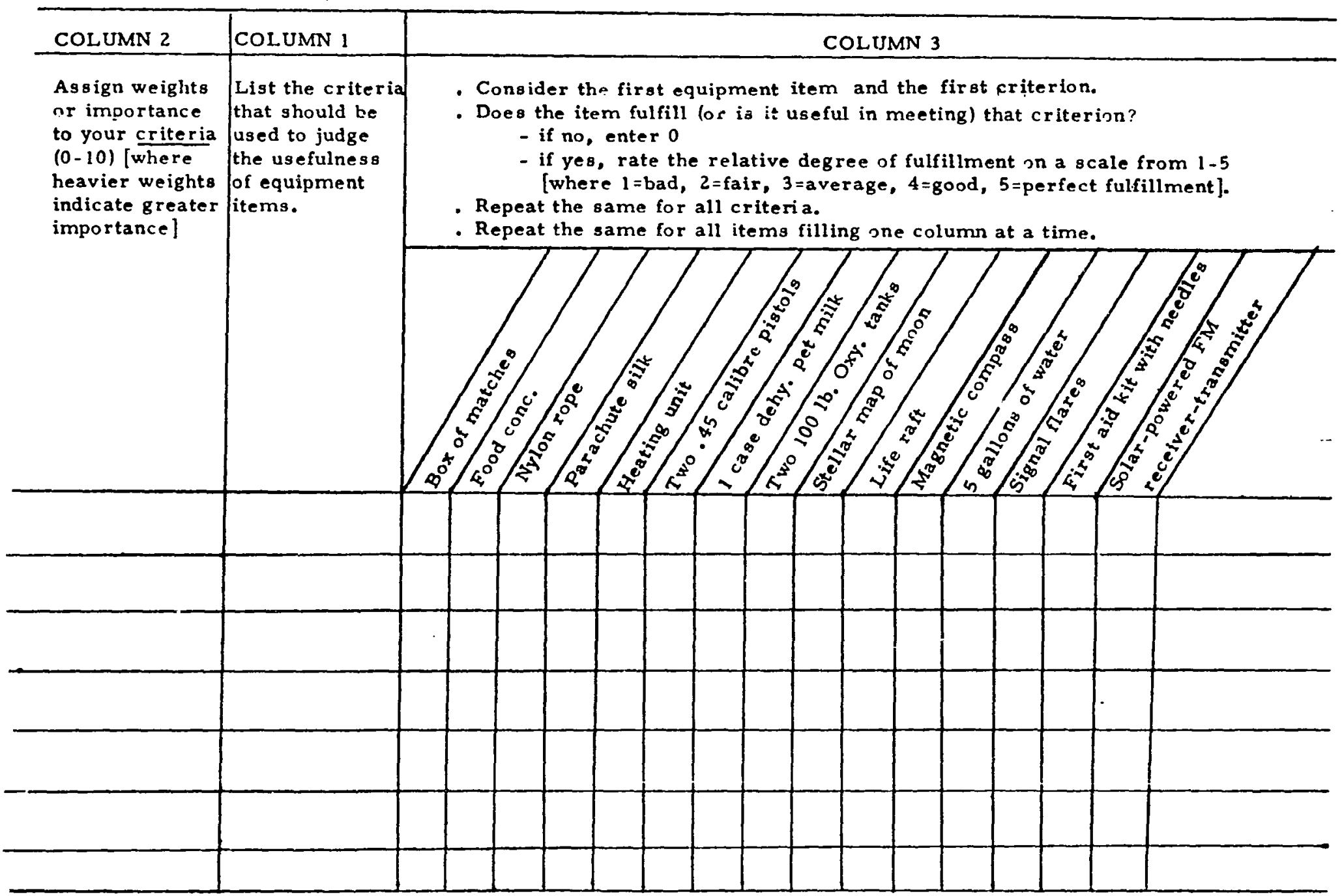




\section{COMPREHENSIVE QUESTIONNAIRE INSTRUCTIONS}

DECISION INSTRUCTIONS FOR FRONT END ELECTRE II GROUPS:

The following instructions are intended for users of the Front End ELECTRE II:

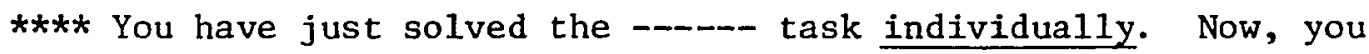
will resolve the same problem, using a different method. I believe this method can upgrade your performance on the stated task.

**** You will also undergo an exercise in group decision making. Your group is to use a method called Front End ELECTRE II.

**** To arrive at the final decision you are to go through the GENERAL ELECTRE II InPut AIDING QUESTIONNAIRE while working on the ELECTRE II worksheet (i.e. references are keyed in to the worksheet).

- The general problem solving strategy aiding questionnaire should help elucidate your preferences as to the more pertinent criteria in this particular problem. Through your answers to the questionnaire, you might discover new criteria or assign different ratings that could replace your a priori judgments.

**** You are to fill the ELECTRE II matrix individually either during and/or after group discussion.

**** After the experiment, a computer program (ELECTRE II) will rankorder items based on the judgments you supply in the matrix. 
COMPREHENSIVE QUESTIONNAIRE

WHAT FOLLOWS IS A GENERAL ELECTRE II INPUT AIDING QUESTIONNAIRE THAT ADOPTS SOME IDEAS FROM THE SYSTEMS APPROACH.

This aid may help improve your score on the ----- task. It is divided in three major parts:

1. General

2. Specific

3. ELECTRE II

You will have to develop and enter the different criteria (or objectives, attributes, etc...) which you consider relevant to your purpose. You also have to assign importance or weights to these criteria (e.g. criteria for ranking items for survival). The third part, ELECTRE II, is a computerized multiple objective optimization technique that will rank order your elements (e.g. items in the moon survival list such as box of matches, nylon rope, first aid kit, etc.) after the experiment.

ELECTRE II will be successful on1y if you enter good data (subjective and technical). The first two parts of this questionnaire are designed to stimulate you to find, visualize, or decide on the pertinent criteria to the (survival) task, assign accurate weights to these criteria, also ascribe (a1lot) accurate ratings to the different items of the (survival) task (such as matches, rope, etc.).

If you are wavering about the accuracy of your data or if you lack information crucial to the adequate fulfillment of your task, follow this questionnaire, review your original work, correct the deficiencies, measure, explott experts' opinion and return to the problem. 
0. The following suggestions are to help provide a general background perspective prior to filling out the ELECTRE II data input ma$\underline{\operatorname{trix}}$

1. Good problem definition is very helpful to problem solving. Carefully identify your problem (your task).

2. Notice the facts given (supplied) in the problem definition.

3. Can you define your task with insight and clarity?

i.e. can you define the essential purpose(s) being pursued in the problem such that the definition aids in providing a secure base for analytic work?

$$
\begin{gathered}
{\left[\begin{array}{cc}
\mathrm{Y} & \mathrm{N}
\end{array}\right]} \\
\text { (if } \mathrm{Y} \text {, go to 5; if } \mathrm{N} \text {, go to 4) }
\end{gathered}
$$

4. (if no) The following are two examples of well defined systems (Systems Science program description 175). They might assist you:

EXAMPLE 1: On a project for a well-known charitable organization, the relevant system is defined as an information transfer system concerned with bringing to the attention of the developed world the problems of the third world in crder to persuade these developed countries to devote more of their resources to aid.

EXAMPLE 2: On another project, this time concerned with a quality control operation, the relevant system is defined as one to balance the cost of achieving a certain level of quality against the cost of lost sales if this quality is not achieved.

Analysis of the system implications could then proceed.

5. (if yes) How many strategies (objects, elements, policies, projects) are you considering? Name them.

(Note that in the NASA problem, items in the survival list were already named, viz. matches, rope, first ald kit, etc.) 
6. Another help to problem solving can be assessment of technological or social impact.

Would a breakthrough in either scientific technologies or social technologies have any impact on your task (e.g. engineering techniques, scientific theories, new components, new materials, managerial skills, marketing techniques, general know-how, etc.)? [ $\mathrm{Y} \quad \mathrm{N}$ ] If the answer to question 6 is yes proceed to consideration of questions 7-9, if no, then go to question 10 .

7. Which aspects would be most affected: (technological, economical, social, managerial, ecological, religious/ethical, Intellectual, political, cultural, other...)?

8. What would be the effect? (Would it increase or decrease cost of production? Labor? Would it increase the number of available projects options?)

9. Is such a breakthrough 1ikely to happen within the time period relevant to your project?

I The following questions are to help you fill out column 1 of the ELECTRE II matrix.

10a. Making indices of performance explicit can also aid dectsion making. What are your indices of performance? 1.e. what are the desired attributes, various criteria on which you will base (weigh) your decision? (At this point, you should fill in column 1 in the ELECTRE II matrix.)

10b. The following is a check list of items that might assist you in selecting neglected criteria, or more pertinent criteria, 
or additional elements.

Is any of the following applicable to your problem?

(If you wish to get more detalled help or suggestions on any

of the following, go to the indicated parts of this questionnaire.)

* Economic: (costs, theorles, etc...more details in

11) if $Y$, go to 11 .

* Managerial: (production, commerclalization, techniques, experfence, etc.) if $Y$, go to 12.

* Political: (theorles, 1aws, dutfes, etc.)

if $Y, 80$ to 13 .

* Socte1: (demography, schools, church, traditions, etc.) if $\mathrm{Y}$, go to 14 .

* Cultural: (values, survival, self-regard, etc.) l* $^{*}$ If $Y, g 0$ to 15 .

* Intellectual: (1deas of intellectual leaders, etc.) 1f $Y, 80$ to 16 .

* Religlous/Ethical: (right and wrong concepts, etc.) if $\mathrm{Y}, 80$ to 17 .

* Ecological: (geography, pollution, etc.)

if $Y, 80$ to 18 .

* Technical: (transportation, navigation, comuntcation, technical aids, energy, etc.)

if $Y, 80$ to 19 .

11. Economic Dimengion Check List:

Have you considered the following aspects of the problem?

Which if any, are relevant?

- cost of a unit - cost of the ent1re system

- social costs - manufacturing costs

- research and development costs

- costs of supporting complementary

activities, Including costs of training

operators and malntenance technicians 
- cost of competitive options

- possibility of substitution

- governing economic theories

- cost over the entire life cycle

- general economic climate

- climate of expansion or contraction

- other...

12. Manageria1 Dimension Check List:

Have you considered the following aspects of the problem?

Which if any, are pertinent?

- production

- commercialization

- experience and training of managerial personnel

- diffusion in market obsolescence

- size and complexity of previous managerial tasks

- management and organization theories

- management science techniques

- procedures for managing the projects

- new policies, etc... - other...

13. Political Dimension Check List:

Have you considered the following aspects of the problem?

Which if any, are applicable?

Real world mode1:

- different parties . groups . individuals

Theoretical model:

- political theories . constitution . laws

- similar normative statements 
- do you need to identify the institutions, administrations, parties, groups, individuals, that will benefit by the different projects?

- do you need to determine the rights and duties, the privileges and obligations of the vartous groups?

14. Social Dimension Check List:

How will your decision affect or be affected by:

- demographic profiles

- geographical distributions

- population densities

- distribution of income per capita

- urban versus rural distribution

- institutions in society

the family

governments schools

businesses
- total population

- age distributions

- others...

churches

traditions of

a society

- motivating images of society

15. Cultural Dimension Check List:

Some values, attitudes, goals which you might consider are:

- stability

- surviva1 . innovation

- success

- self-regard . health

- comfort

- safty - beauty

- economic securit

fairness - charitableness

- physical securit

freedom - justice

- personal power

beauty

- honesty

- personal prestige

- courtesy

- clearness of conscience 
- intelligence and professional recognition

Have you considered strength values such as:

- leadership and order

moral values such as:

- justice and tolerance

economic values such as:

- ownership and jobs

- other...

16. Intellectual Dimension Check List:

The intellectual climate affects the environment. Prevailing ideas of novelists (poets, opinion leaders, essayists and columnists, editors, reporters, news commentators on radio and $T V$, motion picture writers, directors and actors), could affect the preferences and choices of the people in terms of particular projects.

17. Religious and Ethical Dimension Check List:

Have you considered the following aspects of the problem?

Which if any, are applicable?

- concepts of right and wrong

- religious, professional and ethical institutions

- doctrines and teachings of these institutions

18. Ecological Dimension Check List:

You might consider the real world portion of this dimension which implies the world we live in with its:

\footnotetext{
- geography - climate - flora and fauna

you might also consider

- green areas protection
} 
- pollution (noise, air, water, etc...)

You might consider the theoretical model portion:

- existing knowledge and theories about the interactions taking place in the real world, what constitutes socially tolerable levels of damage to the human habitat

- relations between man and his environment

19. Technical Dimension Check List:

Which of the following aspects are pertinent to your problem?

- transportation . highway building

- communication - navigation . technical aids

- energy . housing improvement

- urban districts improvement

- public means of transportation improvement

- more jobs (employment)

Here is an example of how technical data were MEASURED and AGGREGATED to furnish 12 criteria (see next page) in a decision to rank order 5 irrigation systems in Hungary. The technical measurements were:

- ava1lable natural supply . fresh water demand

- water losses (consumption) - water supply capacity

- waste water produced - reused water

- treated waste water - remaining water

The water requirements for the different consumer sectors were estimated:

- irrigation - domestic - industry cooling

- recreation - other livestock - fish ponds 
- others . total

The water requirements were estimated in terms of waste water produced ( $\mathrm{km}^{3} /$ year) for the years 1970 and 2000 , in terms of mean wast water produced ( $\mathrm{km}^{3} /$ year) for 1970 and 2000. For the different criteria:

A. Water requirements: the following were measured:

- consumption uses (different amounts of requirements and yearly losses)

- energy (different energy factors and losses)

- navigation (different lengths of waterways and their losses)

- recreation (different surface water areas and their evaluations)

B. Flood protection:

The various probabilities of flood were calculated with resultant losses and evaluation of social consequences.

C. Used water disposal and drainage:

The drainage areas (million hectares) and their losses were estimated, also the amount of waste water produced and its 1osses.

D. Utllization of water resources: the following were measured :

- water losses $\left(\mathrm{km}^{3} /\right.$ year $)$

- discharge to downstream system and losses

- land and forest area (1000 hectares) and losses, etc... The measurements were finally AGGREGATED into the followIng 12 criteria:

1. $\cos t s$ 
2. water shortage

3. water quality

4. energy

5. recreation

6. flood protection

7. land and forest use

8. manpower impact

9. environmental architecture

10. international cooperation

11. development possibility

12. sensitivity

II The following question is to help you fill out column 2 of the ELECTRE II matrix.

20. Assign weights of importance to performance criteria (i.e. fill in column 2 in your ELECTRE II matrix).

21. Return (and correct if now needed) questionnaire item:

1 (identification of the task);

5 (choice of the different elements [in case of the NASA moon survival problem there was no change, since the items were already given]);

$10 \mathrm{a}, 20$ (redefinition or correction of your criteria and the welghts assigned to them, 1.e. column 1 and column 2).

III The following questions are to help you fill out column 3 in the ELECTRE II input data matrix.

22 Try to determine who are the most knowledgeable, not necessarily the most vocal group members, with respect to the 
problem at hand [1.e. the moon survival problem, in the case of the NASA task].

23. In addition to facts related to the specific way you defined the problem, what other facts are given in the problem?

24. With the information avallable to you (i.e. the information supplied in the statement of the ---- problem) do you think you yourself can make a good decision on criteria to use and the weights to assign to them; or do you need to rely heavily upon the opinion of others; or do you need to gather more facts before you can even begin?

25. With what you personally know, combined with the facts available to you in the problem; what kind of information do you think is still lacking or is needed?

What questions would you like answered?

What clarifications would you like made?

What facts would you like provided?

26. Have you acquired all technical data pertinent to that specific problem?

What other technical information do you need?

Where are the most likely places to furnish it?

27. If you cannot obtain all the technical data, then recheck and reevaluate all the assumptions or judgments you have made about the situation. [Additional insights may be incipient due to the general problem solving aids and the structure of the ELECTRE II matrix.] You do not need to be consistent with your original individual decistons on the --..-- task. In fact, you ought to solve the problem better the second time. 
through.

28. The purpose of assignment of welghts and ratings to criteria and items respectively is to make distinctions on the relative importance of ttems and criteria.

It is generally advantageous not to have all the weights identical unless they really are.

29. Would it be helpful to group items into definitely important, maybe important, and not important, for a start?

30. For difficult rating decisions, comparing two items may help you decide which should be rated higher.

COMPUTER SOFTWARE PACKAGE FOR ELECTRE II

A computer software package for ELECTRE II was developed and programmed as part of the developmental phase of this work. (The actual ELECTRE II computer program was not available, it is kept confidential in Paris.) 
MAIN HYPOTHESIS

The main hypothesis of this study (the null hypothesis) is that both the questionnaire-augmented ELECTRE II and the original ELECTRE II methods will provide equally good bases for group decision making as competitive methods, i.e. no differences will be found in the performances of the various methods used as measured by the decision adequacy index scores and the upgradings due to the various methods. Alternative hypotheses are stated in the third section of this chapter.

Reasons for Expected Equivalence of Improved ELECTRE II with the Well Established SPAN Method

The improved ELECTRE II methodology provides help in the followIng:

1. developing alternatives to be evaluated;

2. generating evaluation criteria;

3. revealing hidden dimensions or solutions to a problem being considered.

By considering all dimensions of a problem (technological, political, economical, social, personal, religious, managerial, etc...) it is hoped that unintentional failure to take into account important solutions will occur less frequently.

Both the improved ELECTRE II and the ELECTRE II methodologies provide help in the following: 
1. in making judgments systematically;

2. in using sensitivity analysis in preference exploration;

3. In taking account of dissenting opinion;

4. In setting thresholds before a preference can be said to exist.

EXPERTMENTAL PHASE

Objective

The objective is to test the ELECTRE II method for decision quality (with and without: "front end", 1.e. the questionnaire) against:

1. a self determined (by the group) verbal discussion format;

2. the formerly tested SPAN method. (Gilmartin, 1974; Willis, 1966; Hitchcock, 1971; Willis, Hitchcock and MacKinnon, 1969; Riker and Brams, year of publication not available).

$\underline{\text { Task }}$

The decision task in the proposed investigation is the solution of the NASA moon survival problem. In this task, the participants are required to rank order 15 items of equipment as to their Importance for survival on the moon. The NASA task is shown in Appendix A.

This task has the following advantages:

1. It has a key produced by NASA officials, i.e. the outcome is known and there is no need to wait for a few years until the applicants can demonstrate their success or failure with respect to the specified problem by noting the eventual outcome of the decision. 
2. It is one page in length and quite simple to administer (the applicants w11l not be bored or overlook reading parts of the task).

3. The conditions on the surface of the moon are not familiar to everybody, thus the task should give a better measure of the effectiveness of the method tested.

4. It does not take a long time to solve.

5. Because it was used by SPAN researchers, it allows convenient comparison of ELECTRE II to SPAN results.

This task has also four possible disadvantages:

1. The problem is not very realistic.

2. Many details are missing; for example: how many crew members were in the space ship? How much food concentrate is left on the space ship? Is it concelvable that the mother ship would not attempt to rescue the crew? etc...

3. The problem may not present mich interest for some people.

4. The problem is unfavorable to ELECTRE II for the following reasons:

4a. The problem appears somewhat simplistic in the sense that it does not present real conflicting multi-criterla decislons and real complexity.

4b. The problem could be vlewed as a measure of the amount of 
Information available in the group rather than a measure of problem solving ability in a complex environment. Having developed an improved version of ELECTRE II in this thesis, future researchers could conduct a controlled experiment where the prime variable was the complexity of the problem.

5. The task was conveniently favorable to the competitive SPAN method. If the NASA task were primarily a test of the amount of information about the moon, SPAN was a very convenient way to maximize the score since the one who does not know, gives his vote to the one who knows.

While bearing in mind the above critical points, the choice of the NASA moon survival problem was still favored because it allowed for reasonable comparison with previous SPAN experiments.

COMPARABILITY OF SPAN SUBJECTS AND ELECTRE II PARTICIPANTS

The subjects utilized in Gilmartin's investigation (1974) of effectiveness of SPAN (with and without training), as compared to any seifdetermined method, were employees of the Veterans Administration Hospital, Tucson, Arizona.

The veterans administration was developing a program of ambulatory care and had already required all staff members to undergo a forty-hour (one week) laboratory training workshop in group problem solving, interpersonal sensitivity, and exercises in group dynamics.

The personnel (156 members) were divided Into 17 groups, each ranging in size from seven to thirteen members (one group included 7 subjects; 
six groups contained 8 members each; four groups consisted of 9 participants each; two groups had 10 subjects each; and the last three groups had $11,12,13$ subjects respectively).

The groups remained together throughout the entire forty-hour workshop. They were interdisciplinary in nature with both professional and non-professional members in each group. In total, 156 subjects, divided into 17 groups, participated in the investigation. The only time limit imposed, was the group discussion of the NASA task and solutions - 15 minutes.

The participants in the SPAN investigation could well be compared to the participants in the present investigation. The latter belong to groups of undergraduate (some graduates) students in Portland State University, enrolled in two psychology classes, one communications class, one economics class, and a group from the Systems Science Program.

An almost identical replication of Gilmartin's experiments (with SPAN) was attempted insofar as the restrictions contribute to the accuracy of the present experiment? For example, no time limit was imposed for the different experiments, except for group discussion duration. Secondly, on the average, an attempt was made to have each group contain about 7-8 subjects. Finally, the various treatments employed about 4 groups each. The mixture of professional and non-professional participants in SPAN, was not duplicated however, since all our subjects were students.

Two other points of difference are presented below:

1. Our groups were ad hoc groups (due to PSU factlities) as compaxed to the majority of Gilmartin's which were established. 
groups. (His established groups scored better than his ad hoc groups). The use of ad hoc versus established groups is, of course, a hindrance to our method.

2. Another hindering point is that we had to explain ELECTRE II in 4 minutes to the various subjects. This sacrifice was made in order to keep all our experiments equivalent in duration.

HYPOTHESES

\section{I) All Participants in the NASA Task}

We start with the null hypothesis stating that:

$\mathrm{H}_{01}$ : All students' and participants' abilities in solving the NASA task (the Author's and Gilmartin's) are equivalent, i.e. on the average, a11 individual scores at the outset are analogous. In more statistical terms: There are no significant differences in the performance of the various participants at the outset, as measured by the individual averages ${ }^{1}$ (1.e. the absolute difference between the standard scores and that of the participants prior to using any group method).

$\mathrm{H}_{01}$ rationale: It is reasonable to assume that in such large samples of 156 and 65 respectively, all of the variability would be represented (with good random assignment of cases and good sample size).

${ }^{1}$ or group resources as named by Gilmartin (1974). 


\section{II) Front End ELECTRE II, ELECTRE II Versus Control Methods: ("Any" Group Method, SPAN and NONSPAN ${ }^{2}$ )}

The second null hypothesis which is the main one to be tested is that:

$\mathrm{H}_{02}$ : The suggested questionnaire format (Front End) together with the ELECTRE II methods will provide equally good bases for decision making as competitive methods, (1.e. there are no differences in the performance of the various methods used, viz. Front End ELECTRE II, ELECTRE II, "any" group method, SPAN and NONSPAN). The performance is measured in terms of the decision adequacy Index scores (i.e. the absolute difference between the correct standard scores and that of the participants after using the different methods).

$\mathrm{H}_{02}$ rationale: The primary advantage toward improved solutions with SPAN is through voluntary vote assignment to group members perceived to have the most expertise in the given problem area. SPAN, however, offers no problem-structuring aid or systematic preference discovery as does ELECTRE II; 1.e. SPAN provides no help in developing alternatives to be evaluated, in generating evaluation criteria, in making judgments systematically, in using sensitivity analysis in preference exploration, in taking account of dissenting opinion, or in setting necessary thresholds before a preference can be said to exist as does Front End ELECTRE II.

2 NONSPAN is the same technique as "any" group method, 1.e. a selfdetermination group method. 
It is beleived that the problem-structuring aid and preference discovery will be as important to good solutions as giving perceived experts extra votes. In more realistic decision environments with more complex and less structured problems, howevei, ELECTRE II would likely have a very great advantage.

${ }_{02}$ comment: SPAN is used as a special type of control group against which to compare ELECTRE II for two basic reasons:

1. We wished to test ELECTRE II and Front End ELECTRE II against realistic and competitive alternatives rather than against unaided groups alone.

2. SPAN researchers have claimed substantial group score improvement (suggesting greater effective group I.Q.) if Front End ELECTRE II performs as well as SPAN, which is so highly acclaimed, then the same claims would apply to Front End ELECTRE II

III) Front End ELECTRE II, ELECTRE II Versus Control Methods ("Any" Group Method, SPAN and NONSPAN)

Given the first and second null hypothesis, this third null hypothesis follows:

$\mathrm{H}_{03}$ : The improvement due to the different methods is also equivalent. 
In more statistical terms: there are no differences in the upgradings ${ }^{3}$ due $t$, the various methods used, as measured by the difference between the individual averages prior to using any method, and the decision adequacy index scores after using any of the specific methods mentioned above.

A corollary follows: Group decision quality in that particular task has improved over individual average scores.

IV) Front End ELECTRE II Versus Regular ELECTRE II

The following is one of many possible alternatives to the nu11 hypothesis:

$\mathrm{H}_{4}$ : All groups using Front End ELECTRE II will do better than those using regular ELECTRE II (measured by the decision adequacy Index scores and the upgradings due to the two different techniques).

H $_{4}$ rationale: The primary weakness of the regular ELECTRE II is in:

1. potential inadequate discovery of relevant criteria/dimensions of evaluation;

2. difficulty in deciding on preferences/ratings;

3. too narrow a set of alternatives being considered.

${ }^{3}$ The upgrading is the difference between the decision adequacy index score of the group (usually alded by ELECTRE II or SPAN) and the averaged decision adequacy index scores of unatded individuals (who worked the problem by themselves before working as a group). 
Front End ELECTRE II provides a methodology for dealing systematically with each of these weaknesses. Thus, there is good reason to believe that Front End ELECTRE II will yield a higher quality solution than regular ELECTRE II.

$$
\text { EXPERIMENTAL TECHNIQUE AND DESIGN }{ }^{4}
$$

The experiment consisted of 65 participants (due to the facilities and the turnout of students at Portland State University at that time). Participants were tested as individuals and then assigned randomly to groups, each containing about 5-8 subjects (with one group contalning 3). Each sequence had 3-4 groups.

What follows will be the different step sequences for the various experiments. $^{5}$ (All subjects completed their tasks in about 35 minutes or less).

Step Sequence for Experiment I (Front End Group ELECTRE II)

1. The NASA task was read silently by the participants and then performed individually. (Participants were allowed as much time as they required, but the maximum needed was about 7 minutes).

2. ELECTRE II was explained in about 4 minutes.

3. The ELECTRE II input alding quest lonnaire was distributed and answered (lasted about 6 minutes).

${ }^{4}$ see Tables IIa, IIb, IIc

${ }^{5}$ Actual instruction sheets in Appendix A. 
4. \& 5. The group discussed and solved the NASA task using Front END ELECTRE II. (15 minutes for group discussion time and 5 minutes for group solving; a total of 20 minutes).

6. Individuals filled out a questionnaire regarding their age, sex, class, major, background, number of training years in math and social sciences, the degree of their satisfaction with the method, etc...

Step Sequence for Experiment II (Regular Group ELECTRE II)

1. The NASA task was read silently by the participants and then performed individually (lasted about 7 minutes).

2. ELECTRE II was explained in about 4 minutes.

3. \& 4. The group discussed and solved the "moon" problem using ELECTRE II in groups of about 5-8 participants each (15 minutes for group discussion time, plus 5 minutes solution; a total of 20 minutes).

5. Individuals filled out a questionnaire regarding their age, sex, class, major, background, number of training years in math and social sciences, the degree of their satisfaction with the method, etc...

Step Sequence for Experiment III (Any Self Determined Group Method)

1. The NASA task was read silently by the participants and then performed individually (lasted about 7 minutes).

2. The group discussed and solved the NASA task (20-25 minutes). 
3. Individuals filled out a questionnaire regarding their age, sex, class, major, background, number of training years in math and social sciences, the degree of their satisfaction with the method, etc...

Step Sequence for Gilmartin's Investigations (SPAN, NONSPAN)

In the formerly tested SPAN investigation, the groups followed the four step sequence below: (Gilmartin, 1974)

1. NASA task read silently by the subjects and then performed individually.

2. Decision instructions read silently by the subjects as the experimenter read them aloud.

3. Group discussion fo the NASA task and solution for 15 minutes, the only time limit imposed.

4. Final decision making by the silent power-making method (SPAN) or the oral self-determination method (Non SPAN-)

In step 2 the experimenter would answer by paraphrasing the instructions and in SPAN groups would demonstrate the SPAN allocative procedure by marking on a pad supported by a hand. In step 4 he would place a NASA-problem answer sheet for the rankings by Non-SPAN consensus on a chalr in the center of the circle of seated members. (Gilmartin, 1974)

TABLE IIa

STEP SEQUENCE FOR THE THREE EXPERIMENTS

PERFORMED IN THIS THESIS

STEP SEQUENCE FOR THE EXPERIMENTAL DESIGN

\begin{tabular}{|c|c|c|c|c|}
\hline EXP I & $\begin{array}{l}\text { Silent reading } \\
\text { and Individual } \\
\text { solving of the } \\
\text { NASA task in } 7 \\
\text { minutes }\end{array}$ & $\begin{array}{l}\text { ELECTRE II } \\
\text { explained in } \\
4 \text { minutes }\end{array}$ & $\begin{array}{l}\text { F.E. ELECTRE } \\
\text { II question- } \\
\text { naire answered } \\
\text { in } 6 \text { minutes }\end{array}$ & $\begin{array}{l}\text { Group dis- } \\
\text { cussion \& } \\
\text { solving of } \\
\text { the NASA } \\
\text { task in } 20 \\
\text { minutes }\end{array}$ \\
\hline EXP II & $"$ & $"$ & - & " \\
\hline EXP III & " & - & & $"$ \\
\hline
\end{tabular}


TABLE IIb

EXPERTMENTAL DESIGN OF THESIS

\begin{tabular}{|c|c|c|c|c|}
\hline \multicolumn{3}{|c|}{ EXPERIMENTAL DESIGN } & \multicolumn{2}{|c|}{$\begin{array}{l}\text { ADDITIONAL INFORMATION } \\
\text { ON THE NATURE OF PARTI- } \\
\text { CIPANTS } 6\end{array}$} \\
\hline $\begin{array}{l}\text { TREAT- } \\
\text { MENT }\end{array}$ & STAGE I & STAGE 2 & GROUP \# & GROUP SIZE \\
\hline I & $\begin{array}{l}\text { Individuals solve } \\
\text { NASA problem }\end{array}$ & $\begin{array}{l}\text { Group solves NASA } \\
\text { problem aided by } \\
\text { F. E. ELECTRE II }\end{array}$ & $\begin{array}{l}1 \\
2 \\
3 \\
4\end{array}$ & $\begin{array}{l}7 \\
3 \\
5 \\
5\end{array}$ \\
\hline II & $\begin{array}{l}\text { Individuals solve } \\
\text { NASA problem }\end{array}$ & $\begin{array}{l}\text { Group solves NASA } \\
\text { problem aided by } \\
\text { ELECTRE II }\end{array}$ & $\begin{array}{l}5 \\
6 \\
7 \\
8\end{array}$ & $\begin{array}{l}7 \\
8 \\
5 \\
6\end{array}$ \\
\hline III & $\begin{array}{l}\text { Individuals solve } \\
\text { NASA problem }\end{array}$ & $\begin{array}{l}\text { Group solves NASA } \\
\text { problem unatded } \\
\text { ("Any" group me- } \\
\text { thod) }\end{array}$ & $\begin{array}{c}9 \\
10 \\
11\end{array}$ & $\begin{array}{l}7 \\
6 \\
6\end{array}$ \\
\hline $\mathrm{IV}^{7}$ & $\begin{array}{l}\text { Individuals solve } \\
\text { NASA problem }\end{array}$ & $\begin{array}{l}\text { Group solves NASA } \\
\text { problem alded by } \\
\text { SPAN or NONSPAN } \\
\text { (formerly tested) }\end{array}$ & many & groups \\
\hline
\end{tabular}

${ }^{6}$ All our groups consisted of students, whlle Gilmartin's groups consisted of a mixture of professional and nonprofessional members.

${ }^{7}$ For additional details, see Table IIb. 
TABLE IIC

EXPERIMENTAL DESIGN USED BY GILMARTIN ${ }^{8}$

\begin{tabular}{|c|c|c|c|c|c|}
\hline \multicolumn{4}{|c|}{ EXPERIMENTAL DESIGN } & \multicolumn{2}{|c|}{$\begin{array}{l}\text { ADDITIONAL INFORMATION } \\
\text { ON THE NATURE OF PARTI- } \\
\text { CIPANTS }\end{array}$} \\
\hline \multirow{3}{*}{$\begin{array}{l}\text { TREAT- } \\
\text { MENT }\end{array}$} & \multirow{3}{*}{ STAGE 1} & \multirow{2}{*}{\multicolumn{2}{|c|}{\begin{tabular}{|c|} 
STAGE 2 \\
Group solves NASA Probl.
\end{tabular}}} & \multirow{3}{*}{ GROUP \# } & \multirow{3}{*}{ GROUP SIZE } \\
\hline & & & & & \\
\hline & & FIRST STEP & SECOND STEP & & \\
\hline$I$ & $\begin{array}{l}\text { Individuals solve } \\
\text { NASA problem }\end{array}$ & $\begin{array}{l}\text { SPAN (no } \\
\text { training) }\end{array}$ & $\begin{array}{l}\text { SPAN (with } \\
\text { training) }\end{array}$ & $\begin{array}{l}1 \\
2 \\
3 \\
4 \\
5\end{array}$ & $\begin{array}{r}10 \\
11 \\
13 \\
8 \\
9\end{array}$ \\
\hline II & $\begin{array}{l}\text { Individuals solve } \\
\text { NASA problem }\end{array}$ & $\begin{array}{l}\text { SPAN } \\
\text { (with } \\
\text { training) }\end{array}$ & & $\begin{array}{r}6 \\
7 \\
8 \\
9 \\
10\end{array}$ & $\begin{array}{r}8 \\
9 \\
8 \\
12 \\
9\end{array}$ \\
\hline III & $\begin{array}{l}\text { Individuals solve } \\
\text { NASA problem }\end{array}$ & $\begin{array}{l}\text { ANY GROUP } \\
\text { method (no } \\
\text { training) }\end{array}$ & $\begin{array}{l}\text { ANY GROUP } \\
\text { method } \\
\text { (with } \\
\text { training) }\end{array}$ & $\begin{array}{l}11 \\
12 \\
13 \\
14\end{array}$ & $\begin{array}{l}7 \\
8 \\
8 \\
9\end{array}$ \\
\hline IV & $\begin{array}{l}\text { Individuals solve } \\
\text { NASA problem }\end{array}$ & $\begin{array}{l}\text { ANY GROUP } \\
\text { method } \\
\text { (with } \\
\text { training) }\end{array}$ & & $\begin{array}{l}15 \\
16 \\
17\end{array}$ & $\begin{array}{r}10 \\
8 \\
9\end{array}$ \\
\hline
\end{tabular}

${ }^{8}$ For further details, see Gilmartin (1975). 


\section{MEASURES}

The following measures were used to test the degree of upgrading of decision quality achieved by the different techniques.

\section{Decision Adequacy Index (Gilmartin, 1974):}

It is a comparison of the participants'rankings of the items with the ranking produced by NASA officials. This index is expressed in terms of the summed deviations between the individual's rankings and that of the NASA experts. The summed deviation score is an error score inversely proportional to decision quality. The error score can vary from 0 to 112 points away from absolute accuracy.

The decision adequacy score is computed for each individual's rankings and for each group in the following way. If one individual ranks 4 items a, b, c, d as 4, 3, 2, 1; and the correct ranking is $1,2,3,4$, then the following computations are performed: $([4-1]+[2-3]+[3-2]+$ [1-4] $=8$ ). A score of 8 is obtained where the lower the score the higher the quality.

(Ha1l's research - stated in Gilmartin, 1974 - has shown that an average individual error score of 39.30 is obtained in the NASA task).

The individual averages ${ }^{9}$ are obtained for each group by averaging the summed deviation scores (or dectsion adequacy indices), which are inversely proportional to decision quality of the participants in that group. $\bar{x}$ in that case (i.e. the group adequacy index score), is obtalned by averaging the individual averages of each group.

Representirg the above in a compact form:

${ }^{9}$ or group resources as denoted by Gilmartin (1974). 
$\mathrm{N}=$ number of 1tems to be rank ordered

$M_{k}=$ number of participants within group $k$

$\mathrm{L}=$ number of groups

$\mathrm{X}=$ individual score

$x_{j 1}-x_{i}=$ score deviation of $j^{\text {th }}$ individual in $1^{\text {th }}$ item

therefore:

$$
\begin{aligned}
& \text { Individual averages }=\bar{x}_{k}=\frac{1}{M_{k}} \sum_{j=1}^{M} \sum_{i=1}^{N}\left|\left(x_{j i}-x_{1}\right)\right| \quad \underbrace{{ }_{j}^{t h}}_{i}{ }_{\text {item }}^{\text {individual }} \\
& \overline{\mathrm{X}}=\frac{1}{\mathrm{~L}} \sum_{\mathrm{k}=1}^{\mathrm{L}} \overline{\mathrm{X}}_{\mathrm{k}}
\end{aligned}
$$

\section{Upgrading}

The upgrading is the difference between the decision adequacy index score of the group (usually aided by ELECTRE II or SPAN) and the averaged decision adequacy index scores of unaided individuals who worked the problem by themselves before working as a group.

\section{STATISTICAL TESTS}

An analysis of variance (using the .05 significance level) was performed on the individual averages, the group dectsion adequacy indices (test scores after using the different methods) and the upgradings for al1 methods used in this investigation. We used the analysis of variance to test the different null hypotheses concerning various sets of data. The choice of the analysis of variance test over a multitude of t-tests is explained in footnote at the end of this section. ${ }^{10}$ Scheffe's method was used to Eurther investigate the alternative hypotheses.

Three t-tests were then used to compare the means of our partictpants with those of Gilmartin's prior to and after using the respective 
${ }^{10}$ Reason for Choosing Analysis of Variance Over $n$ t-tests (Willem-

sen, 1974)

The level of significance $(\alpha)$, which is set a priori, is itself the probability of type 1 error for the F-test. This type of error arises when the decision is made, that at least one of the several differences between means is not zero when in fact all of them are zero.

Using a sufficient number of t-tests to compare each mean to each other mean would result in a higher type 1 error than the one we get in an F-test designed to test the same hypothesis.

In an F-test; the probability of at least one erroneous judgment is approximately equal to $\alpha$. This probability is substantially larger for $n$ t-tests. For example, applying the F-test to study 3 means and setting $\alpha$ at a value of 0.1 results in a $10 \%$ probability of having at least one error. Adopting the $t$ procedure, 3 tests would be required $\left(\bar{Y}_{1}-\bar{Y}_{2}, \bar{Y}_{1}-\bar{Y}_{3}, \bar{Y}_{2}-\bar{Y}_{3}\right)$ and they will not be independent. For each of them having a 0.1 ". Levej. of significance; they introduce a probability of at least one error exceeding 0.1 .

It is for this principal reason (this descrepancy in error rates) that the F-test is preferred to multiple t-tests.

When the following assumptions

1. $F=\hat{s}_{\text {bet }}^{2} / \hat{s}^{2}$ with is a good estimate of $\sigma_{\text {bet }}^{2} / \sigma_{\text {with }}^{2}$ (this is strictly true only in case $\sigma_{1}^{2}=\sigma_{2}^{2}=\ldots=\sigma_{k}^{2}=\sigma^{2}$, that is, the population values of the group variances are equal.

2. F follows an $F$ distribution for various $\mathrm{df}$, are met; the F-test is uniformly most powerful.

This means that the power $(1-\beta)$ is higher and the probability of $(B)$ of type II error smaller than for any other hypothesis test procedure. 
group methods, (viz. Front End ELECTRE II, SPAN and NONSPAN).

Results showed that groups using Front End ELECTRE II performed as well as groups using other methods.

\section{Qualitative Test:}

Application of the SPAN technique achleved an improvement of about $47 \%$ in the best conditions (1.e. in one incident of prior human relations training workshop for the participants), and about $23.5 \%$ in other conditions (i.e. with and without a prior human relations training workshop for the participants). This percentage was relative to the unaided individual decision making. ${ }^{11}$ Such upgrading is relatively quite large and brings the gitoup decision closer to reference decision. The same degree of improvement achieved by Front End ELECTRE II would also be meaningful.

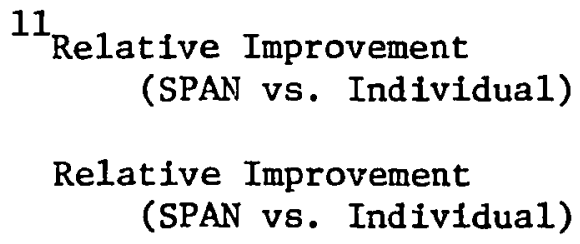

${ }^{11}$ Relative Improvement (SPAN vs. Individual) (SPAN vs. Individual)

$$
\begin{array}{ll}
=\frac{46.8-24.6}{46.8} & 47 \% \\
=\frac{46.8-35.8}{46.8} & 23.5 \%
\end{array}
$$


CHAPTER V

ANALYSIS AND DISCUSSION OF RESULTS

DESCRIPTIVE AND QUALITATIVE SECTION

In this section the raw data is presented with a few qualitative remarks. Statistical discussion will follow. This presentation sequence permits the use of narrowly focussed tribles to highlight specific aspects of the research at the outset. Later, the statistical analysis is performed across several tables simultaneously.

\section{$\underline{\text { Raw Data }}$}

Tables III to $\mathrm{V}$ present all the raw data for the three experiments performed.

Focus on Decision Adequacy Index Scores

Tables VI to VIII are selected subsets of the raw data to focus attention on comparative analysis between the performance of the group and that of the individual members of the group in terms of the group dectsion adequacy index scores.

\section{Focus on Relative Upgrading}

Tables $X$ and XII are selected subsets of the raw data to focus attencion on comparative analysis between the performance of the group and that of the individual members of the group in terms of the relative upgrading caused by the three different methods. 
Comparison of ELECTRE II, Front End ELECTRE II, and any Group Method

Tables XIII to XVIII compare results of the NASA task using our three different techniques.

Comparison of ELECTRE II, Front End ELECTRE II, any group method, SPAN and NONSPAN

Tables XIX to XXIV are selected subsets of the raw data to compare results of the NASA task using our three different techniques with that of SPAN. It is these tables which are later discussed statistically.

GENERAL RESULTS (ALL THE BASIC DATA: TABLES III, IV, V)

Tables III, IV, $\mathrm{V}$ show all our raw results of the NASA task administered to PSU students utilizing Front End ELECTRE II, ELECTRE II and "any" group method respectively.

Table III shows the decision adequacy index (DAI) [explained in "Measures" in chapter IV] for the Individual averages and the Front End ELECTRE II. The third column shows the scores of individual averages (i.e. summed deviations [from standard] scores of group members) prior to utflizing any group method. The fourth column shows the scores of the individual averages after ut1lizing a group method. The fifth column is the difference between the fourth and third column denoted as the relative upgrading due to the particular group method utilized. We notice that the decision adequacy index scores for the F.E. ELECTRE II groups are lower than the deciston adequacy Index scores (DAI) for the individual averages (1.e. F.E. ELECTRE II scores better than the averages of Individuals prior to using it as their group 
method. $\bar{x}=32.55$ as compared to $\bar{x}=41.90$ for the same group of people; with an average relative upgrading of 9.35). Table II suggests that F.E. ELECTRE II upgrades the performance of the group as compared to the averages of the individual scores of that same group.

Tables IV and $V$ show similar results obtained for ELECTRE II and a self-determination method ("any" group method) respectively. The results show that the performance of the group surpasses the averages of the individual scores in the case of "any" group method, but not for ELECTRE II.

We notice a group DAI for ELECTRE II of $\bar{x}=46.03$ as compared to a DAI for the individuals of the same group of people of $\bar{x}=46.55$; with an average upgrading of .52. The group DAI for "any" group method was $\bar{x}=31.33$ as compared to the DAI of the individuals of the same group of $\bar{x}=42.57$; with an average upgrading of 11.24 .

TABLE III

GROUP ADEQUACY INDEX SCORES ${ }^{1}$

FOR F.E. ELECTRE II

\begin{tabular}{|c|c|c|c|c|}
\hline GROUP \# & $\begin{array}{c}\text { NUMBER OF } \\
\text { PARTICIPANTS }\end{array}$ & $\begin{array}{l}\text { INDIVIDUAL } \\
\text { AVERAGES }\end{array}$ & $\begin{array}{c}\text { F.E. } \\
\text { ELECTRE }\end{array}$ & $\begin{array}{c}\text { IMPROVEMENT or } \\
\text { DIFFERENCE or } \\
\text { UPGRADING }\end{array}$ \\
\hline 1 & 7 & 41.29 & 36.71 & 4.58 \\
\hline 2 & 3 & 44.00 & 30.00 & 14.00 \\
\hline 3 & 5 & 40.50 & 33.50 & 7.00 \\
\hline \multirow[t]{3}{*}{4} & 5 & 41.80 & 30.00 & 11.80 \\
\hline & & $\bar{x}=41.90$ & $\bar{x}=32.55$ & $\bar{x}=9.35$ \\
\hline & & $s=1.50$ & $s=3.23$ & $s=4.32$ \\
\hline
\end{tabular}


TABLE IV

\section{GROUP ADEQUACY INDEX SCORES \\ FOR REGULAR ELECTRE II}

\begin{tabular}{ccccc}
\hline GROUP & $\begin{array}{c}\text { NUMBER of } \\
\text { PARTICIPANTS }\end{array}$ & $\begin{array}{c}\text { INDIVIDUAL } \\
\text { AVERAGES }\end{array}$ & ELECTRE II & $\begin{array}{c}\text { DIFFERENCE or } \\
\text { UPGRADING }\end{array}$ \\
\hline 5 & 7 & 41.86 & 41.00 & .86 \\
6 & 8 & 42.38 & 44.13 & -1.75 \\
7 & 5 & 49.80 & 49.40 & .40 \\
8 & 7 & 52.17 & 49.60 & 2.57 \\
& & $\bar{x}=46.55$ & $\bar{x}=46.03$ & $\bar{x}=$ \\
& & $s=5.21$ & $\mathrm{~s}=4.20$ & $\mathrm{~s}=1.78$ \\
\hline
\end{tabular}

TABLE V

GROUP ADEQUACY INDEX SCORES

FOR "ANY" GROUP METHOD

\begin{tabular}{ccccc}
\hline GROUP \# & $\begin{array}{c}\text { NUMBER of } \\
\text { PARTICIPANTS }\end{array}$ & $\begin{array}{c}\text { INDIVIDUAL } \\
\text { AVERAGES }\end{array}$ & $\begin{array}{c}\text { ANY GROUP } \\
\text { METHOD }\end{array}$ & $\begin{array}{c}\text { DIFFERENCE } \\
\text { or UPGRADING }\end{array}$ \\
\hline 9 & 7 & 37.71 & 36.00 & 1.71 \\
10 & 6 & 38.00 & 20.00 & 18.00 \\
11 & 6 & 52.00 & 38.00 & 14.00 \\
& & $\bar{x}=42.57$ & $\overline{\mathrm{x}}=31.33$ & $\overline{\mathrm{x}}=11.24$ \\
& $\mathrm{~s}=8.17$ & $\mathrm{~s}=9.87$ & $\mathrm{~s}=8.49$ \\
\hline
\end{tabular}

Note: lower scores represent better performance. 
GROUP ADEQUACY INDEX SCORES FOR EXPERIMENT I, II, III AND SPAN (TABLES VI, VII, VIII, IX)

Table VI compares the decision adequacy index scores of the average individual scores prior to using Front End ELECTRE II with the scores achieved by Front End ELECTRE II. The results suggest that Front End ELECTRE II upgrades the performance of the group as compared to the averages of the individual scores of that same group. Thus, in that spezific Instance (the NASA task and a sample of students at PSU) we observe a group decision quality (due to F.E. ELECTRE II) higher than the averages of the Individual decision making ability.

TABLE VI

$$
\begin{aligned}
& \text { RESULTS OF NASA TASK EXPERIMENT I: } \\
& \text { GROUP ADEQUACY INDEX SCORES } \\
& \text { FOR F.E. ELECTRE II }
\end{aligned}
$$

\begin{tabular}{cccc}
\hline GROUP \# & $\begin{array}{c}\text { NUMBER of } \\
\text { PARTICIPANTS }\end{array}$ & $\begin{array}{c}\text { INDIVIDUAL } \\
\text { AVERAGES }\end{array}$ & F.E. ELECTRE \\
\hline 1 & 7 & 41.29 & 36.71 \\
2 & 3 & 44.00 & 30.00 \\
3 & 5 & 40.50 & 33.50 \\
4 & 5 & 41.80 & 30.00 \\
& & $\overline{\mathrm{x}}=41.90$ & $\overline{\mathrm{x}}=32.55$ \\
& & $\mathrm{~s}=1.50$ & $\mathrm{~s}=3.23$ \\
\hline
\end{tabular}

$2 \bar{x}=$ group adequacy index score

Tables VII and VIII are simflar to table VI, yet show the results for ELECTRE II and "any" group method respectively. The results show that ELECTKE II does not ameliorate the performance of the group while 
"any" group method does increase the deciston adequacy index scores of Its respective groups. Thus, the unimproved version of ELECTRE II appeared to have no positive effect on prior individual performance. ${ }^{3}$

TABLE VII

EXPERIMENT II: GROUP ADEQUACY INDEX SCORES FOR REGULAR ELECTRE II

\begin{tabular}{cccc}
\hline GROUP \# & $\begin{array}{c}\text { NUMBER of } \\
\text { PARTICIPANTS }\end{array}$ & $\begin{array}{c}\text { INDIVIDUAL } \\
\text { AVERAGES }\end{array}$ & REGULAR ELECTRE II \\
\hline 5 & 7 & 41.86 & 41.00 \\
6 & 8 & 42.38 & 44.13 \\
7 & 5 & 49.80 & 49.40 \\
8 & 7 & 52.17 & 49.60 \\
& & $\overline{\mathrm{x}}=46.55$ & $\overline{\mathrm{x}}=46.03$ \\
& & $\mathrm{~s}=5.21$ & $\mathrm{~s}=4.20$ \\
\hline
\end{tabular}

TABLE VIII

EXPERIMENT III: GROUP ADEQUACY INDEX SCORES

FOR SELF-DETERMINATION (ANY GROUP) METHOD

\begin{tabular}{cccc}
\hline GROUP & $\begin{array}{c}\text { NUMBER of } \\
\text { PARTICIPANTS }\end{array}$ & $\begin{array}{c}\text { INDIVIDUAL } \\
\text { AVERAGES }\end{array}$ & ANY METHON \\
\hline 9 & 7 & 37.71 & 36.00 \\
10 & 6 & 38.00 & 20.00 \\
11 & 6 & 52.00 & 38.00 \\
& & $\bar{x}=42.57$ & $\bar{x}=31.33$ \\
& $s=8.17$ & $s=9.87$ \\
\hline
\end{tabular}

${ }^{3}$ Possible reasons for this phenomenon are advancer in the second subsection of the experimental design. 
Table IX shows actual results obtained by Gilmartin (1974) with SPAN groups. PreSPAN represents SPAN group performing without any prior human relations training workshop $(\bar{x}=35.8)$, while postSPAN represents the same groups performing after a forty hour human relations training workshop $(\bar{x}=31.0)$. The postSPAN with no preSPAN represents groups that performed only after the human relations training workshop $(\bar{x}=24.6),{ }^{4}$ where the average of the different experimental SPAN conditions is $\bar{x}^{\prime}=30.47$.

TABLE IX

GROUP ADEQUACY INDEX SCORES FOR SPAN GROUPS 5

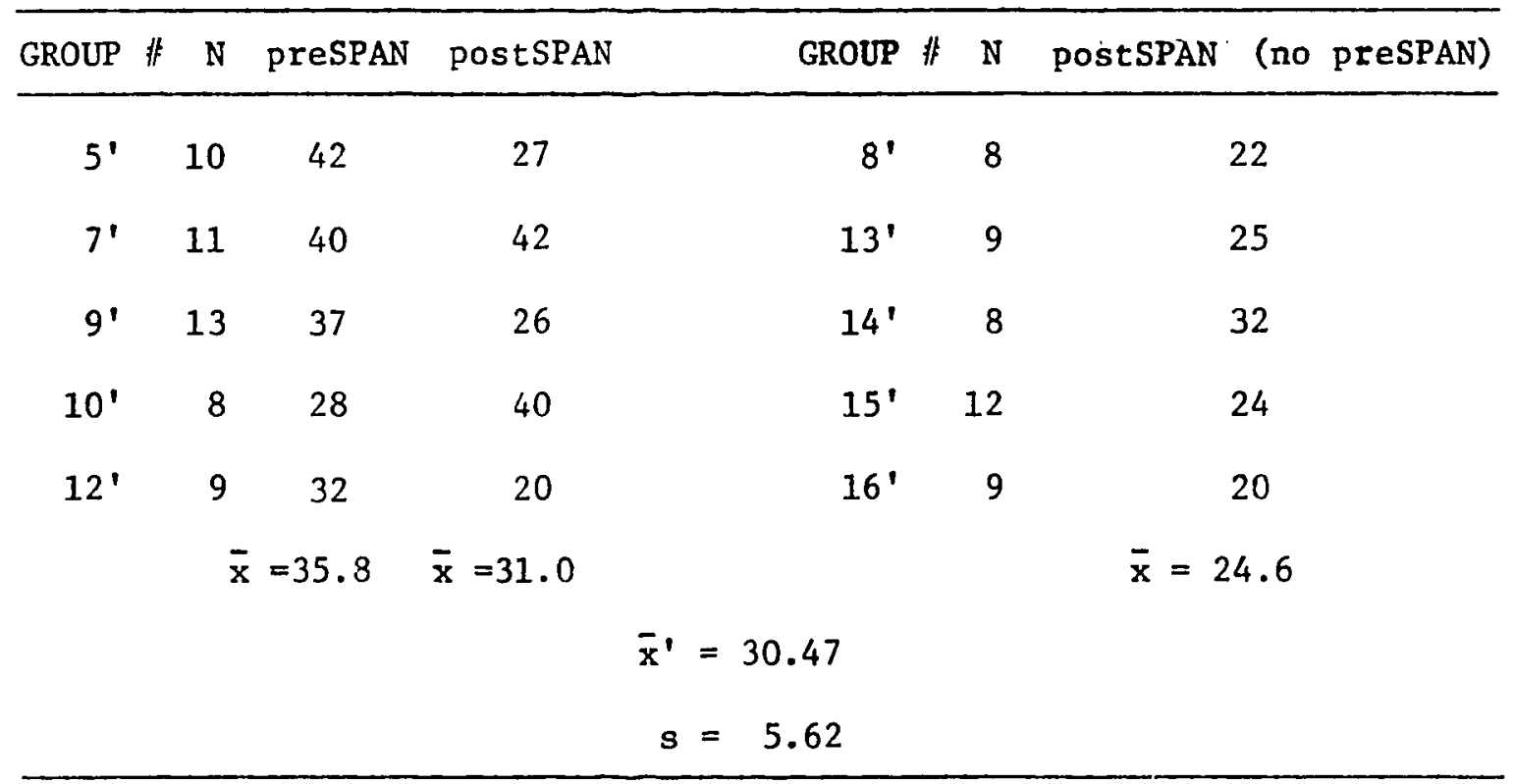

${ }^{4}$ For further details, see "SPAN..." in chapter II and "Comparability of SPAN subjects..." in chapter IV.

${ }^{5}$ The above table is assembled from Gilmartin's work (1974). It represents the group adequacy index scores for al.1 three SPAN situations grouped together for ease of comparison. 
RELATIVE UPGRADING, AND GROUP RESOURCES

FOR EXPERIMENT I, II, III

TABLES $X, X I, X I I$

Tables X, XI, and XII show the group decision adequacy Index scores, the group resources (i.e. the individual averages) and the relative upgrading (from individual scores) achieved by the different group methods due to F.E. ELECTRE II, ELECTRE II and "ANY" group method respectively.

We notice that while F.E. ELECTRE II and "ANY" group method have relatively high upgrading (i.e. a substantial difference between their individual averages and the scores due to the different methods used exists: $\bar{x}=9.35$ for F.E. ELECTRE II and $\bar{x}=11.24$ for "any" group method); ELECTRE II has almost none $(\bar{x}=.52)$. The results also suggest that F.E. ELECTRE II developed as part of this thesis represents a significant improvement to the original ELECTRE II.

TABLE $X$

INDEX OF RELATIVE UPGRADING FOR F.E. ELECTRE II VERSUS GROUP RESOURCES 6

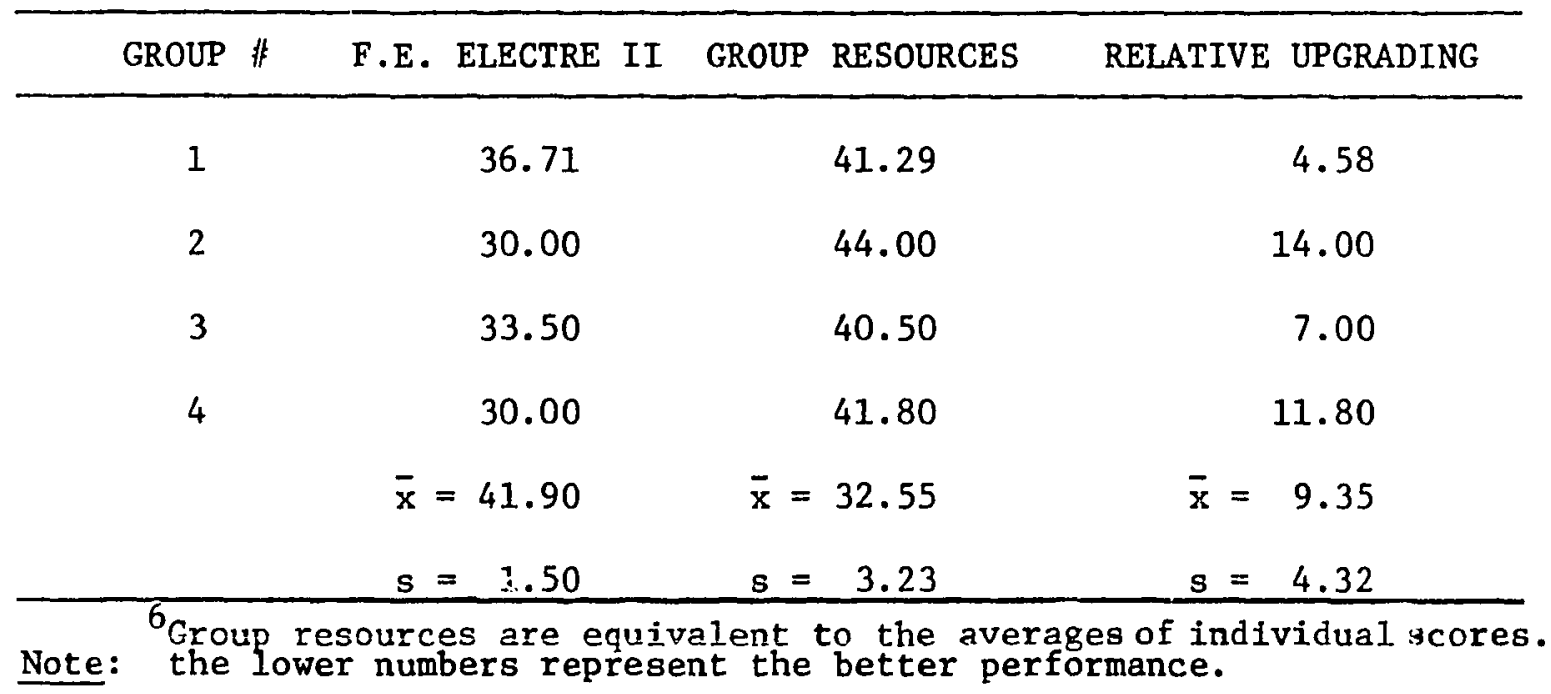


TABLE XI

INDEX OF RELATIVE UPGRADING FOR ELECTRE II VERSUS GROUP RESOURCES7

\begin{tabular}{cccc}
\hline GROUP \# & REGULAR ELECTRE II & GROUP RESOURCES & RELATIVE UPGRADING \\
\hline 5 & 41.00 & 41.86 & .86 \\
6 & 44.13 & 42.38 & -1.75 \\
7 & 49.40 & 49.80 & .40 \\
8 & 49.60 & 52.17 & 2.57 \\
& $\overline{\mathrm{x}}=46.03$ & $\overline{\mathrm{x}}=46.55$ & $\overline{\mathrm{x}}=\mathbf{. 5 2}$ \\
& $\mathrm{s}=4.20$ & $\mathrm{~s}=5.21$ & $\mathrm{~s}=1.78$ \\
\hline
\end{tabular}

TABLE XII

INDEX OF RELATIVE UPGRADING FOR "ANY" GROUP METHOD, VERSUS GROUP RESOURCES

\begin{tabular}{cccc}
\hline GROUP & ANY METHOD & GROUP RESOURCES & RELATIVE UPGRADING \\
\hline 9 & 36.00 & 37.71 & 1.71 \\
10 & 20.00 & 38.00 & 18.00 \\
11 & 38.00 & 52.00 & 14.00 \\
& $\bar{x}=31.33$ & $\bar{x}=42.57$ & $\bar{x}=11.24$ \\
& $s=9.87$ & $s=8.17$ & $s=8.49$ \\
\hline
\end{tabular}

${ }^{7}$ Group resources are equivalent to the averages of Individual scores. Lower scores represent better performance. 
RESULTS ON THE NASA TASK COMPARING "DECISION ADEQUACY" AND

"UPGRADING" PERFORMANCE MEASURES FOR FRONT END

ELECTRE II, ELECTRE II AND "ANY" GROUP METHOD

(TABLES XIII, XIV, XV, XVI, XVII, XVIII)

Tables XIII and XIV compare F.E. ELECTRE II and ELECTRE II group decision adequacy index scores and relative upgrading respectively. We notice a difference (d) of 13.48 between their group decision adequacy index scores and a difference ( $d^{\prime}$ ) of 8.83 between their relative upgradings; with F.E. ELECTRE II outperforming ELECTRE II. The results indicate that the improved ELECTRE II (Front End ELECTRE II) represents a significant improvement to the original ELECTRE II in that particular experiment. Thus, the relatively poor showing of unimproved ELECTRE II would tend to support the contention that the conditions in the NASA moon survival problem were not favorable to ELECTRE II.

TABLE XIII

F.E. ELECTRE II AND ELECTRE II GROUP ADEQUACY INDEX SCORES

\begin{tabular}{crcc}
\hline GROUP \# & F.E. ELECTRE II & GROUP & ELECTRE II \\
\hline 1 & 36.71 & 5 & 41.00 \\
2 & 30.00 & 6 & 44.13 \\
3 & 33.50 & 7 & 49.40 \\
4 & 30.00 & 8 & 49.60 \\
& $\overline{\mathrm{x}}=32.55$ & & $\mathrm{x}=46.03$ \\
& $\mathrm{~s}=3.23$ & $\mathrm{~s}=4.20$ \\
& $\mathrm{~d}=13.48$ &
\end{tabular}


TABLE XIV

F.E. ELECTRE AND ELECTRE

RELATIVE UPGRADING

\begin{tabular}{|c|c|c|c|c|}
\hline GROUP \# & F.E. & ELECTRE II & GROUP \# & ELECTRE II \\
\hline 1 & & 4.58 & 5 & .86 \\
\hline 2 & & 14.00 & 6 & -1.75 \\
\hline 3 & & 7.00 & 7 & .40 \\
\hline \multirow[t]{4}{*}{4} & & 11.80 & 8 & 2.57 \\
\hline & $\overline{\mathrm{x}}=$ & 9.35 & & $\bar{x}=$ \\
\hline & $s=$ & 4.32 & & $s=1.78$ \\
\hline & \multicolumn{3}{|c|}{$d^{\prime}=8.83$} & \\
\hline
\end{tabular}

Tables XV and XVI compare F.E. ELECTRE II and "any" group method decision adequacy index scores and relative upgrading respectively. The difference in scores is 1.22 and 1.27 which demonstrate there is no difference in their performance. Thus, F.E. ELECTRE II and "any" group method have had equivalent group decision quality in that particular task. Had the conditions been more complex, F.E. ELECTRE II might have had a higher chance of improving group decision quality over "any" group method. 
TABLE XV

FRONT END ELECTRE II AND "ANY" GROUP METHOD

GROUP ADEQUACY INDEX SCORES

\begin{tabular}{crrr}
\hline GROUP \# & F.E. ELECTRE II & GROUP \# & ANY METHOD \\
\hline 1 & 36.71 & 9 & 36.00 \\
2 & 30.00 & 10 & 20.00 \\
3 & 33.50 & 11 & 38.00 \\
4 & 30.00 & & \\
& $\bar{x}=32.55$ & & $\bar{x}=31.33$ \\
& $\mathrm{~s}=$ & 3.23 & $\mathrm{~s}=9.87$ \\
& & $\mathrm{~d}=1.22$ \\
\hline
\end{tabular}

TABLE XVI

FRONT END ELECTRE II AND "ANY" GROUP

METHOD RELATIVE UPGRADING

\begin{tabular}{crcc}
\hline GROUP \# & F.E. ELECTRE II & GROUP \# & ANY METHOD \\
\hline 1 & 4.58 & 9 & 1.71 \\
2 & 14.00 & 10 & 18.00 \\
3 & 7.00 & 11 & 14.00 \\
4 & 11.80 & & \\
& $\bar{x}=9.35$ & & $\bar{x}=11.24$ \\
& $\mathrm{~s}=4.32$ & $\mathrm{~s}=8.49$ \\
& & $\mathrm{~d}=1.89$ \\
\hline
\end{tabular}

Tables XVII and XVIII compare ELECTRE II and "any" group method decision adequacy index scores and relative upgrading respectively. The 
difference is 14.70 and 10.72 with the group method outperforming

ELECTRE II. Thus, it appears that in these particular conditions, "any" group method performed better than ELECTRE II, which suggests again that the NASA task was not particularly favorable for ELECTRE II.

TABLE XVII

ELECTRE II AND "ANY" GROUP METHOD

GROUP ADEQUACY INDEX SCORES

\begin{tabular}{crrr}
\hline GROUP \# & ELECTRE II & GROUP \# & ANY METHOD \\
\hline 5 & 41.00 & 9 & 36.00 \\
6 & 44.13 & 10 & 20.00 \\
7 & 49.40 & 11 & 38.00 \\
8 & 49.60 & & \\
& $\bar{x}=46.03$ & & $\bar{x}=31.33$ \\
& $\mathrm{~s}=4.20$ & $\mathrm{~s}=9.87$ \\
& & $\mathrm{~d}=14.70$ \\
\hline
\end{tabular}

TABLE XVIII

ELECTRE II AND "ANY" GROUP METHOD

RELATIVE UPGRADING

\begin{tabular}{|c|c|c|c|}
\hline GROUP 非 & ELECTRE II & GROUP \# & ANY METHOD \\
\hline 5 & .86 & 9 & 1.71 \\
\hline 6 & -1.75 & 10 & 18.00 \\
\hline 7 & .40 & 11 & 14.00 \\
\hline \multirow[t]{2}{*}{8} & 2.57 & & \\
\hline & $\begin{array}{l}\bar{x}=.52 \\
s=1.78\end{array}$ & $\mathrm{~d}=10.72$ & $\begin{array}{r}\overline{\mathrm{x}}=11.24 \\
\mathrm{~s}=8.49\end{array}$ \\
\hline
\end{tabular}


COMPARISON OF OUR RESULTS WITH SPAN (TABLES XIX, $\mathrm{XX}, \mathrm{XXI}, \mathrm{XXII}, \mathrm{XXIII}, \mathrm{XXIV})$

Tables XIX and XX compare results of our experiments using F.E. ELECTRE II with SPAN (under its different experimental conditions ${ }^{8}$ ). The decision adequacy index scores for the SPAN groups were $35.8,31.0$, 24.6 with an average of 30.47 ; while group decision adequacy index scores for F.E. ELECTRE was 32.33. The relative upgrading scores for the SPAN groups were $9.78,8.79,20.03$ with an average of 12.84 ; while F.E. ELECTRE II has a relative upgrading of 9.35 . The results show that there is no substantial difference in the performance of both methods. (A1though Front End ELECTRE II groups were al1 ad hoc groups as compared to the majority of SPAN's which were established.) (Experiments by Hall and Will lam [1966́, Cited in Gllmartin, 1974], mentioned earlier, had proved that established groups perform better than ad hoc ones.) Thus, these results propound that the improved ELECTRE II developed as part of this thesis performs as well as the much acclaimed SPAN.

${ }^{8}$ For further details, see description of Table IX. 
TABLE XIX

COMPARISON OF OUR RESULTS WITH SPAN. F.E. ELECTRE II AND SPAN GROUP ADEQUACY INDEX SCORES

\begin{tabular}{|c|c|c|c|c|c|c|c|c|c|}
\hline GROUP & 非 & PreSPAN & PostSPAN & GROUP & \# & $\begin{array}{c}\text { PostSPAN } \\
\text { (no } \\
\text { preSPAN) }\end{array}$ & GROUP & 非 & F.E.E. \\
\hline $5^{\prime}$ & & 42 & 27 & $8^{\prime}$ & & 22 & 1 & & 36.71 \\
\hline $7^{\prime}$ & & 40 & 42 & $13^{\prime}$ & & 25 & 2 & & 30.00 \\
\hline $9^{\prime}$ & & 37 & 26 & $14^{\circ}$ & & 32 & 3 & & 33.50 \\
\hline $10^{\prime}$ & & 28 & 40 & $15^{\prime}$ & & 24 & 4 & & 30.00 \\
\hline \multirow[t]{3}{*}{$12^{\prime}$} & & 32 & 20 & $16^{\circ}$ & & 20 & & & \\
\hline & & $=35.8$ & $\bar{x}=31.00$ & & & $=24.60$ & & & $=32.30$ \\
\hline & & & & 30.4 & & & $=1.86$ & & \\
\hline
\end{tabular}

TABLE XX

COMPARISON OF OUR RESULTS WITH SPAN. F.E. ELECTRE II AND SPAN GROUP RELATIVF UPGRADING

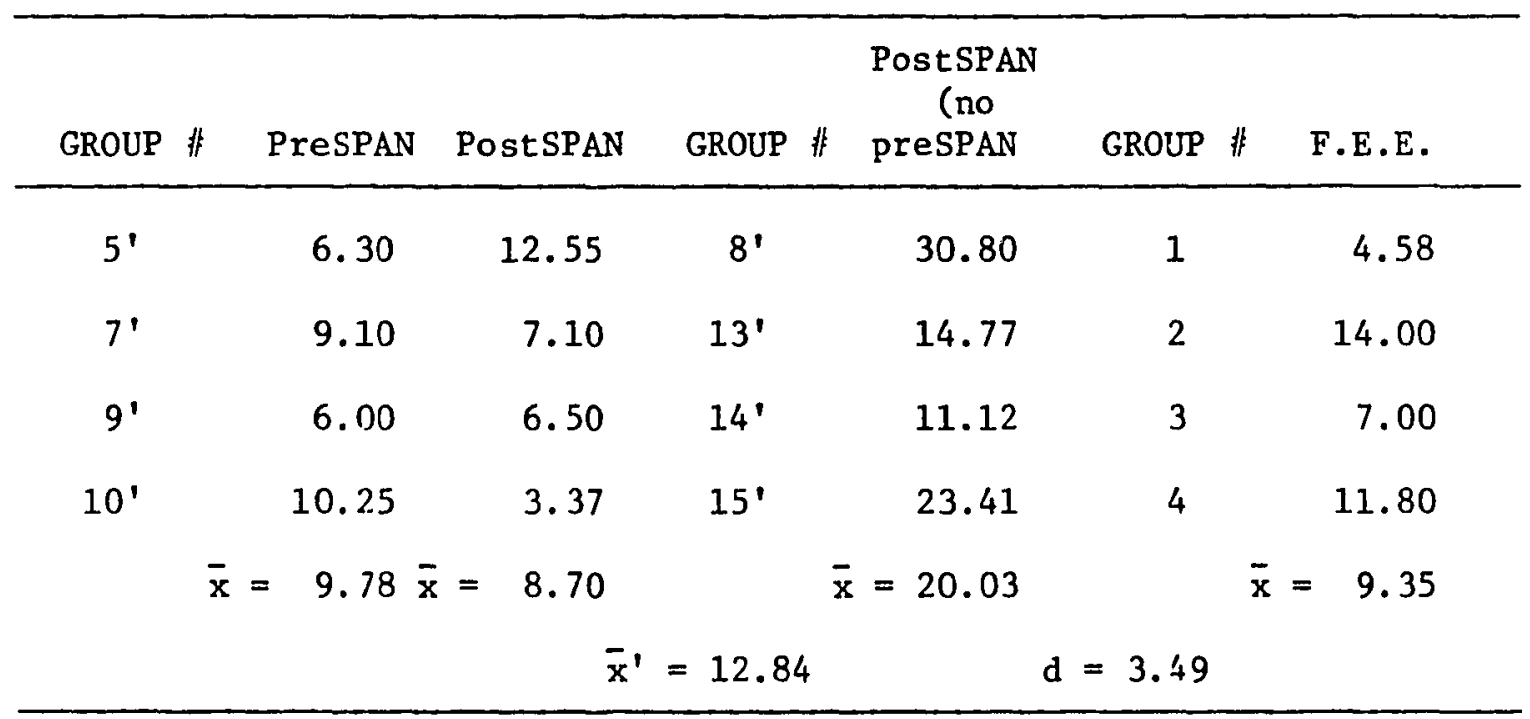

Tables XXI and XXII compare results of our experiments using 
ELECTRE II with SPAN under its different experimental conditions. These results suggest that ELECTRE II did not perform as well as SPAN.

TABLE XXI

ELECTRE II AND SPAN GROUP

ADEQUACY INDEX SCORES

\begin{tabular}{|c|c|c|c|c|c|c|c|c|c|}
\hline GROUP & \# & PresPAN & PostSPAN & GROUP & 非 & $\begin{array}{l}\text { PostSPAN } \\
\text { (no } \\
\text { preSPAN) }\end{array}$ & GROUP & $\#$ & ELECTRE \\
\hline $5^{\prime}$ & & 42 & 27 & $8^{\prime}$ & & 22 & 5 & & 41.00 \\
\hline $7^{\prime}$ & & 40 & 42 & $13^{\prime}$ & & 25 & 6 & & 44.13 \\
\hline $9^{\prime}$ & & 37 & 26 & $14^{\prime}$ & & 32 & 7 & & 49.40 \\
\hline $10^{\prime}$ & & 28 & 40 & $15^{\prime}$ & & 24 & 8 & & 49.60 \\
\hline \multirow[t]{3}{*}{$12^{\prime}$} & & 32 & 20 & $16^{\prime}$ & & 20 & & & \\
\hline & \multirow{2}{*}{\multicolumn{2}{|c|}{$\bar{x}=35.8$}} & \multirow[t]{2}{*}{$\bar{x}=31.0$} & \multicolumn{4}{|c|}{$\bar{x}=24.6$} & & $\begin{array}{l}=46.03 \\
=4.20\end{array}$ \\
\hline & & & & $\bar{x}^{\prime}=30$. & 47 & & $d=15$ & & \\
\hline
\end{tabular}


TABLE XXII

ELECTRE II AND SPAN RELATIVE UPGRADING

\begin{tabular}{|c|c|c|c|c|c|c|c|c|c|}
\hline GROUP & 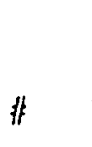 & PresPAN & PostSPAN & GROUP & 非 & $\begin{array}{c}\text { Post SPAN } \\
\text { (no } \\
\text { presPAN) }\end{array}$ & GROUP & 非 & ELECTRE II \\
\hline $5^{\prime}$ & & 6.30 & 12.55 & $8^{\prime}$ & & 30.80 & 5 & & .86 \\
\hline $7^{\prime}$ & & 9.10 & 7.10 & $13^{\prime}$ & & 14.77 & 6 & & -1.75 \\
\hline $9^{\prime}$ & & 6.00 & 6.50 & $14^{\prime}$ & & 11.12 & 7 & & .40 \\
\hline $10^{\prime}$ & & 10.25 & 3.37 & $15^{\prime}$ & & 23.41 & 8 & & 2.57 \\
\hline \multirow[t]{3}{*}{$12^{\prime}$} & & 17.25 & 14.00 & $16^{\prime}$ & & 20.08 & & & \\
\hline & \multirow[t]{2}{*}{$\bar{x}=$} & $=9.78 \bar{x}=$ & $=8.70$ & \multicolumn{4}{|c|}{$\bar{x}=20.03$} & & $\begin{array}{r}=.52 \\
=1.78\end{array}$ \\
\hline & & & & $\bar{x}^{\prime}=1$ & & & $\mathrm{~d}=\mathrm{I}$ & 32 & \\
\hline
\end{tabular}

Tables XXIII and XXIV compare our results of "any" group method with SPAN under its different experimental conditions. We observe that there is no difference in the performance of "any" group method with SPAN, thus both "any" group method and SPAN appear to be equivalent in the group decision quality of that particular task. 
TABLE XXIII

ANY GROUP METHOD AND SPAN GROUP ADEQUACY INDEX SCORES

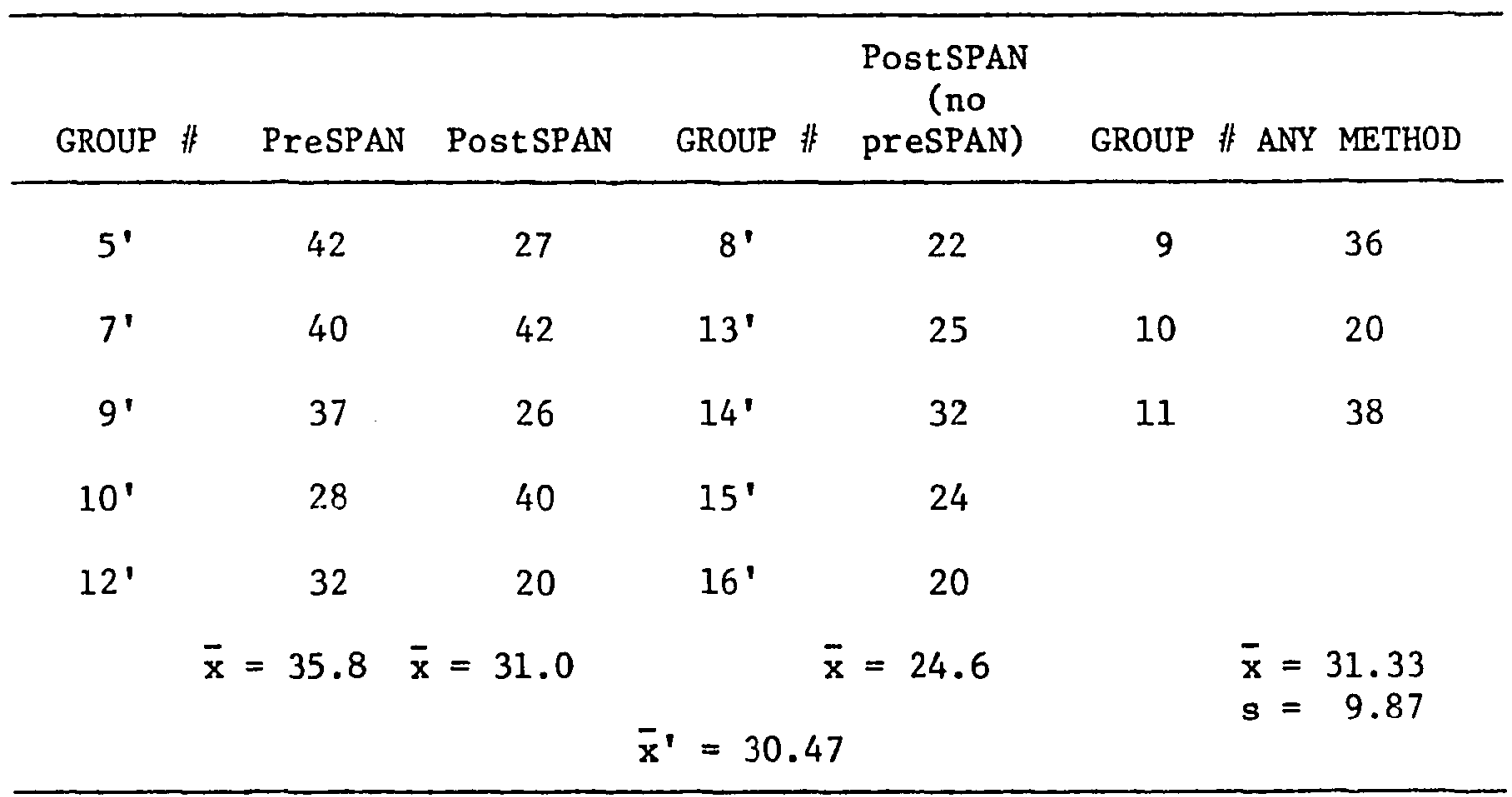

TABLE XXIV

ANY GROUP METHOD AND SPAN

RELATIVE UPGRADING

\begin{tabular}{|c|c|c|c|c|c|c|c|c|c|}
\hline GROUP & $\#$ & PresPAN & PostSPAN & GROUP & 非 & $\begin{array}{c}\text { PostSPAN } \\
\text { (no } \\
\text { preSPAN) }\end{array}$ & GROUP & \# ANY & METHOD \\
\hline $5^{i}$ & & 6.30 & 12.55 & $8^{\prime}$ & & 30.80 & 9 & & 1.71 \\
\hline $7^{\prime}$ & & 9.10 & 7.10 & $13^{\prime}$ & & 14.77 & 10 & & 18.00 \\
\hline $9^{\prime}$ & & 6.00 & 6.50 & $14^{\prime}$ & & 11.12 & 11 & & 14.00 \\
\hline $10^{\prime}$ & & 10.25 & 3.37 & $15^{\prime}$ & & 23.41 & & & \\
\hline \multirow[t]{3}{*}{$12^{\prime}$} & & 17.25 & 14.00 & $16^{\prime}$ & & 20.08 & & & \\
\hline & $\bar{x}=$ & $=9.78 \bar{x}$ & $=8.70$ & & & $=20.03$ & & $\bar{x}=$ & 11.24 \\
\hline & & & & $\bar{x}^{\prime}=12.8$ & 84 & & $\mathrm{~d}=1.60$ & & \\
\hline
\end{tabular}


CŨICLLDING QUALITATIVE REMARKS

In conclusion, Front End ELECTRE II, "any" group method and SPAN performed equivalently, i.e. there was no substantial difference in their performances, while ELECTRE II did not perform as well. The relatively poor showing of regular ELECTRE II would tend to support the contention that the NASA moon survival task was not favorable to ELECTRE II. The full value of both regular ELECTRE II and Front End ELECTRE II can probably be observed only with a task of considerably more complexity than the NASA moon survival task that was used. Also the ELECTRE II methodology was explained in only four minutes which could have hindered its performance.

Front End ELECTRE II might have even performed better had the conditions been adequate, i.e. more complexity, more time to explain how it works and established groups or at least more interested groups were utilized.

The results also indicate that Front End ELECTRE II developed as part of this thesis represents a significant improvement to the originai ELECTRE II.

\section{STATISTICAL RESULTS AND DISCUSSION}

The reason for choosing analyses of variance tests is explained in the last section of chapter IV.

Table XXV shows an analysis of variance table ${ }^{9}$ for the different individual averages prior to utilizing the various group methods

9 Due to the lack of availability of statistical packages at the time at Portland State Iniversity, our own programs were developed and then checked for accuracy when the former became avallable later. 
utilized in this thesis (viz. Front End ELECTRE II, ELECTRE II and "any" group method). The F-test shows that the observed difference is not statistically significant (minimum $F$ from tables for two and eight degrees of freedom is 4.46, while our calculated F is .890009). Therefore, we cannot reject the null hypothesis that states that at the outset all individuals are similar in their performance, or that we start with no difference in individual performance before using the various group methods.

TABLE XXV

ANALYSIS OF VARIANCE FOR FRONT END ELECTRE II, ELECTRE II AND "ANY" GROUP METHOD INDIVIDUAL AVERAGES

PRIOR TO USING THESE GROUP TECHNIQUES

SUMMARY OF THE ANALYSIS OF VARIANCE

\begin{tabular}{lcccc}
\hline \multicolumn{1}{c}{ SOURCE } & DF & SS & MS & F \\
Between Groups & $\mathrm{K}-1=2$ & 49.3318 & 24.6659 & .890009 \\
Within Groups & $\mathrm{N}-\mathrm{K}=8$ & 221.713 & 27.7142 & \\
Total & $\mathrm{N}-1=10$ & 271.045 & & \\
\hline
\end{tabular}

Table XXVI shows an analysis of variance table for Front End ELECTRE II, ELECTRE II, and "any" group method post group scores (group decision adequacy index scores). The F-test shows that the difference among these techniques is statistically significant (minimum F from tables for two and eight degrees of freedom is 4.46, while our calculated $F$ is 
7.2318.), i.e. we can reject the null hypothesis that states that Front End ELECTRE II, ELECTRE II and "any" group method group performance are similar, i.e. there is a difference in the performance of these methods.

TABLE XXVI

ANALYSIS OF VARIANCE FOR FRONT END ELECTRE II, ELECTRE II, AND

"ANY" GROUP METHOD DECISION INDEX SCORES (i.e. SCORES AFTER USING THE VARIOUS GROUP TECHNIQUES)

SUMMARY OF THE ANALYSIS OF VARIANCE

\begin{tabular}{lcccc}
\hline \multicolumn{1}{c}{ SOURCE } & DF & SS & MS & F \\
Between Groups & $\mathrm{K}-1=2$ & 504.224 & 252.112 & 7.23181 \\
Within Groups & $\mathrm{N}-\mathrm{K}=8$ & 278.893 & 34.8616 & \\
Total & $\mathrm{N}-1=10$ & 783.117 & &
\end{tabular}

***For further investigation, we use the Scheffe method:

critical ratio: $\left(\overline{\mathrm{Y}}_{1}-\overline{\mathrm{Y}}_{2}\right) / \sqrt{\mathrm{MS}_{\mathrm{er}}\left(1 / \mathrm{n}_{1}+1 / \mathrm{n}_{2}\right)}$

$*_{1}$ and $n_{2}$ are the number of observations in group 1 and 2 respectively.

$\bar{Y}_{1}$ and $\bar{Y}_{2}$ are the means of groups 1 and 2 respectively.

This critical ratio should be higher than the critical value.

critical value: $V=\sqrt{\text { df }_{\text {bet }} F_{\alpha}}$

(one can also use the t-test with MS error term:

$t \times \sqrt{M_{\text {er }}\left(1 / \mathrm{n}_{1}+1 / \mathrm{n}_{2}\right)}>\left(\overline{\mathrm{Y}}_{1}-\overline{\mathrm{Y}}_{2}\right)$

the first term should be higher than the second term for least significant 
difference), (Clarkson, 1976).

Calculations of Scheffé for Table XXIV:

$v=\sqrt{2 \times 4.46}=2.99$

- $\mathrm{CR}=13.48 / \sqrt{34.8616(2 / 4)}=3.22873$

$C R$ is greater than $V$, therefore the difference between the performance of F. E. ELECTRE II and that of ELECTRE II is significant. This implies that the means of the groups using F. E. ELECTRE II are significantly lower than the means of the groups using ELECTRE II.

i.e. F. E. ELECTRE II outperformed ELECTRE II in that particular task.

. $\mathrm{CR}=14.7 / \sqrt{34.8616(1 / 4+1 / 3)}=3.2598$

CR is greater than $V$, therefore, the difference is significant between the performance of "any" group method and ELECTRE II, which implies that the means of the groups using "any" group method are significantly lower than the means of the groups using ELECTRE II, i.e. "any" group method outperformed ELECTRE II in that particular task.

Table XXVII shows an analysis of vartance table for the relative upgrading due to F. E. ELECTRE II, ELECTRE II, and "any" method. The F-test shows a significant difference (minimum $F$ from the tables for 2 and 8 degrees of freedom is 4.46, while our calculated F is 4.68916), i.e. we can reject the null hypothesis that states that the upgrading in Front End ELECTRE II, ELECTRE II and "any" group method is similar or that any improvement observed is only due to chance (in $95 \%$ of the cases). 
Scheffé:

$\mathrm{V}=2.99$

- $\mathrm{CR}=(9.97-.52) / \sqrt{27.5605(2 / 4)}=2.54568$

CR less then $V$ for F. E. ELECTRE II AND ELECTRE II, i.e. the upgrading difference is not significant.

$\cdot \mathrm{CR}=(11.24-.52) / \sqrt{27.5605(1 / 4+1 / 3)}=2.67359$

$C R$ is less than V for "any" group method and ELECTRE II, i.e. the upgrading difference is not significant.

TABLE XXVII

ANALYSIS OF VARIANCE FOR FRONT END ELECTRE II, ELECTRE II, AND

"ANY" GROUP METHOD DECISION INDEX SCORES (i.e. SCORES

AFTER USING THE VARIOUS GROUP TECHNIQUES)

SUMMARY OF THE ANALYSIS OF THE VARIANCE

\begin{tabular}{lcccc}
\hline \multicolumn{1}{c}{ SOURCE } & DF & SS & MS & F \\
Between Groups & $\mathrm{K}-1=2$ & 258.472 & 129.236 & 4.68916 \\
Within Groups & $\mathrm{N}-\mathrm{K}=8$ & 220.484 & 27.5606 & \\
Total & $\mathrm{N}-1=10$ & 478.956 & & \\
\hline
\end{tabular}

COMPARISON OF THE MEANS AND STANDARD DEVIATIONS OF THE THREE METHODS USED IN THIS INVESTIGATION (TABLE XXVIII)

Table XXVIII summarizes part of the results of this study by comparing the mearis and standard deviations of the 3 techniques used in this investigation. Two important aspects are observed.

1. Front End ELECTRE II and "any" group method upgrade the performance of the group as compared to the averages of the individual scores of 
group members. Thus, in that specific instance (the NASA task and a sample of students at PSU) we observe a group decision quality higher. than the averages of the individual decision making ability. We should realize the importance of such a discovery since policy decisions are more often than not, taken in groups and not by Individuals alone. A development in any group deciston making technique should be considered an important step ahead.

2. The Front End ELECTRE II and ELECTRE II means differ significantly at the .05 level (an analysis of variance and a Scheffé test were used). This indicates that the means of the Front End ELECTRE II groups is significantly lower than the means of ELECTRE II which imply that the improved ELECTRE II (developed as part of this work) performed better than ELECTRE II, a recent, yet well established, technique that prominent scientists have used to solve international problems. 
TABLE XXVIII

COMPARISON OF MEANS AND STANDARD DEVIATIONS OF FRONT END ELECTRE II, ELECTRE II, AND "ANY" GROUP METHOD

\begin{tabular}{|c|c|c|c|c|}
\hline & $\begin{array}{l}\text { Means and S.D. } \\
\text { prior to uti- } \\
\text { lize group } \\
\text { method }\end{array}$ & $\begin{array}{l}\text { Post group } \\
\text { method means } \\
\text { and S.D. }\end{array}$ & $\begin{array}{l}\text { Difference } \\
\text { Scores }\end{array}$ & \\
\hline $\begin{array}{l}\text { EXPERIMENT I } \\
\text { F. E. ELECTRE }\end{array}$ & $\begin{array}{l}41.90 \\
s=1.50\end{array}$ & $\begin{array}{c}32.55 \\
s=3.23\end{array}$ & $\begin{array}{c}9.35 \\
s=4.32\end{array}$ & $\begin{array}{c}\text { Scheffé } \\
.05\end{array}$ \\
\hline $\begin{array}{l}\text { EXPERIMENT II } \\
\text { ELECTRE II }\end{array}$ & $\begin{array}{c}46.55 \\
s=5.21\end{array}$ & $\begin{array}{l}46.03 \\
s=4.20\end{array}$ & $\begin{array}{c}.52 \\
s=1.78\end{array}$ & $\begin{array}{c}\text { Scheffé } \\
.05\end{array}$ \\
\hline \multirow[t]{2}{*}{$\begin{array}{l}\text { EXPERIMENT III } \\
\text { "any" group } \\
\text { method }\end{array}$} & $\begin{array}{l}42.57 \\
s=8.17\end{array}$ & $\begin{array}{c}31.33 \\
s=9.87\end{array}$ & $\begin{array}{l}11.25 \\
s=8.49\end{array}$ & \\
\hline & $\begin{array}{l}\text { ANOVA } \\
.05\end{array}$ & $\begin{array}{l}\text { ANOVA } \\
.05\end{array}$ & & \\
\hline
\end{tabular}

COMPARISON OF SPAN'S AND NONSPAN'S MEANS WITH FRONT END ELECTRE II' $\underline{\underline{s}}$ MEANS

1. A t-test was used to compare the individual averages of members prior to utilizing Front End ELECTRE II and the individual averages of members prior to utilizing SPAN (under its three different experimental conditions, using SPAN's [prior] means as norms). The within groups error term of the F-test (for means prior to the three treatments examined in this study) was used (Clarkson, 1976).

$$
t_{c}=\frac{\bar{y}-\mu}{\sqrt{s^{2} / n}}
$$

Where $\mu$ : Gilmartin's (pre) mean treated as norm

$\bar{y}$ : Individual average means of members prior to utilizing Front End ELECTRE II 


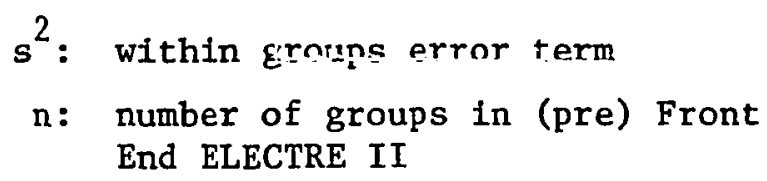

i. Individual averages prior to utilizing Front End ELECTRE II and pre SPAN (i.e. SPAN with no human relations training workshop).

$$
t_{c}=\frac{41.90-45.58}{\sqrt{27.7142 / 4}}=-1.40
$$

ii. Individual averages prior to utilizing Front End ELECTRE II and post SPAN (1.e. the same subjects as pre SPAN after a forty-hour human relations workshop).

$$
t_{c}=\frac{41.90-39.70}{\sqrt{27.7142 / 4}}=1.22
$$

iii. Individual averages prior to utllizing Front End ELECTRE II and post SPAN with no pre SPAN (i.e. SPAN with a human relations training workshop with no pre SPAN).

$$
t_{c}=\frac{41.90-44.63}{\sqrt{27.7142 / 4}}=-1.04
$$

For a Two-Tailed Test:

The value of $t$ at .025 significance level and 8 degrees of freedom is 2.262. The difference between the hypothesized value and the sample mean tested in $i, i i$, and $i 11$ above 1 s not significant at the $5 \%$ level. The results suggest that the performances of participants in both methods are equivalent at the outset. 
For a One-Tailed Test:

The value of $t$ at .05 significance level and 8 degrees of freedom is 1.860 . The results are similar to the two-tailed test.

2. In order to show that Front End ELECTRE II provides an equally good basis for group dectsion making as SPAN, a t-test was applied (Clarkson 1976), using the within groups error term of the 3 treatments examined in this study (i.e. Front End ELECTRE II, ELECTRE II, and "any" group method).

The F-test results were:

alternative hypothesis: $\mu_{1}=\mu_{3}>\mu_{2}$

where $\mu_{1}$ : is the mean for Front End ELECTRE II.

$\mu_{2}:$ is the mean for ELECTRE II.

$\mu_{3}$ : is the mean for "any" group method.

From the above 3 techniques we chose to compare Front End ELECTRE II $\left(\mu_{1}\right)$ with SPAN (using SPAN as a norm) since the former is our main concern.

$$
\begin{aligned}
& t_{c}=\bar{y}-\mu \quad \text { Where } \mu: \text { Gllmartin's (SPAN) mean treated } \\
& \sqrt{s^{2} / n} \quad \text { as norm } \\
& \bar{y} \text { : Front End ELECTRE II mean } \\
& s^{2} \text { : within groups error term } \\
& \mathrm{n} \text { : number of groups in Front End } \\
& \text { ELECTRE II }
\end{aligned}
$$

1. Front End ELECTRE II and pre SPAN (i.e. SPAN with no human relations training workshop).

$$
t_{c}=\frac{32.30-35.8}{\sqrt{34.8616 / 4}}=-1.19
$$


ii. Front End ELECTRE II and post SPAN (1.e. the same subjects as pre SPAN after a forty-hour human relations workshop).

$$
t_{c}=\frac{32.30-31.0}{\sqrt{34.8616 / 4}}=.44
$$

1ii. Front End ELECTRE II and post SPAN with no pre SPAN (i.e. SPAN with a human relations training workshop with no pre SPAN)

$$
t_{c}=\frac{32.30-24.6}{\sqrt{34.8616 / 4}}=2.61
$$

For a Two-Tailed Test:

The value of $t$ at .025 significance level and 8 degrees of freedom is 2.262. The difference between the hypothesized value and the sample mean tested in $i$ and $i i$ above is not significant at the 5\% level. The results suggest that Front End ELECTRE II provides an equally good basis for group decision making as pre SPAN and post SPAN with pre SPAN. The difference between the norm and the sample mean tested in iii above is significant at the $5 \%$ level. This suggests that Front End ELECTRE II did not perform as well as post SPAN with no pre SPAN. We conclude that at the $5 \%$ level and conditions iil the sample mean is significantly higher than the norm.

\section{For a One-Tailed Test:}

The value of $t$ at .05 significance level and 8 degrees of freedom is 1.860 . The results are similar to the two-tailed test.

The t-test fintroduces a higher probability of type I error (rejecting a true null hypothesis) than an F-test. But we cannot use the F-test 
in this instance since we cannot assure the randomization of all participants. Another limitation here is that we are not considering the variance in SPAN (since we have chosen it as norm). Had we considered the variance, the finding does change, and all SPAN's results become equivalent to Front End ELECTRE II.

This point raises the suggestion that, ideally, SPAN should have been included as an actual part of the experimental design of this study, (of course, other limitations prevented that).

3. In order to show that Front End ELECTRE II provides an equally good basis for group decision making as NONSPAN, a t-test was applied, using the within groups error term of the 3 treatments investigated in this study (1.e. Front End ELECTRE II, ELECTRE II, and "any" group method).

$$
t_{c}=\frac{\bar{y}-\mu}{\sqrt{s^{2} / n}} \quad \mu: \begin{aligned}
& \text { Gilmartin's (NONSPAN) mean } \\
& \text { treated as norm. }
\end{aligned}
$$

1. Front End ELECTRE II and pre NONSPAN

$$
t_{c}=\frac{32.30-32}{\sqrt{34.8616 / 4}}=.10
$$

ii. Front End ELECTRE II and post NONSPAN

$$
t_{c}=\frac{32.30-33}{\sqrt{34.8616 / 4}}=-.24
$$

1ii. Front End ELECTRE II and post NONSPAN with no pre NONSPAN.

$$
t_{c}=\frac{32.30-30.66}{\sqrt{34.8616 / 4}}=.56
$$


The results are the same as case 1, 1.e. there is no significant difference between Front End ELECTRE II and NONSPAN at the .05 significance leve1, which indicates that both are equivalent methods to solve the NASA task. 
CHAPTER VI

CONCLUSION

CONCLUDING REMARKS: GENERAL SUMMARY OF THE FINDINGS

1. The Author performed an analysis of variance on all three methods used to solve the NASA task in this investigation (viz. Front End ELECTRE II, ELECTRE II, and "any" group method). A significant statistical difference was observed (i.e. the null hypothesis, stating that all used methods were equivalent as measured by the decision adequacy index scores and the relative upgradings due to the various methods utilized, cannot be accepted); which indicates that one or more of these techniques differ in their decision quality output from the rest.

Scheffé's method was used to further investigate the statistical significant difference. The difference in the case of ELECTRE II was enough to reject the null hypothesis regarding decision adequacy index scores. This means that the obtained or observed differences in decision quality output in the case of ELECTRE II are not in the realm of expected chance variation, i.e. there is some difference in the perfornance of the methods used.

2. A t-test was then used to compare the individual averages of members prior to utilizing Front End ELECTRE II and the individual averages of members prior to utilizing SPAN (under its three different experimental conditions, using 'prior' means as norms). The within-groups error term of the F-test (for the means prior to the three treatments 
examined in this study) was used. The results suggest that we cannot reject the first null hypothesis that states that the performances of subjects are equivalent at the outset.

A t-test was also used to compare the Front End ELECTRE II and SPAN (under its three different experimental conditions) decision adequacy index scores, using SPAN's means as norms. The within groups error term of the F-test (for the three treatments investigated in this present study) was used. The results suggest that Front End ELECTRE II and SPAN appear to be equivalent methods to solve the NASA task.

Finally, a t-test was used to compare Front End ELECTRE II and NONSPAN (under its three different experimental conditions) deciston adequacy index scores, using NONSPAN's means as norms. The within-groups error term of the F-test for the three treatments examined in this study was used. The results indicate that Front End ELECTRE II and NONSPAN appear to be equivalent methods to solve the NASA task.

In conclusion, the majority of methods used by the Author and Gilmartin viz. Front End Electre II, "any" group method, SPAN and NONSPAN are equivalent in the decision quality output concerning the specific case of the NASA task as tested on students in PSU and employees of the Veterans Administration Hospital, Tucson, Arizona. ELECTRE II did not perform as well. The relatively poor showing of ELECTRE II would tend to support the contention that the NASA moon survival task was not favorable to ELECTRE II. The full value of both ELECTRE II and Front End ELECTRE II can probably be observed only with a task of considerably more complexity than the NASA moon survival task that was used. Also the ELECTRE II methodology was explained in only 4 minutes which could have hindered its performance. 
Front End ELECTRE II might have even performed better had the conditions been adequate, i.e. more complexity, more time (than 4 minutes) to explain how it works, and established groups or at least more interested groups than were utilized.

3. Front End ELECTRE II scored better than ELECTRE II. It showed a significant improvement when compared with ELECTRE II, a recent, yet, well established technique that prominent scientists have used to solve international problems. We should realize the importance of such a discovery since policy decisions are more often than not, taken in groups and not by individuals alone. A development in any group decision technique is of great potential importance. However, one should bear in mind that the circumstances were unfavorable for the use of a complex method such as ELECTRE II.

4. We should also realize that the choice of the NASA task was not the most favorable for Front End ELECTRE II since that task represents a measure of the amount of information rather than a measure of complexity of the problem. (This task was chosen, however, due to the advantages listed - the experimental design section).

5. Front End ELECTRE II and "any" group method upgraded the performance of the individuals forming the group and thus amelforated the decision quality output of the group versus that of the individuals. In that instance, we observe a group decision quality higher than the averages of the individual decision making ability.

The currently available group decision making methods improve the quality of decisions substantially. This is tantamount to enhancing (upgrading) human intelligence. With further development, such techniques are expected to improve to a point where they will revolutionize the 
decision making quality output.

If SPAN increases the effective I.Q. of the problem solving group as claimed by its developers; then Front End ELECTRE II might do the same for even more complex problems (1.e. those policy issues which cannot be crammed into an optimization technique). So any slight improvement in these policies or strategies will constitute substantial contribution.

6. The designed "front end" for ELECTRE II is probably not the optimum "front end" that can be developed. The author of this study wanted to test the idea of a front end. The results have shown the idea to work for that specific task.

7. One should further note that all our groups were ad hoc groups, (i.e. no emotional commitment, no interest). Also there was no adequate time for the participants to assimilate the ELECTRE II technique. Better results might have been obtained were the task more complex.

8. An alternative (and possibly better) experimental design would have been to include SPAN as a fourth treatment among Front End ELECTRE II, ELECTRE II, and "any" group method. We then could have performed an F-test on all methods used. Two drawbacks appear, though, the number of students needed for such an endeavor would increase substantially the man-hours needed to conduct such research. The impracticability of forming a forty-hour human relations program which simulates that of the Gilmartin experiment of these are limiting factors in view of the resources available.

9. An alternative way to carry out the statistical analysis would have been possible if we were interested in the individual performances. We would have performed a nested analysis of variance, (Clarkson, 1976). 
In our case, this would not have worked, however, since we are interested in the group performances rather than the individual performances. Also the individual performance after using any particular group method is definitely affected by the group discussion. Thus, the scores in that case would not be representative of the actual individual performances.

GUIDELINES FOR USING FRONT END ELECTRE II

Genera1

1. Front End ELECTRE II should be used in complex problems where human information alone is insufficient for good performance (i.e. where analysis and evaluation are important but difficult).

2. The potential benefits of a superior method are not automatically forthcoming. It might be that in hurried situations, simpler methods work best. Certaln conditions are required for complex techniques to work well (e.g. adequate time, training in use of the methods, etc...).

3. The interest and commitment of the user in the method as an effective problem solving device would appear to be important.

4. Established groups may be able to assimflate new methods like Front End ELECTRE II more rapidly than ad hoc groups.

For the User

1. The degree of participant motivation is probably more critical for the more complex methodologies like Front End ELECTRE II than for simple or intuitive methods due to the greater effort that is required. In other words, better methods may well require more effort by the user. 2. Knowledge of the problem: understanding the task fully, 
understanding different indices of performance and their relative importance, is essential for good Front End ELECTRE II results.

3. Lack of good technical and factual data cannot be overcome by superior analysis with a method such as Front End ELECTRE II.

4. Adequate time for the user to understand the method and think about each entry is important. More complex methods require more startup time.

5. Crucial: The assignment of different weights to criteria, if applicable, and different coefficients to the various items is crucial, i.e. individuals should be willing to make judgments.

\section{RECOMMENDATIONS FOR FUTURE RESEARCH}

The NASA task chosen in this thesis could be viewed as a measure of the amount of information available in the group rather than a measure of problem solving ability in a complex environment. Having developed an improved version of ELECTRE II in this thesis, future researchers could conduct a controlled experiment where the prime variable was the complexity of the task and where the amount of information available in the "group" was carefully controlled.

The "front" end developed in this study seemed to upgrade the performance of ELECTRE II in the specific NASA task. Future improvements on the "front end" are both possible and desirable.

The notion of using other existing research for comparison or analysis may lead to extracting knowledge from the myriad of individual research efforts and the hundreds of mute dissertations. The concept of comparing and analyzing accumulated research ("review" research as compared to "original" research) and extracting relevant Implications is a 
complex and important methodological problem to which future researchers should focus on, (Glass, 1976). This thesis attempted one small step in this direction by using SPAN results as a norm for comparison as well as using the usual naive controls.

One should exercise caution in generalizing from the findings of the reserach. A student population may not have exactly the same characteristics as a real life decision making team. For example, it is possible that the Front End ELECTRE II may have helped the relatively inexperienced students more than it would help a broader sample of decision makers. In cther words, a more experienced group might benefit less from the Front End ELECTRE II than a less experienced one. This question could be addressed in future research. 


\section{REFERENCES}

Aguilar, R. J. 1973. Systems Analysis and Design - in Engineering, Architecture, Construction, and Planning. Prentice-Ha11, Inc. Englewood Cliffs, New Jersey.

Andrews, Frank M., and Laura Klem, Terrence N. Davidson, Patrick M. O'Ma1ley, Willard L. Rodgers 1974. "A Guide for Selecting Statistical Techniques for Analyzing Social Sciences Data," Survey Research Center, Institute for Social Research, The University of Michigan.

Belenson, S. M. and Kapur C. Kailash 1973. "An Algorithm for Solving Multicriterion Linear Programming Problems with Examples," Operationa1 Research Quarterly, 24(1), pp. 65-77.

Bellman, R. E. and Stuart E. Dreyfus 1962. Applied Dynamic Programming. Princeton University Press, Princeton, New Jersey.

Bertier, Patrice and Jean De Montgolfier 1973. "On Multicriteria Analysis, An Application to a Forest Management Problem," Reprinted from Working papers of NATO Conference, Mathematical Analysis of Decision Problems in Ecology, Istambul, July 9-13 (1973).

Bloch, Alan 1970. "You Can Make The Systems Approach Work," Innovations, No. $13, \mathrm{pp} .26-33$.

Brockhaus, W. L. 1975. "A Quantitative Analytical Methodology for Judgmental and Policy Decisions," Techn. Forec. And Social Change, Vol. 7, No. 2, pp. 127-139.

Buffet, Pierre and Jean-Paul Grémy, Marcel Marc, and Bernard Sussmann 1967. "Peut-on Choisir en Tenant Compte de Critères Multiples, Une Méthode (ELECTRE) et Trois Applications," METRA 6, No. 2.

Castano, E. May 1975. "A Computer Implementation of the Method ELECTRE I," Project in University of Arizona, Dept. of Systems and Industrial Eng.

Chorafas, D. N. 1965. Systems and Simulation. Academic Press, New York, New York.

Clarkson, Quentin D. 1976. Portland State University. (Informal Discussion Meetings). 
Cochran, William G. and Gertrude M. Cox 1957. Experimental Designs, New York, John Wiley and Sons, Inc.

Cochrane, J. L. and Milan Zeleny, Editors. 1973. Multiple Criteria Decision Making. University of South Carolina Press, Columbia, South Carolina.

The following articles are from the above book that represents a seminar on the above topic at the above university.

Briskin, L. E. "Establishing a Generalized Multi-Attribute Utility Function," pp. 236-48.

Collins, D. C. "Applications of Multiple Criteria Evaluation to Decision Aiding," pp. 477-505.

Di Roccafferrera, G. M. F. "Behavioral Aspects of Decision Making Under Multiple Goals," pp. 635-56.

Easton, A. "One-of-a Kind Decisions Involving Weighted Multiple Objectives and Disparate Alternatives," pp. 657-67.

MacCrimmon, K. R. "An Overview of Multiple Objective Decision Making," pp. 18-46.

Melsel, W. S. "Tradeoff Decisions in Multiple Criteria Decision Making," pp. 461-67.

Minnehan, R. F. "Multiple Objectives and Multigroup Decision Making in Physical Design Situations," pp. 536-16.

Ören, T. I. and Ören, Yüksel. "Solution Techniques for Decision Making in Complex Systems," pp. 764-67.

Roy, B. "How Outranking Relation Helps Multiple Criteria Decision Making," pp. 179-201.

Zadeh, L. A. "Outline of a New Approach to the Analysis of Complex Systems and Decision Processes," pp. 686-728.

Zeleny, M. M. "A Selected Bibliography of Works Related to Multiple Criteria Decision Making," pp. 779-96.

Zeleny, M. "Comprise Programing," pp. 262-302.

Da Cunha, N. O. and Polak, E. 1967. "Constrained Minimization Under Vector-Valued Criteria in Linear Topological Spaces," in Mathematical Theory of Control, pp. 96-108. Edited by A. V. Balakrishnan and L. W. Neustadt, Academic Press, New York, New York.

Davis, R. E. and Robert E. Larson 1973. "Optimum Selection of MultiBenefit Civil Works Projects," In the Supplement to the Sixth Proceedings of the Hawail International Conference on System 
Sciences, 1973, at the University of Hawaii, Honolulu, Hawaii, Edited by Art Lew.

Duckstein, Lucien and David Laszlo November 1975. "Multi-Criterion Ranking of Long-Range Water Resource Development Plans," Paper Presented at the Multiple Criteria Optimization Fall Annual Meeting of the Operations Research Society of America, November 1975, at Las Vegas, Nevada.

Duckstein, Lucien 1976. Dept. of Systems - Industrial Eng., Univ. of Arizona. (Correspondence)

Duffin, R. J., Elmor L. Peterson, and Clarence Zener 1967. Geometric Programming - Theory and Application. John Wiley and Sons, Inc., New York, New York.

Fishburn, Peter C. 1964. Decision and Value Theory. John Wiley and Sons, Inc., New York.

Foes, C. L. 1972. "Complex Systems and the Price-Resource Directive Coordination Procedure," Ph.D Dissertation, Portland State University.

Frehe1, Jean 1973. Problèmes Multicritères, Théorie de la Domination De Yu et Efficacité de Pareto," SEMA, Direction Scientifique.

Giffin, W. C. 1971. Introduction to Operations Engineering. Richard D. Irwin, Inc., Homewood, Illinois.

Hillier, F. S. and Gerald Lieberman 1974. Operations Research. HoldenDay, Inc., San Francisco, California.

Hitchcock, J. D. Jr. 1967. "The SPAN Group Decision-Making Method in Fraternities," M.A., University of Arizona.

Hitchcock, James Donald 1971. "Performance of Dyadic SPAN as a Function of Success, Failure, and Self Reports on Test Anxiety and Social Desirability," Ph.D Dissertation, University of Arizona.

Gilmartin, Kevin Michae1 1974. "The Relative Effectiveness of SPAN and Laboratory Training in Upgrading Group Decision Making," Ph.D Dissertation, Dept. of Psychology, University of Arizona.

Glass, Gene V. November 1976. "Primary, Secondary, and Meta-Analysis of Research," Educational Researcher, Vo1. 5, No. 10, pp. 3-8.

Goldberg, Lewis R. 1968. "Simple Models or Simple Processes - Some Research on Clinical Judgments," American Psychologist, 68, 23, pp. 483-495.

Goode, H. H. and Robert E. Machol 1957. Systems Engineering - An Introduction to the Design of Large-Scale Systems. McGraw-Hill Book 
Company, Inc., New York, New York,

Grolleau, J. L. and J. Tergny December 1971. "Manuel de Référence du Programme ELECTRE II (Méthode de Classement ELECTRE II en Présence de Critères Multiples)," Groupe METRA, Direction Scientifique, Document Technique No. 24.

Ha11, III, Arthur D. April 1969. "The Three-Dimensional Morphology of Systems Engineering," IEEE Transactions on Systems Science and Cybernetics, Vol. ssc-5, No. 2, pp. 156-160.

Hoffman, L. R. 1959. "Homogeneity of Member Personality and its Effect on Group Problem-Solving," Journal of Abnormal and Social Psychology, 58 (1), pp. 27-32.

Hoffman, L. R. and N. R. F. Maier 1961. "Quality and Acceptance of Problem Solutions by Members of Homogeneous and Heterogeneous Groups," Journal of Abnormal and Social Psychology, 62, pp. 401-407.

Jacquet-Lagrèze, E. 1973. "How We Can Use the Notion of Semiorders to Build Outranking Relations in Multicriteria Decision Making," Paper Presented at the Fourth Research Conference on Subjective Probability, Utility, and Decision-Making, at Rome, 1973.

Kauffmann, A. 1967. Graphs, Dynamic Programming, and Finite Games. (tr. by Henry C. Sneyd), Academic Press, New York, New York.

Kazmier, Leonard J. 1973. Statistical Analysis for Business and Economics. McGraw-Hill Book Company, New York.

Kempthorne, Oscar 1952. Design and Analysis of Experiments. Wiley Publications in Statistics, New York.

Kerlinger, Fred N. 1967. Foundations of Behavioral Research, Holt, Rinehart and Winston, Inc. New York, Chicago, San Francisco.

Lendaris, George 1976. "Graphic Representation," Systems Science Institute, Portland State University, Adapted from Materials prepared by J. Warfield, Battelle Research Laboratories, Columbus, Ohio.

Li, Ching Chun 1959. Numbers From Experiments, a Basic Analysis of Variation. (Ph.D Dissertation, Graduate School of Public Health, Univ. of Pittsburgh), The Boxwood Press, Pittsburgh 13, Pennsylvania.

1964. Introduction to Experimental Statistics. McGraw-Hill Book Company, New York, San Francisco.

Lloyd, C. 1967. Microeconomic Analysis. Richard D. Irwin, Inc., Homewood, Illinois.

Lorge, I. and H. Solomon 1955. "Two Models of Group Behavior in the Solution of Eureka-Type Problems," Psychometrika, 20 pp. 139-149. 
Lorge, I., J. Tuckman, L. Aikman, J. Spiegel, and Gilda Moss 1955. "Solutions by Teams and by Individuals to a Field Problem at Different Levels of Reality," Journal of Educational Psychology, 46, pp. 17-24.

Lorge, I., D. Fox, J. Davitz, and M. Brenner 1958. "A Survey of Studies Contrasting the Quality of Group Performance and Individual Performance 1929-1957," Psychological Bulletin, 55 (6), pp. 337-372.

Lorge, I. and H. Solomon 1959. "Individual Performance and Group Performance in Problem Solving Related to Group Size and Previous Exposure to the Problem," Journal of Psychology, 48, July, pp. 107-114.

1960. "Group and Individual Performance in Problem Solving Related to Previous Exposure to Problem, Level of Aspiration, and Group Size," Behavioral Science, 5, pp. 28-38.

MacKinnon, William J. May 1966. "Development of the SPAN Technique for Making Decisions in Human Groups," American Behavioral Scientist, 9 (9) pp. 9-13.

1966. "Elements of the SPAN Technique for Making Group Decisions," Journal of Social Psychology, 70, pp. 149-164.

MacKinnon, William J. and Mary M. McKinnon March 1969. "The Decisional Design and Cyclic Computation of SPAN," Behavioral Science, 14 (3) pp. 244-247.

Major, D. C. 1969. "Benefit-Cost Ratios for Projects in Multiple-Objective Investment Programs," Water Resources Research, 25 (6), pp. 1174-1178.

Martin, R. H. (To be Pub. June - July 1977). Consensus-Formation Technology Utilization. (Scenario Reality Planning Bibliography Series, Number 2). A council of Planning Librarians (CPL) exchange bibliography. Paper copy availability unlimited through CPL. Microfiche availability unlimited through National Technical Information Service, U. S. Department of Commerce, Springfield, VA 22161. Council of Planning Librarians Exchange Bibliographies, Post Office Box 229, Montice11o, IL 61856.

Martino, Joseph 1972. Technological Forecasting for Decision Making. American Elsevier Publishing Company, Inc. New York.

Monarchi, E. E., Chester C. Kisie1 and Lucien Duckstein 1973. "Interactive Multiobjective Programming in Water Resources - A Case Study," Water Resources Research (4), $837 \mathrm{PF}$.

M'Pherson, P. K. June 1974. "A Perspective on Systems Science and Systems Philosophy," Futures, pp. 219-239.

Notes on Operations Research. 1958. MIT Press, Cambridge, Mass. 
Ogata, K. 1970. Modern Control Engineering. Prentice-Ha11, Inc., Englewood Cliffs, New Jersy.

Pareto, V. 1971. Manual of Political Economy. (tr. by Ann S. Schwier. Ed. by Ann S. Schwier and Alfred N. Page), Augustus M. Kelley Publ., New York, New York.

Park, W. R. 1970. Cost Engineering Analysis - A Guide to the Economic Evaluation of Engineering Projects. (Wiley-Interscience), John Wiley and Sons, New York, New York.

Reid, R. W. and V. Vemuri 1971. "On the Noninferior Index Approach to Large-Scale Multi-Criteria Systems," Journal of the Franklin Institute 291 (4), pp. 241-254.

Riker, William H. and Steven Jbrams. "The Paradox of Vote Trading," The American Political Science Review, Vo1. 67, pp. 1235-1247.

Roy, B. and P. Bertier 1973. "La Méthode ELECTRE II, Une Application au Media-Planning," In the Proceedings of the Sixth IFORS International Conference on Operational Research, 21-25 August 1972, at Dublin, Ireland, pp. 291-302.

1971. "La Méthode ELECTRE II. (Une Méthode de Classement en Présence de Critères Multiples)," N. T. No. 142, D. S., Groupe METRA.

Roy, B. 1969. Algèbre Moderne et Théorie Des Graphes. Dunod, Paris.

Roy, B. 1972. "Problems and Methods With Multiple Objective Functions," Mathematical Programming 1 (2), pp. 239-266.

Sakawa, M. and Y. Sawaragi 1975. "Multiple-Objective Optimization for Environment Development Systems," International Journal of System Science 6 (2), pp. 157-164.

Seiler, K., III 1969. Introduction to Systems Cost-Effectiveness. (Wiley-Intersicence), John Wiley and Sons, New York, New York.

Starr, A. W. and Y. C. Ho 1969. "Further Properties of Non-Zero-Sum Differential Games," Journal of Optimization Theory and Applications, Vol. 3, No. 3, pp. 184-206.

1969. "Further Properties of Non-Zero-Sum Differential Games," Journal of Optimization Theory and Applications, Vol. 3, No. 4, pp. 207-219.

"Systems Science Program Description," August 1975. Dept. of Systems, University of Lancaster, School of Management and Organizational Sciences.

"The System Analyst's Decalogue," June 1972. A Unified Systems Engineering Concept, A Battelle Monograph, No. 1. Ch. 15. 
Tuckman, J. and I. Lorge 1962. "Individual Ability as a Determinant of Group Superiority," Human Relations, 15 (1), pp. 45-51.

Vemuri, V. 1974. "Multiple-Objective Optimization in Water Resources Systems:" Water Resources Research, 10 (1).

Wilde, D. J. 1964. Optimum Seeking Methods. Prentice-Hall, Inc., Englewood Cliffs, New Jersey.

Willemsen, Eleanor, W. 1974. Understanding Statistical Reasoning. W. H. Freeman and Company, San Fransisco.

Willis, Joe E. 1966. "A Comparative Study of Different Quantitative Methods of Obtaining Group Decisions by Collecting Synthesizing Individual Decisions," Ph.D Dissertation, Univ. of Arizona.

Willis, Joe E., James D. Hitchcock, and William J. Mackinnon 1969. "SPAN Decision Making in Established Groups," The Journal of Social Pgychology, 78, pp. 185-203.

Zadeh, L. A. 1963. "Optimality and Non-Scalar-Valued Performance Criteria," IEEE Transactions on Automatic Control, Vol. A-8 (1), pp. 59-60. 


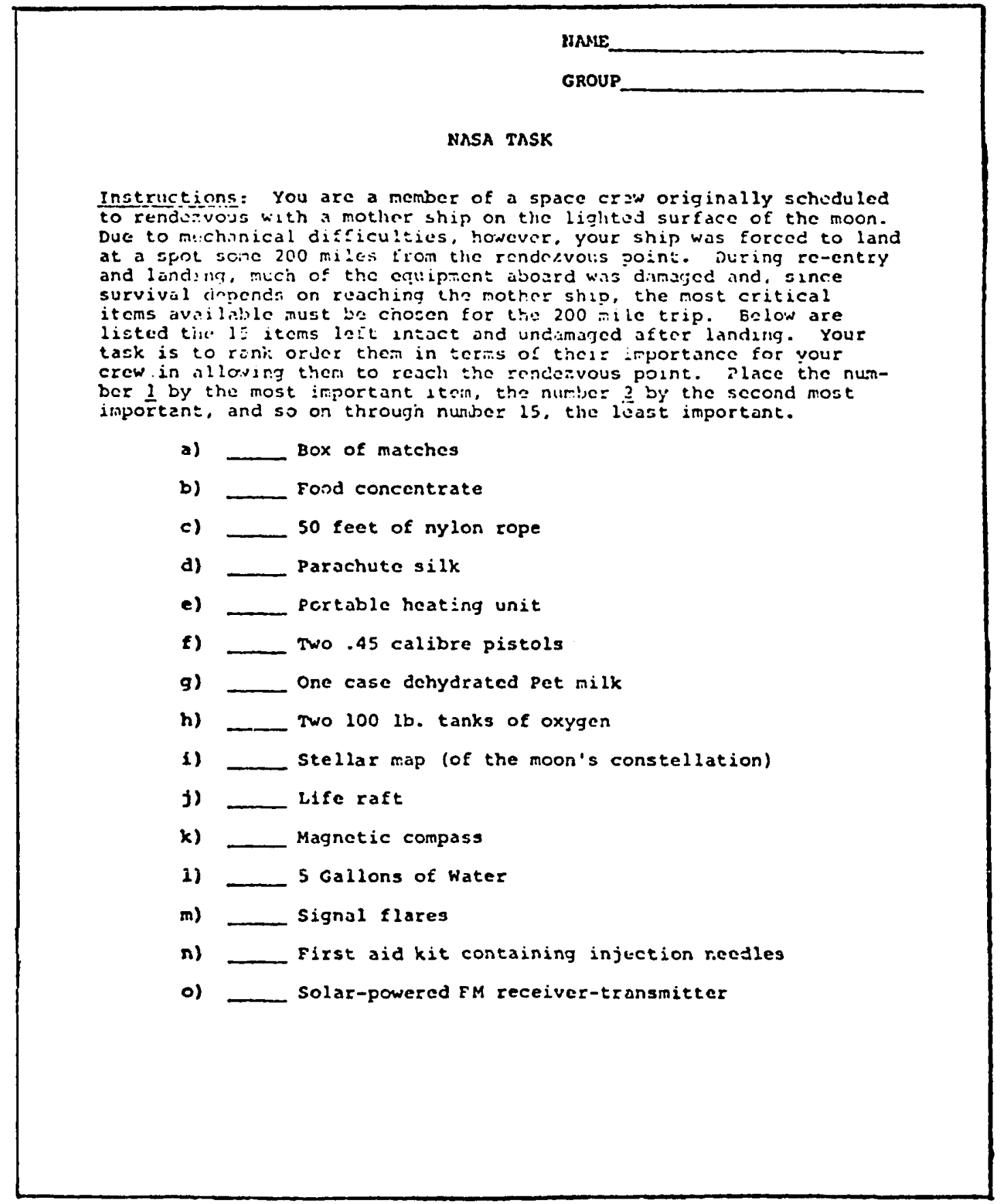

Figure 3. NASA Moon Survival Problem. 
Decision Instructions for F. E. ELECTRE II Groups:

The following instructions will be given to members of the F. E. ELECTRE II groups:

This is an exercise in group decision making. Your group is to use the method of F. E. ELECTRE II. To arrive at the final decision you are to answer the questionnaire then you are to fill the matrix through the ELECTRE II method that will be expla1ned to you on the board. The questionnaire should help elucidate your preferences as to the relevant criteria in that particular problem. Through your answers to the questionnaire you might discover new criteria or assign different ratings than you would originally have done. After answering the questionnalre, you are to solve the problem with the ELECTRE II method. The ELECTRE II matrix can be filled out (Individually) efther during and/or after group discussion. 


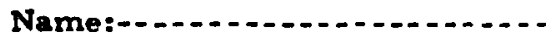

Group number:

O. The following questions are to help provide a general background perspective prior io fllling out the ELECTRE II matrix.

1. Carefully define the problem (or the task).

2. Notice the facts given in the problem definition.

3. Try to determine who are the most knowledgeable. not necessarily the most vocal group menbers, with respect to the problem at hand (i.e. the monn survival problem).

4. Recheck and reevaluate assumptions or judgments you have made about the situation.

[You do not need to be consistent with your original individual decisions on the NASA task. In fact, you ought to solve the problem, the second time through, better, if you are able].

I. The following questions are to help you fill out column lof the ELECTRE II matrix.

5. What are the criteria on which you will base (weigh) your decision? (fill in column 1 in your ELECTRE II matrix),

5a. Carefully read instructions for column 1.

II. The following questions are th help you fall out column 2 of the ELECTRE II matrix.

6. Assign weights or importance to theve criteria (i, e. fill in column 2 in your ELECTRE II matrix).

6a. Carefully read instructions for column 2 .

7. It is generally better not th have all the weights ideatical unless they really are.

III. The following questions are to help you fill out column 3 of the ELECTRE II matrix.

8. [first hint]: would it be helpful to group items into definitely important, maybe important, and not important?

9. [second hint]: for difficult rating decisions, comparing 2 items may help you declde which should be rated higher.

10. Carefully read instructions for column 3 . 
Name: - -

Group number: $-\ldots$

DIRECTIONS: Each individual should fill out the following matrix. It may be done either during and/or after group discussion.

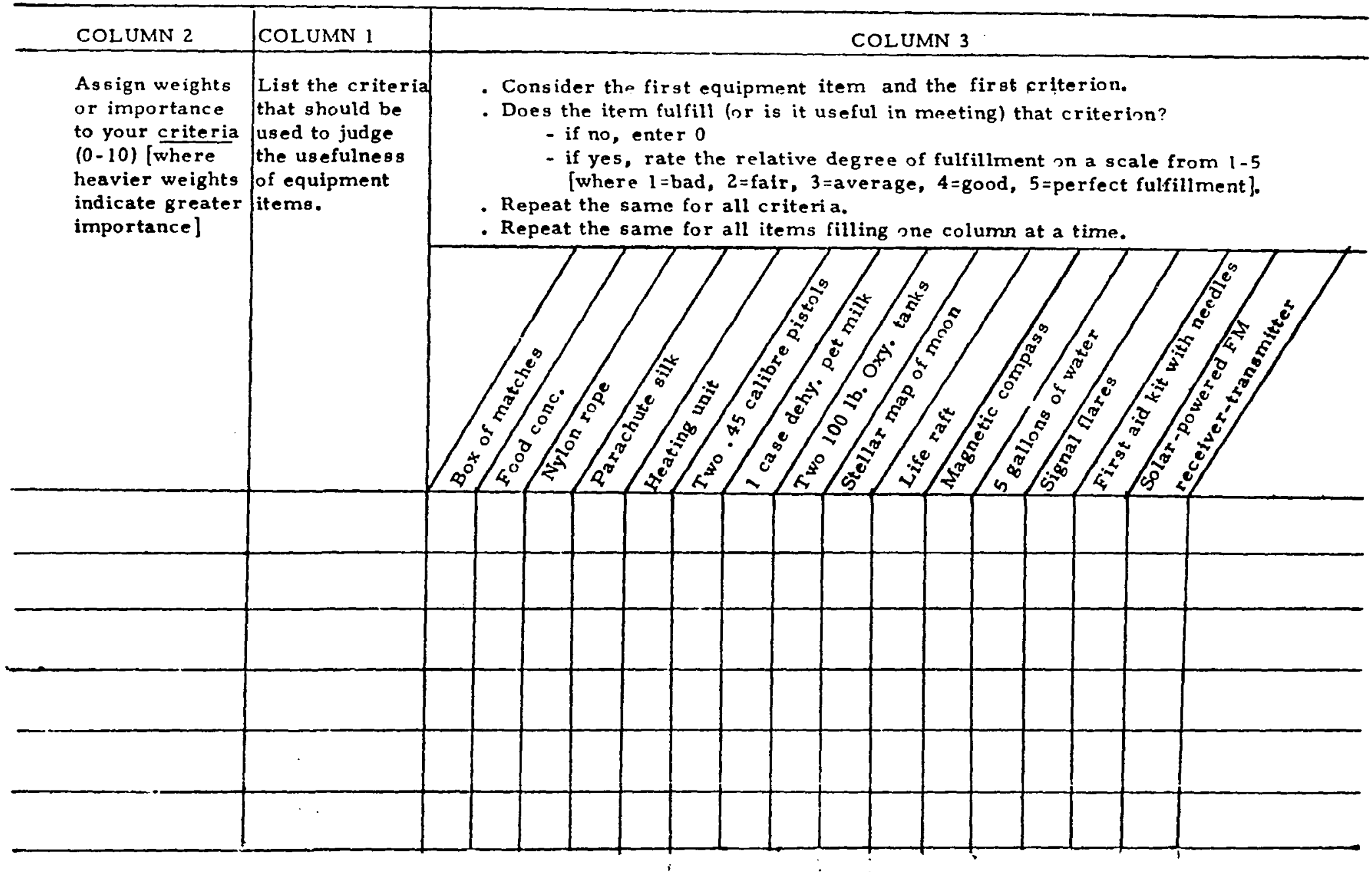


Name:

Group Number:

Academic Major:
Class:

Age:

Sex:

1. Which of these categories best describe your background:

Fine Arts:

Humanities:

Social Sciences:
Business :

Hard Sclences:

Other:

2. Indicate the highest level of Mathematics you have achieved?

very poor:

high school maths.:

lst year college: 2nd year college:

3rd year college:

higher:

3. Indicate your degree of competence in Maths: (Answer on a scale from 1-5 where: 1=bad, $2=$ fair, $3=$ average, 4=good, 5=excellent)

4. Do you consider yourself proficient in social sciences subjects? (Answer on a scale from $1-5$, 11ke the above rating)

5. How confident are you in the perceived quality of your decision? (3=fully, 2=average, $1=$ not at all)

6. Indicate the degree of your satisfaction with the process (or the method) used to arrive at the decision. (3=very satisfied, 2=satisfied, $1=$ not satisfied)

This demographic questionnaire was also given to members of the ELECTRE II groups and self-determination groups. 
Decision Instructions for ELECTRE II Groups:

The following instructions will be given to members of the ELECTRE II groups:

This is an exercise in group decision making. Your group is to use the method of ELECTRE II. To arrive at the final decision you are to fill the matrix:

1. choose criteria;

2. assign weights or importance for these criteria;

3. grade each object according to its fulfillment of criteria. If the object does not fulfill the criterion, leave blank.

The ELECTRE II matrix to to be filled out individually either during and/or after group discussion.

The ELECTRE II matrix (presented 2 pages earlier) follows. 
Decision Instructions for Self-Determination Groups:

The following instructions will be given to members of the selfdetermination groups:

This is an exercise in group deciston making. Your group is to use the method of self-determination in which the members will arrive at a group decision by whatever procedure the group adopts or devises. Each of you can contribute positively to the final group decision by making correct judgments. The final goal of the task is to develop the best posstble group decision.

Would one member of the group please write the letters indicating the group's final rankings on the single blank problem sheet provided for this purpose.

NASA sheet and demographic questionnaire follows. 


\section{APPENDIX B}

BRIEF DESCRIPTION OF THE METHOD

We have the following elements when we have a problem of choice of multiple attributes: (Castano, 1975)

- A set of objects $\left(A_{1}, A_{2}, \ldots, A_{n}\right)$ among which a choice should be made. We can call this set (A).

- A set of viewpoints, criteria or attributes $\left(p_{1}, p_{2}, \ldots, p_{n}\right)$, according to which the objects should be judged. We can call this set $(P)$.

The preference among the attributes (criteria) is assumed to be known in ELECTRE so that the attributes can be weighted according to their importance or desirability. This is a severe limitant of the applicability of the method, since in various real situations the decision maker is not able to define his preferences consistently. (The Front End of ELECTRE II should provide a remedy to this limitation). We should also be aware that the use of welghts presupposes the additivity of the objectives which this constitutes.

For every viewpoint or criterion, a set of appreciations should be defined; as examples, we have:

- (excellent, good, fair, poor, bad)

- (A, B, C, D, E, F)

- $(30,25,20,15,10)$

- $(1,0)$ or (acceptable and not acceptable) 
For every viewpoint or criterion, a mapping of the apprectation into a numerical scale is defined, In such a way that the two consecutive appreciations is to be proportional to the importance of the viewpoint (criterion).

Finally, the viewpoints or criteria are weighted according to their importance; and every object is graded with respect to each viewpoint (criterion), either utilizing the appreciation or directly giving the corresponding scale values.

\section{Outranking Relations:}

The ELECTRE II method is founded on the primary concept of an outranking relation (introduced by Benayoun, Roy, Sussmann, 1966), which is a binary relation defined on $X$ such that: " $x$ pref $y$ " or (x S y) or $(x, y \varepsilon X)$ translates a preference of $x$ relative to $y$ in spite of characteristics 1 and 2 referred to in the introduction of this work.

The above definition does not imply that the binary outranking relation $S$ is transitive. Actually, if one can take the risk to accept $\mathrm{xSy}$ and $\mathrm{ySz}$, it does not necessarily result that one can take the risk to accept $\mathrm{xS} z$ : since $\mathrm{x}$ and $z$ can be incommensurable or incomparabie according to $S$. One can even have $z \mathrm{~S} x$ (which creates a circuit). Whenever two objects $x$ and $x^{\prime}$ appear indifferent it is natural to adopt $x \mathrm{~S}^{\prime}$ and $x^{\prime} S x$. Even when $S$ is not transitive, it will be legitimate to consider two objects $x$ and $x^{\prime}$ as indifferent belonging to a same circuit in S.

In ELECTRE II, an outranking relation is defined according to a concord test and a non-discord test between criteria: For every pair $(x, y)$ of objects of $x$, we accept the risk to decide " $x$ outranks $y$ " if 
a concord test and a non-discord are satisfied.

Concord Test (Grolleau and Tergny, 1971)

We ask the DM to define for each criterion $i$ an importance $p_{i}$ (notion related to weight but will result in no multiplication with $\left.\gamma_{i}(x)\right)$. For each pair $(x, y)$ three super criteria (trichotomy) of set I are then computed as follows:

Let:

$$
\begin{aligned}
& I^{+}(x, y)=\left[1 / \gamma_{i}(x)>\gamma_{1}(y)\right] \\
& I^{=}(x, y)=\left[1 / \gamma_{i}(x)=\gamma_{i}(y)\right] \\
& I^{-}(x, y)=\left[i / \gamma_{i}(x)<\gamma_{1}(y)\right]
\end{aligned}
$$

We make the nonrestrictive hypotheses of preferences increasing proportionally to the $\gamma_{1}$ and introduce:

$$
\begin{array}{ll}
\mathrm{P}^{+}(\mathrm{x}, \mathrm{y})=\sum_{i \in I^{+}} \mathrm{p}_{i} & \text { for }(\mathrm{x}, \mathrm{y}) \\
\mathrm{P}^{=}(\mathrm{x}, \mathrm{y})=\sum_{i \in I^{-}} \mathrm{p}_{i} & \text { for }(\mathrm{x}, \mathrm{y}) \\
\mathrm{P}^{-}(\mathrm{x}, \mathrm{y})=\sum_{i \in I^{-}} \mathrm{p}_{i} & \text { for }(\mathrm{x}, \mathrm{y}) \\
\mathrm{P}=\mathrm{P}^{+}+\mathrm{P}^{=}+\mathrm{P}^{-} &
\end{array}
$$

Then, the concord test may be satisfied if:

$$
\left\{\mathrm{P}^{+}(\mathrm{x}, \mathrm{y})+\mathrm{P}^{=}(\mathrm{x}, \mathrm{y})\right\} / \mathrm{P} \geq \mathrm{C}
$$

and if:

$$
\mathrm{P}^{+}(\mathrm{x}, \mathrm{y}) / \mathrm{P}^{-}(\mathrm{x}, \mathrm{y}) \geq 1
$$

c being a parameter (minimum level of concordance), the value of which one may choose. (More sophisticated formula may easily be imagined). 
In other words, the concord test is satisfied if the relative importance in the set of n criteria of "super-criteria" formed from the union for which $\mathrm{x}$ is better than $\mathrm{y}$ is "sufficiently strong."

A more compact form for the concord Index is: $c_{x y}$ is defined as a measure of the agreement with the hypothesis: " $x$ is preferred to $y$ " and is computed as:

$$
c_{x y}=\sum_{k \varepsilon c_{x y}} \pi_{k} / \sum_{k \in p_{x y}} \pi_{k}
$$

where:

$c_{x y}=\{k:$ ( $x$ is not preferred to $y$ according to viewpoint $k$ ), ( $k \in P$ ) $\}$ $\pi_{k}=$ the weight of viewpoint $k$.

Non-Discord Test (Castano, 1975)

$D_{x y}$ is the set:

$D_{x y}=\{k:$ ( $x$ is not preferred to $y$ according to viewpoint $\left.k),(k \in P)\right\}$

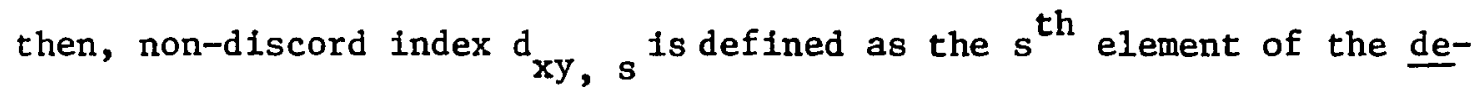
creasing ordered set $\mathrm{R}$, where:

$$
R=\left\{r_{k}: r_{k}=\left(\left|r_{k}(x)-r_{k}(y)\right|\right) / \operatorname{RMAX}, K \varepsilon D_{x y}\right\} \text {, }
$$

where:

$\gamma_{k}(x)$ is the scale value of the appreciation of object $x$ according to viewpoint $k$, and RMAX is the absolute scale range among all viewpoints defined (Castano, 1975).

We then use concord and non-discord indices to form graphs. A graph is defined as follows: 
$G(p, q, s)=G(Z, U)$

Where $A$ is the set of nodes corresponding to the set of objects, and $U$, the set of arcs defined as follows:
$\operatorname{arc}(\mathrm{x}, \mathrm{y}) \in \mathrm{U}$
iff :
a) $x \neq y$
b) $c_{\mathrm{xy}} \geq \mathrm{p}, \quad 0 \leq \mathrm{p} \leq 1$
c) $\mathrm{d}_{\mathrm{xy}}, \mathrm{s} \leq \mathrm{q} \quad 0 \leq 9 \leq 1$

When we reduce the value of $p$ we are actually relaxing the requirements about the degree of agreement necessary to declare that " $x$ is preferred to $y . "$ When we increase the value of $q$ we are willing to declare that " $\mathrm{X}$ is preferred to $\mathrm{Y}$ " against a higher degree of opposition from the $s^{\text {th }}$ strongest opponent. Finally, making $s=k, k=1,2, \ldots, m$ is equivalent to disregarding the "opinion" of the $(k-1)$ strongest opponents when declaring that " $\mathrm{x}$ is preferred to $\mathrm{y} . "$

The graph G (p, $q, s)$ is not necessarily complete nor transitive. We assume that all nodes in a circuit are equivalent. This will permit the reduction of $G(p, q, s)$ to a clrcuit free graph $G^{\prime}(p, q, s)$. The set of nodes of the graph $G^{\prime}$ are then divided into two exclustve subsets: 1) the core $(\mathrm{N})$, consisting of all nodes In $G$; that are not dominated by any other node (this also includes the 1solated or non-comparable nodes); 2) The complement of the core $(\overline{\mathrm{N}})$, consists of all nodes that are dominated by some other node. A set theoretic definition of the core is: Given the transitive graph $G^{\prime}(A, U)$ where $A$ is the set of nodes and $U$ is the set of (orfented) arcs, the core $\mathrm{N}$ is the set of nodes such that: 
$N \subset A, E=\bar{N}$ (the complement of $N$ with respect to $A$ )

$\forall x \in \bar{N}, \exists y \in N \quad$ are $(y, x) \varepsilon U$, and

$\forall x, y \in N$, are $(x, y) \notin U$ and $\operatorname{arc}(y, x) \notin U$.

The core for a given $(p, q, s)$ is the output of ELECTRE I. If the core contains one node, this node becomes the best cholce reflecting the DM's preferences expressed by the weights of the viewpoints (criteria), and the weakness or strength of the comparisons implied by the values $\mathrm{p}, \mathrm{q}, \mathrm{s}$. In general, the closer $\mathrm{p}, \mathrm{q}, \mathrm{s}$ is to the unanimity graph $1,0,1$, the stronger the choice is. If the core contains more than one node, then the choice set is generally smaller (less elements) than the original one. (We then rank order according to ELECTRE II). 
APPENDIX C

NUMERICAL EXAMPLE: (USING THE ELECTRE II METHOD)

$\begin{array}{ll}3 \text { REGIONAL } & \text { ALTERNATE } \\ \text { DEVELOPMENT } & \text { SETS OF CRITE- } \\ \text { PLANS } & \text { RIA WEIGHTS }\end{array}$

$\begin{array}{ll}\text { EVALUATION CRITERIA } & \\ \text { Technical Feasibility. } & \# 1 \\ \text { Cost. } & \# 2 \\ \text { Reduced Death Rate. } & \# 3 \\ \text { Regional Needs. } & \# 4 \\ \text { Misc. } & \# 5\end{array}$

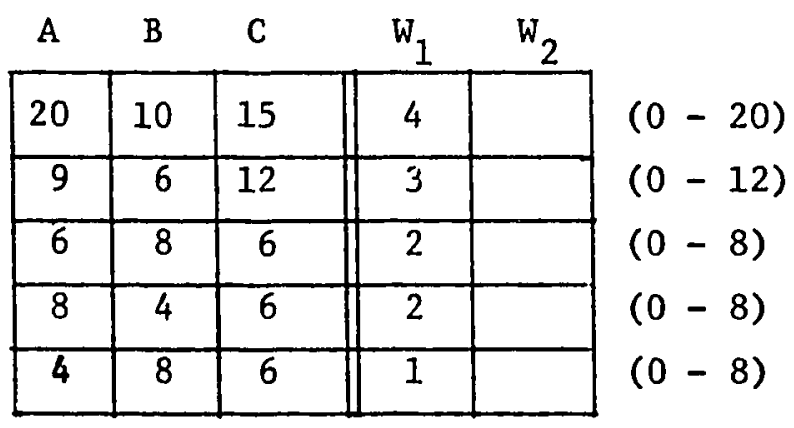

Test to determine if one plan is preferred to another; compare all pairs of plans.

First pair compared $=A$ and $B$ :

\section{TEST 非}

A strongly preferred to $B$ if $c_{1} \geq 3 / 4$

Where $c_{1}$ is obtained in the following manner:

For each criterion on which $A$ is preferred to $B$, find the weight of that criterion. Sum the weights in those instances and divide by the sum of the weights for all criteria. 


$\begin{array}{lccc} & \text { A }>\text { B } & \text { wt. } & \text { all wts. } \\ \# 1 & \text { yes } & 4 & 4 \\ \# 2 & \text { yes } & 3 & 3 \\ \# 3 & & 2 & 2 \\ \# 4 & \text { yes } & 9 & 2 \\ \# 5 & & \frac{1}{12} \\ & & 9 / 12=3 / 4 \quad \begin{array}{l}\text { test } \begin{array}{l}\text { is therefore passed. } \\ \end{array} \\ \end{array} & \end{array}$

$\underline{\text { TEST } \# 2}$

Strength of disagreement (1.e. B > A) is not too great on any criterion. In other terms, if $d_{1} \leq 1 / 4$

Where $d_{1}$ is obtained in the following manner:

Select criterion of greatest disagreement; and divide actual difference (i.e. B - A) by total possible difference (1.e. the range in that scale).
$\mathrm{B}>\mathrm{A}$
(B-A): Amt.
Scale
$(B-A) /$ Scale

\#1

$\# 2$

\#3

yes

2

$(0-8)$

$2 / 8=1 / 4$

\#⿰

\#5

yes

$4 \quad(0-8)$

$4 / 8=1 / 2$

\#5 has the greatest disagreement; test 2 not passed.

Since test $\| 2$ is not passed at $d_{1}=1 / 4$ limit, Then A is not Strongly preferred to $B$. Yet, if we relax the $d$ limit to $d_{2}=1 / 2$, then $A$ can be weakly preferred to $B$, (given that test $\# 3$ is passed also). (We will set $d=1 / 2$ so that $A$ can be weakly preferred to $B$ ).

Note: If it is not possible to get $A$ even weakly preferred to $B$, then no 
lines w1ll be drawn in the graphing stage.

TEST \#3

The number of disagreement $s<3$

Where $s$ is the number of instances of disagreement (1.e. where $B>A$ ). In this case $s=2$, therefore test $\# 3$ is passed.

Therefore A is weakly preferred to $B$.

REPEAT for pairs: $A$ and $C, B$ and $C$.

TEST 非 1 A vs. C
$\underline{A}>\mathrm{C}$
wt.
al1 wts.

\#1 $\quad$ yes 4

\#2

\#3

\#4 yes 2

\#5

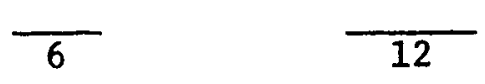

$c_{1}=6 / 12=1 / 2 ; c_{1}$ is not $>3 / 4$, therefore test $\|_{1}$ is not passed. If the first test is not passed, then there is no sense in continuing. Decide not to, therefore not even a weak preference exists.

TEST \#1_C vs. B

$\underline{C>B} \quad$ wt. all wts.

\#1 1 yes 4

\#3

\#4 yes

\#5

4

3

Therefore $c_{1} \geq 3 / 4$ and test $\# 1$ passed. 
TEST \#2 C vs. B
$\mathrm{B}>\mathrm{C}$
$B-C$
Scale
$(B-C) /$ Scale

非

非 2

非3

yes

2

$(0-8)$

$2 / 8=1 / 4$

非

\#5

yes

$(0-8)$

$2 / 8=1 / 4$

d is not $>1 / 4$, therefore test $\# 2$ passed.

TEST \#3 C VS. B

Number of instances of disagreement (1.e. where $B>C$ was not more than

3, therefore test $\# 3$ passed.

Because all 3 tests have passed, we can say that $C$ strongly preferred to

B.

CONCLUSION - SUMMARY

$C$ is strongly preferred to $B$

$A$ is weakly preferred to $B$

$A$ vs. C indifferent

$\underline{\text { GRAPH }}$

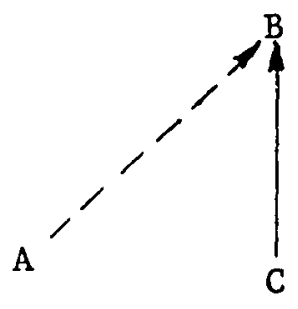

Going out (rank largest number of nodes first)
strongly
$\mathrm{C}>\mathrm{B}$
2 nodes
weakly
$\mathrm{A}>\mathrm{B}$
2 nodes 
Coming to (rank smallest number of nodes first)

strongly $\mathrm{C}<\mathrm{B} \quad 2$ nodes

weak1y $\quad A<B \quad 2$ nodes

The final (called median) ranking is obtained by summing the 2 rankings and dividing by 2 . 


\section{ELECTRE II COMPUTER PROGRAM}
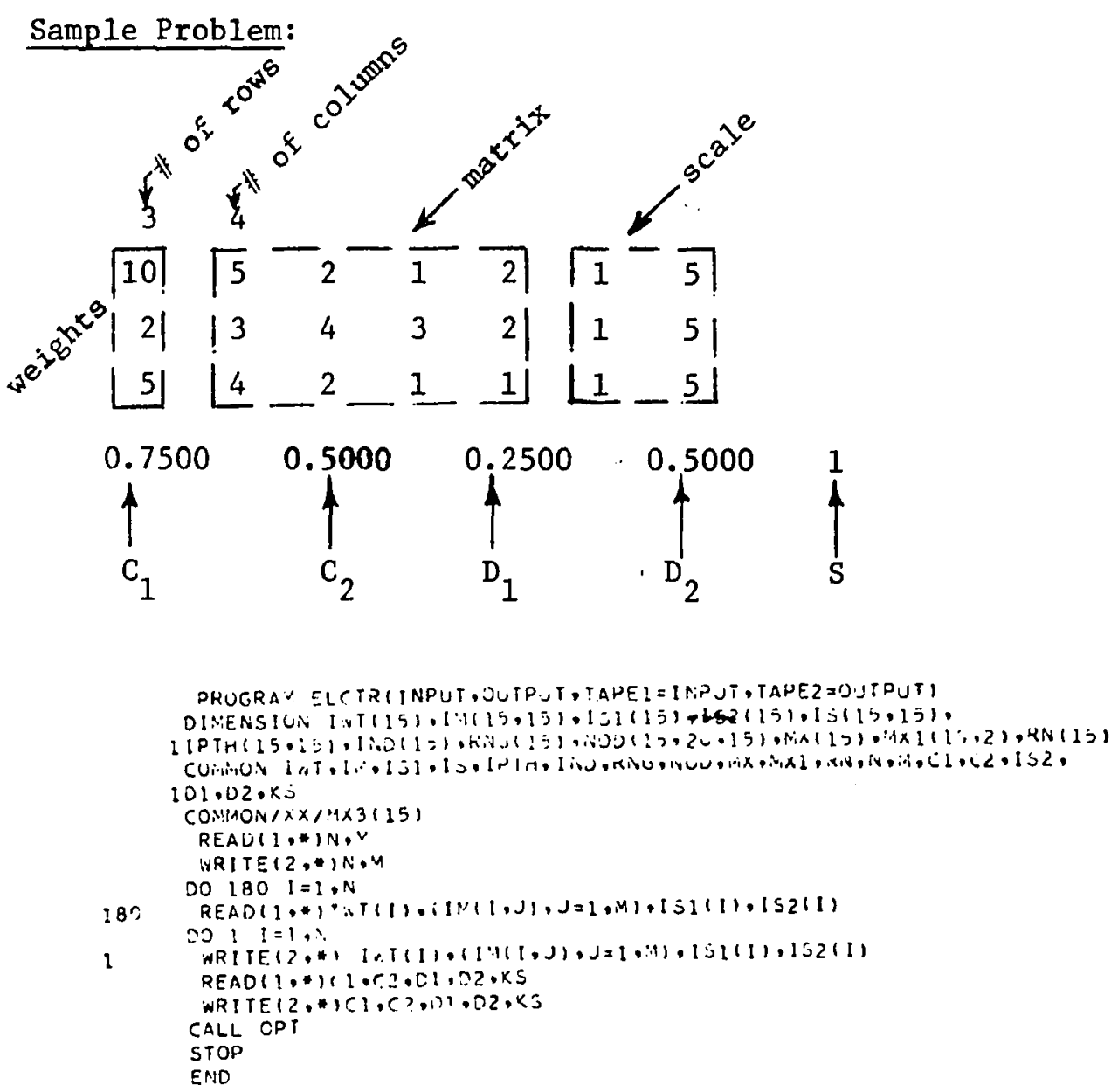


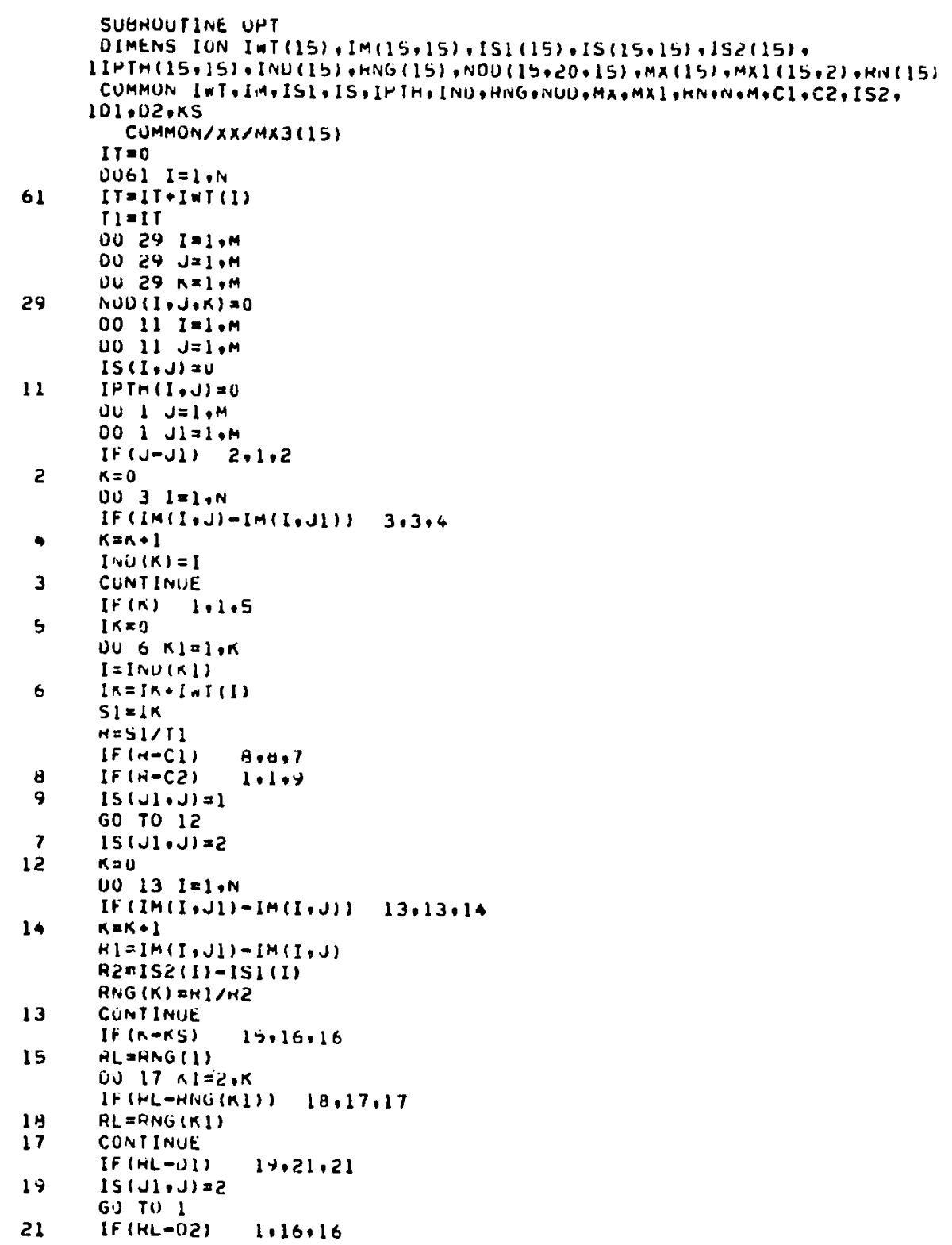




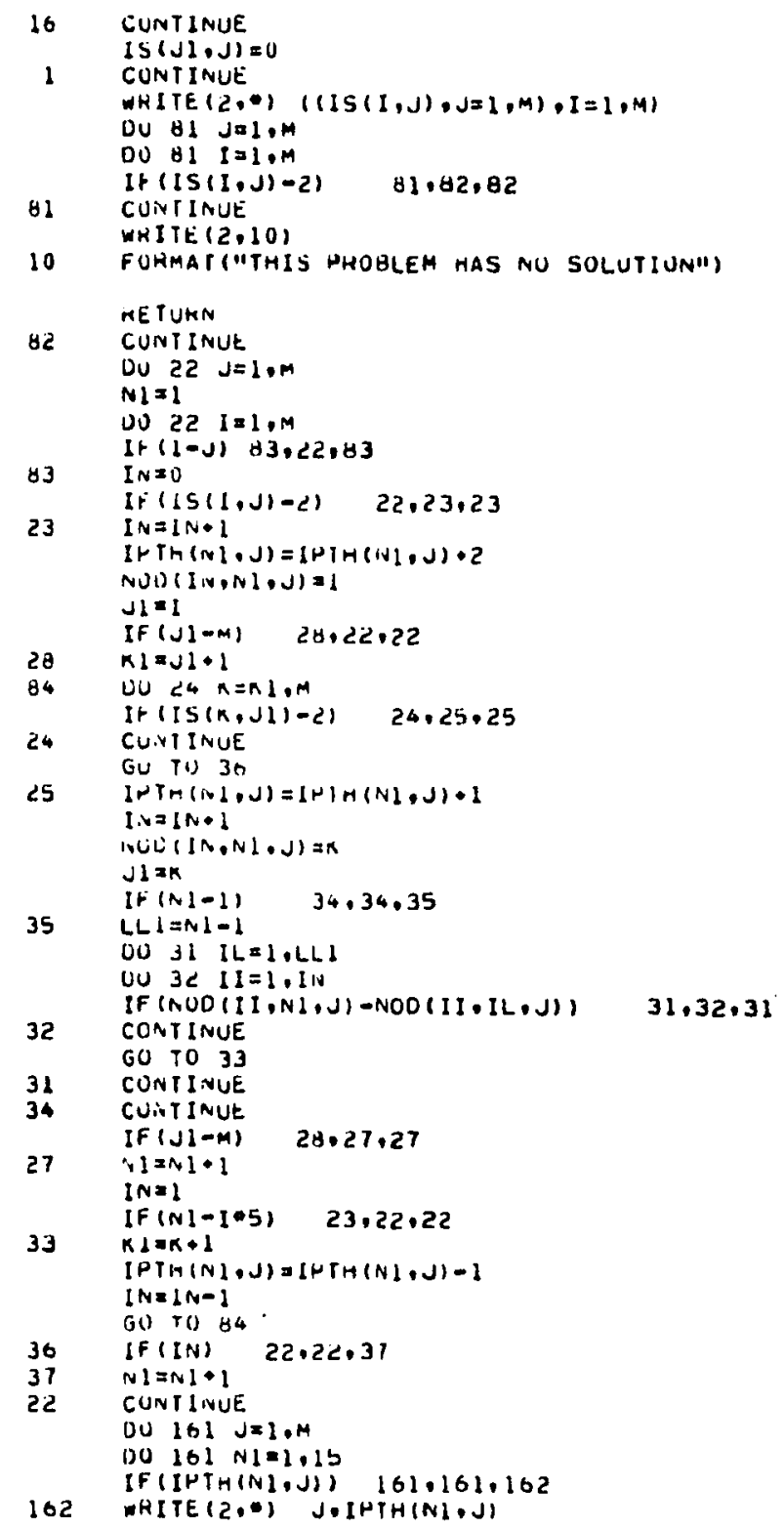




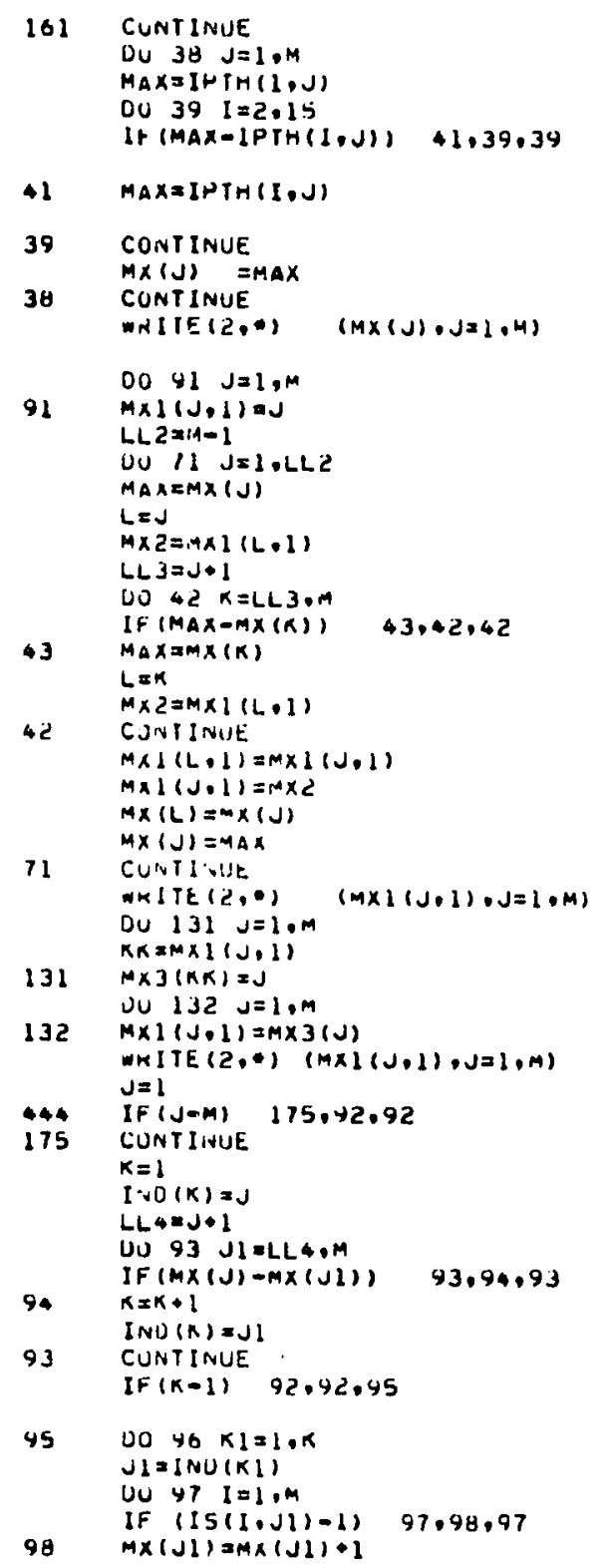




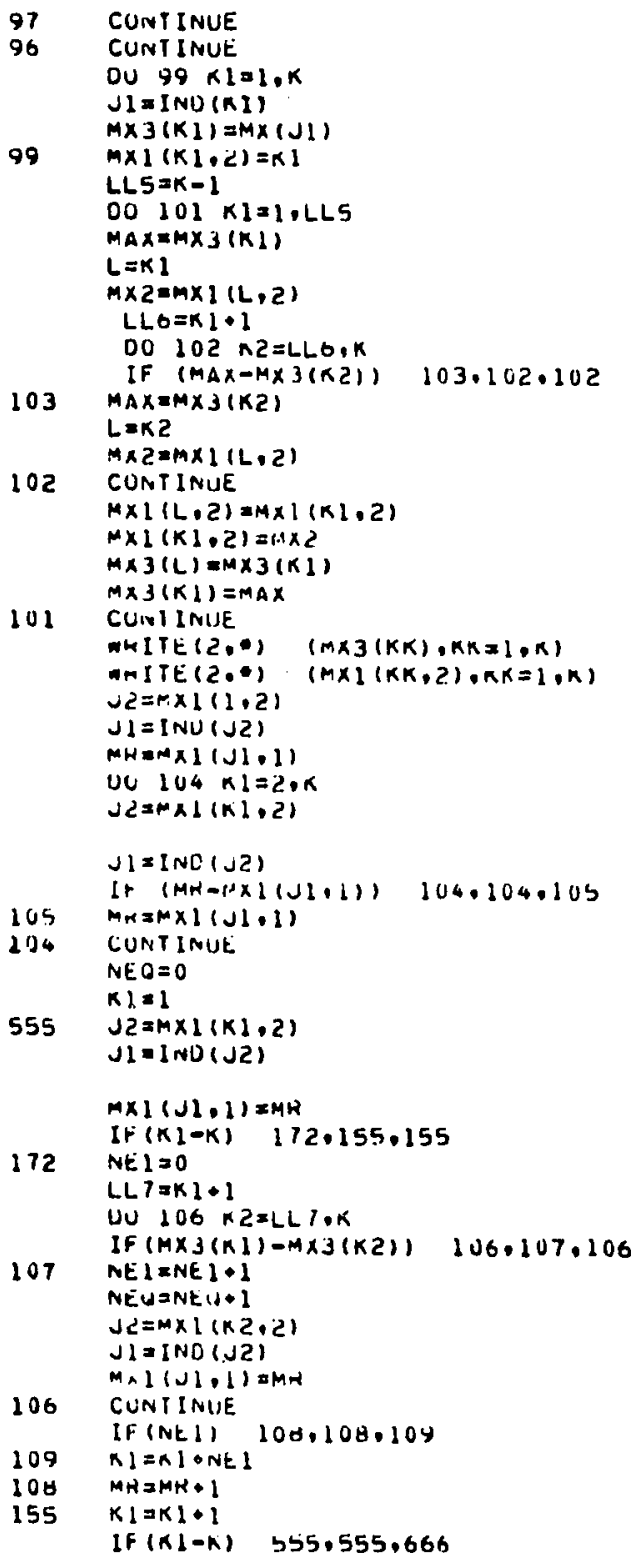




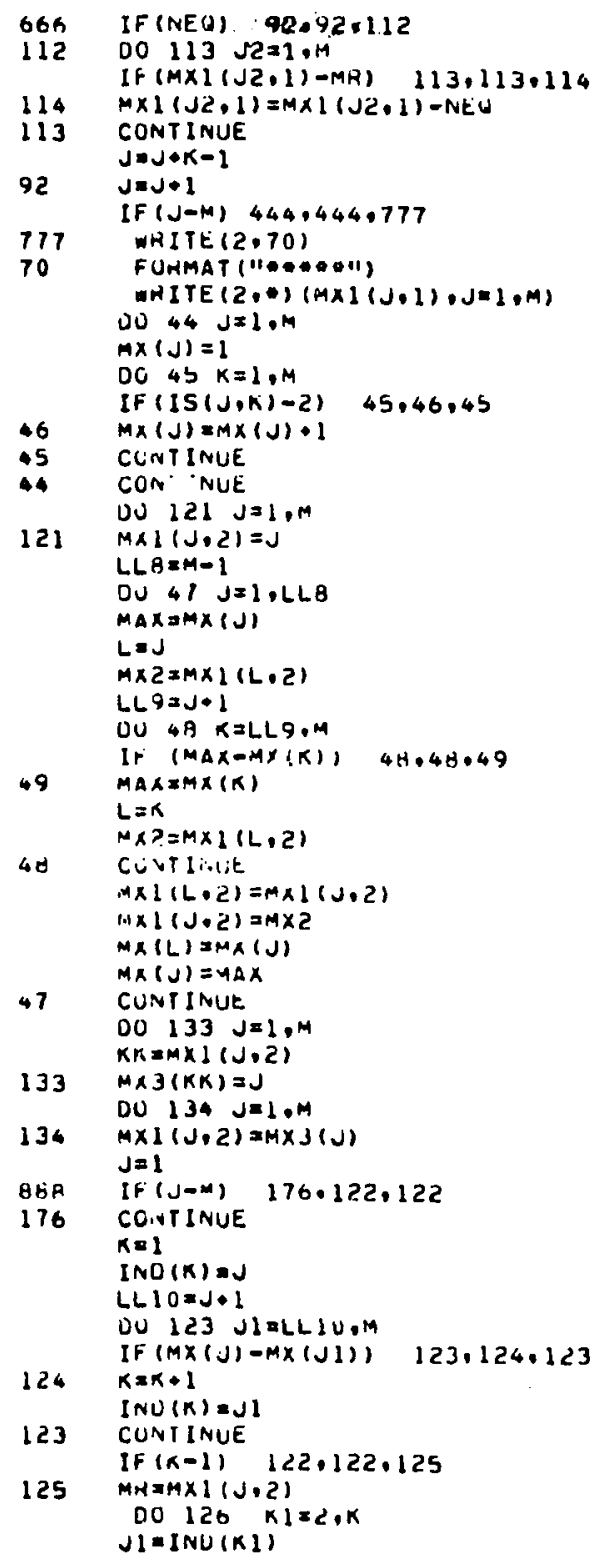




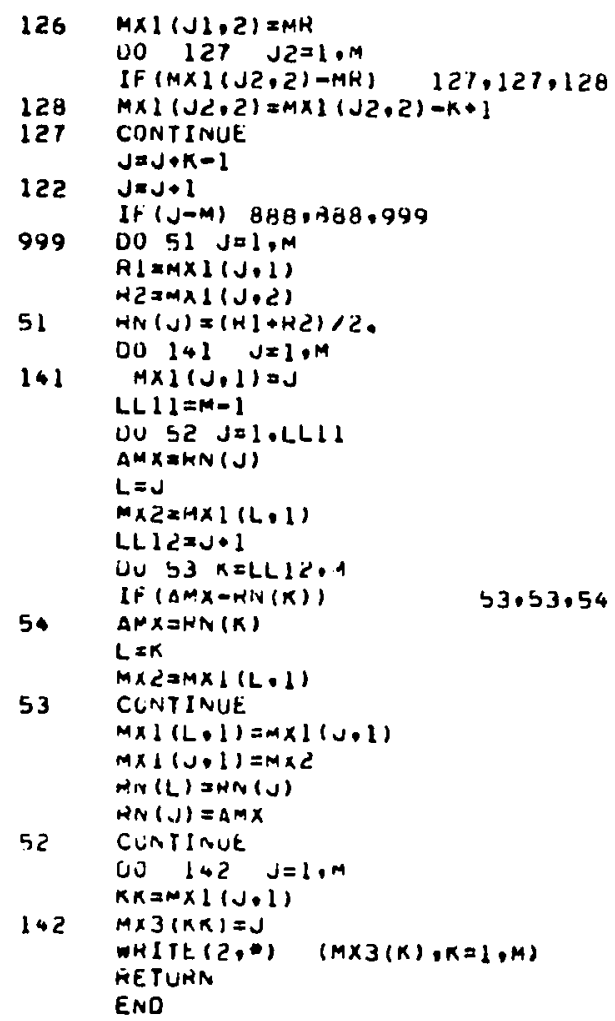

